\title{
Uma arquitetura para agentes inteligentes com personalidade e emoção
}

\author{
Ary Fagundes Bressane Neto \\ DissertaçÃo APRESENTAda \\ $\mathrm{AO}$ \\ Instituto De Matemática e Estatística \\ DA \\ Universidade De São Paulo \\ PARA \\ OBTENÇÃO DO TÍTULO \\ $\mathrm{DE}$ \\ Mestre Em CiÊnCIAS
}

Programa: Ciência da Computação

Orientador: Prof. Dr. Flávio Soares Corrêa da Silva

Durante o desenvolvimento deste trabalho o autor recebeu auxílio financeiro da FAPESP/Microsoft Research

São Paulo, junho de 2010 


\title{
Uma arquitetura para agentes inteligentes com personalidade e emoção
}

\author{
Esta versão definitiva da tese/dissertação \\ contém as correções e alterações sugeridas pela \\ Comissão Julgadora durante a defesa realizada \\ por (Ary Fagundes Bressane Neto) em 02/06/2010.
}

Comissão Julgadora:

- Prof. Dr. Flávio Soares Corrêa da Silva - IME-USP

- Profa. Dra. Renata Wassermann - IME-USP

- Prof. Dr. Marcio Lobo Netto - EP-USP 
À minha avó Catarina 

"A questão não é se as máquinas inteligentes podem ter alguma emoção, mas se as máquinas podem ser inteligentes, sem emoções"

Marvin Minsky, A Sociedade da Mente 


\section{Agradecimentos}

Eu gostaria de agradecer às instituições e pessoas que, de alguma maneira, contribuíram para tornar esse trabalho possível:

À Universidade de São Paulo, ao Instituto de Matemática e Estatística e ao Departamento de Ciência da Computação, pela formação acadêmica e oportunidade de realizar meus estudos durante os anos de mestrado.

À Microsoft Research, pelo apoio financeiro oferecido para a execução deste trabalho.

Ao Prof. Dr. Flávio Soares Corrêa da Silva, meu orientador, pelas oportunidades oferecidas, por ter aceitado o desafio de juntos explorarmos conteúdos multidisciplinares que estão na fronteira da Inteligência Artificial, com outras tantas áreas igualmente interessantes, e pela amizade que tem para com seus alunos.

Aos membros da banca de qualificação, o Prof. Dr. Marcio Lobo Netto e a Profa. Dr. Renata Wassermann, pelas valiosas discussões e comentários sobre a minha pesquisa.

Aos professores do Programa de Pós-Graduação em Ciência da Computação.

Aos funcionários do Instituto de Matemática e Estatística, que sempre atenderam prontamente minhas dúvidas e solicitações.

À FAPESP, ao Prof. Dr. Fabio Kon e ao Prof. Dr. Fernando Iazzetta, pela oportunidade e apoio financeiro que possibilitou a apresentação dos resultados parciais deste trabalho no IVA 2009 (Amsterdã, Holanda).

A toda a minha família pelo suporte, atenção e motivação.

À Keila, amiga, parceira, companheira, namorada e esposa, que sempre tinha as palavras certas para acalmarem os meus anseios, e outras tantas que me lançaram ao desafio, mesmo quando isto significasse ficar mais distante dela.

Ao meu pai Eduardo, minha mãe Regina e minha avó Catarina, que sempre me proporcionaram oportunidades de realizar meus sonhos.

Ao meu irmão Felipe, pela companhia durante noites de trabalho.

As minhas tias Maria Lúcia e Sandra, que trocaram seus momentos de lazer por leituras e sugestões que muito contribuíram para esse trabalho.

Aos meus amigos do poker, Nilson, Graziella, Newton, Bianca e Marco, pelos momentos únicos de descontração que, por algumas vezes, serviram de laboratório para a observação da influência dos estados afetivos nas atividades cognitivas.

Ao amigo Cleber Okida, pelas conversas, debates, risadas e dias e noites de estudo para a disciplina Análise de Algoritmo. 
Aos amigos do Laboratório de Ictiogenética, em especial a Caroline, Raquel, Karina, Cláudia, e também ao Douglas e a Márcia que, sempre bem-humorados, proporcionaram momentos de boas risadas.

Aos amigos Leonardo Ramalho de Oliveira e Sérgio Prado Scolari, que muito contribuíram para a minha formação acadêmica.

Aos meus amigos do LIDET, por toda a motivação e parceria oferecida durante nosso convívio.

O meu Muito Obrigado a todos! 


\section{Resumo}

Uma das principais motivações da Inteligência Artificial no contexto dos sistemas de entretenimento digital é criar personagens adaptáveis a novas situações, pouco previsíveis, com aprendizado rápido, memória de situações passadas e uma grande diversidade de comportamentos consistente e convincente ao longo do tempo. De acordo com recentes estudos desenvolvidos nos campos da Neurociência e da Psicologia, a capacidade de resolução de problemas não está unicamente atrelada à facilidade na manipulação de símbolos, mas também à exploração das características do ambiente e à interação social, que pode ser expressa na forma de fenômenos emocionais. Os resultados desses estudos confirmam o papel fundamental que cumprem a personalidade e as emoções nas atividades de percepção, planejamento, raciocínio, criatividade, aprendizagem, memória e tomada de decisão. Quando módulos para a manipulação de personalidade e emoções são incorporados à teoria de agentes, é possível a construção de Agentes com Comportamento Convincente (Believable Agents).

O objetivo principal deste trabalho é desenvolver e implementar uma arquitetura de agentes inteligentes para construir personagens sintéticos cujos estados afetivos influenciam em suas atividades cognitivas.

Para o desenvolvimento de tal arquitetura utilizou-se o modelo BDI (Beliefs, Desires e Intentions) como base e aos módulos existentes em uma implementação desse modelo foi incluído um Módulo Afetivo. Esse Módulo Afetivo é constituído por três submódulos (Personalidade, Humor e Emoção) e deve impactar nas atividades cognitivas de percepção, memória e tomada de decisão do agente.

Duas provas de conceito (experimentos) foram construídas : a simulação do problema do "Dilema do Prisioneiro Iterado" e a versão computadorizada do "Jogo da Memória". A construção desses experimentos permitiu avaliar empiricamente a influência da personalidade, humor e emoção nas atividades cognitivas dos agentes, e consequentemente no seu comportamento.

Os resultados evidenciam que a utilização da nova arquitetura permite a construção de agentes com comportamentos mais coerentes, adaptativos e cooperativos quando comparados aos de agentes construídos com arquiteturas cujas atividades cognitivas não consideram o estado afetivo, e também produz um comportamento mais próximo de um agente humano que de um comportamento ótimo ou aleatório. Essa evidência de sucesso, apresentada nos resultados, mostra que os agentes construídos com a arquitetura proposta nessa dissertação indicam um avanço na direção do desenvolvimento dos Agentes com Comportamento Convincente.

Palavras-chave: Agentes Afetivos, Computação Afetiva, Agentes Inteligentes e Inteligência Artificial. 


\section{Abstract}

One of the main motivations of Artificial Intelligence in the context of the digital entertainment systems is to create characters that are adaptable to new situations, unpredictable, fast learners, enable with memory of past situations and a variety of consistent and convincing behavior over time. According to recent studies conducted in the fields of Neuroscience and Psychology, the ability to solve problems is not only related to the capacity to manipulate symbols, but also to the ability to explore the environment and to engage into social interaction, which can be expressed as emotional phenomena. The results of these studies confirm the key role the personality and emotions play in the activities of perception, attention, planning, reasoning, creativity, learning, memory and decision making. When modules for handling personality and emotion, are incorporated in a theory of agents, it is possible to build Believable Agents.

The main objective of this work is to develop and implement an intelligent agent architecture to build synthetic characters whose affective states influence their cognitive activities.

To develop such architecture the BDI model (Beliefs, Desires and Intentions) was used as a basis, to which an Affective Module was included. The Affective Module consists of three sub-modules (Personality, Mood and Emotion), which influence the cognitive activities of perception, memory and decision making.

Finally, two proofs of concept were built: the simulation of the problem of "Iterated Prisoner's Dilemma" and the computerized version of the "Memory Game." The construction of these experiments allowed to evaluate empirically the influence of personality, mood and emotion in cognitive activities of agents and consequently in their behavior.

The results show that using the proposed architecture one can build agents with more consistent, adaptive and cooperative behaviors when compared to agents built with architectures whose affective states do not influence their cognitive activities. It also produces a behavior that is closer to a human user than that of optimal or random behavior. This evidence of success, presented in the obtained results, show that agents built with the proposed architecture indicate an advance towards the development of Believable Agents.

Keywords: Affective Agents, Affective Computing, Intelligent Agents, Artificial Intelligence. 


\section{Sumário}

Lista de Figuras

Lista de Tabelas $\quad$ xiii

1 Introdução $\quad 1$

1.1 Agente com Comportamento Convincente . . . . . . . . . . . . . . 3

1.2 Trabalhos Relacionados . . . . . . . . . . . . . . . . . . . 5

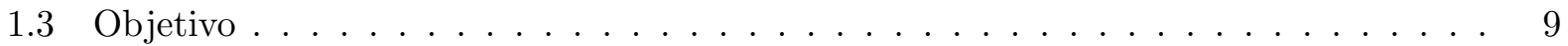

1.4 Estrutura do trabalho . . . . . . . . . . . . . . . . . . 10

2 Modelos da Psicologia e Neurociência $\quad 13$

2.1 Personalidade . . . . . . . . . . . . . . . . . . . . . . . 13

2.1.1 Modelo dos 16 Fatores de Cattell $(16 \mathrm{~F}) \ldots \ldots \ldots$. . . . . . . . . 15

2.1.2 Modelo dos três "Superfatores" de Eysenck . . . . . . . . . . . . . . . . . 16

2.1.3 O modelo dos Cinco Grandes Fatores . . . . . . . . . . . . . . . . . 18

2.2 Humor . . . . . . . . . . . . . . . . . . . . . . . . . . . . . . . . 21

2.3 Emoção . . . . . . . . . . . . . . . . . . . . . . 21

2.3 .1 Emoções Básicas . . . . . . . . . . . . . . . . . . . . . 22

2.3.2 Emoções na Teoria da Avaliação . . . . . . . . . . . . . . . . . . . . . 24

2.3.3 Emoções Primárias, Secundárias e Terciárias . . . . . . . . . . . . . . 25

2.4 Componentes da Emoção . . . . . . . . . . . . . . . . . . . . . . 26

2.4 .1 Expressão Facial . . . . . . . . . . . . . . . . . . . . . 27

2.4 Gestos . . . . . . . . . . . . . . . . . . . . . 29

2.4.3 Entonação de $\mathrm{Voz} \ldots \ldots \ldots$. . . . . . . . . . . . . . . . . 29

2.4 .4 Percepção . . . . . . . . . . . . . . . . . . . . . 29

2.4 Memória . . . . . . . . . . . . . . . . . . . . 30

2.4.6 Tomada de Decisão . . . . . . . . . . . . . . . . . . . . . . . . 31

3 Arquitetura $\quad 33$

3.1 Bases Conceituais . . . . . . . . . . . . . . . . . . . . . 33

3.1 .1 Arquiteturas dos Agentes Inteligentes . . . . . . . . . . . . . 33

3.1.2 Frameworks do modelo BDI . . . . . . . . . . . . . . . . . 35 
3.1.3 Framework Jason . . . . . . . . . . . . . . . . . . . . 37

3.2 A Arquitetura . . . . . . . . . . . . . . . . . . 43

4 Provas de Conceito $\quad \mathbf{5 5}$

4.1 Critérios de Avaliação . . . . . . . . . . . . . . . . . . 55

4.2 Experimento 1: O Dilema do Prisioneiro Iterado . . . . . . . . . . . . . . 56

4.3 Experimento 2: O Jogo da Memória . . . . . . . . . . . . . . . . . . . 68

4.4 Discussão dos Resultados . . . . . . . . . . . . . . . . . . 77

5 Considerações Finais $\quad \mathbf{8 5}$

5.1 Trabalhos Futuros . . . . . . . . . . . . . . . . . . 86

$\begin{array}{lrr}\text { A Anexo A } & 89\end{array}$

$\begin{array}{ll}\text { B Anexo B } & 97\end{array}$

Referências Bibliográficas $\quad 105$ 


\section{Lista de Figuras}

1.1 Cena da narrativa interativa e os Woogles [Bates et al., 1992] . . . . . . . . . . 5

1.2 Expressões Faciais geradas pelo Modelo de Personalidade de Multicamada [Kshirsagar e Magnenat-Thalmann, 2002]. . . . . . . . . . . . . . . . 6

1.3 (a) Ações para a interação do usuário com o robô virtual. (b) Estado afetivo atual do personagem $[\mathrm{Yu}$ e Choi, 2005] . . . . . . . . . . . . . . . 7

1.4 Interface do sistema Virtual Human [Gebhard, 2005] . . . . . . . . . . . . . 8

1.5 Interface de configuração dos estados afetivos da professora virtual [Kasap et al., 2009]. 9

2.1 Classificação de personalidade no modelo de Eysenck [Garcia, 2006] . . . . . . . . 18

2.2 Uma versão reduzida do Inventário de Traços Bipolares [Pervin e John, 2003] . . . . 20

2.3 Espaço tridimensional do modelo PAD [Gebhard, 2005] . . . . . . . . . . . . . . 22

2.4 Representação gráfica do modelo de Plutchik [Plutchik, 2002] . . . . . . . . . . . 23

2.5 A estrutura cognitiva do modelo OCC [Ortony et al., 1988] . . . . . . . . . . . . 25

2.6 A estrutura cognitiva do modelo Roseman [Picard, 1997] . . . . . . . . . . . . . 26

2.7 Unidades identificadas nas sobrancelhas e testa em ação [Isbister, 2006] . . . . . . . . 28

2.8 Expressão facial das seis emoções básicas de Ekman. Da esquerda para a direita e de cima para baixo: raiva, medo, desagrado, surpresa, alegria e tristeza [Rodrigues, 2007]. . . . . . . . . . . . . . . . . . . . 28

2.9 Diagrama do modelo de Atkinson e Shiffrin de memória [Gazzaniga e Heatherton,

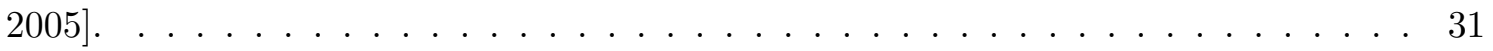

3.1 Diagrama de funcionamento da arquitetura do Jason [Bordini et al., 2007]. . . . . . 41

3.2 Diagrama de funcionamento da arquitetura proposta. . . . . . . . . . . . . . . 44

3.3 Diagrama de funcionamento do Módulo Afetivo. . . . . . . . . . . . . . . 46

3.4 Diagrama de funcionamento do Filtro de Percepção. . . . . . . . . . . . . . . . . . 49

3.5 Diagrama de funcionamento do Filtro de Memória. . . . . . . . . . . . . . . . . 50

3.6 Diagrama de funcionamento do Filtro de Planos. . . . . . . . . . . . . . . . 51

4.1 Primeira interface do Jogo da Memória. . . . . . . . . . . . . . . . . . . 69

4.2 Segunda interface do Jogo da Memória. . . . . . . . . . . . . . . . . . . . 69

4.3 Os 16 bonecos utilizados no Jogo da Memória separados pelo tipo de emoção e ordenados por intensidade. . . . . . . . . . . . . . . . . . 70 
4.4 Resultado do jogo Usuário U1 x Computador Afetivo. . . . . . . . . . . . . . . 77

4.5 Resultado do Desvio Padrão das Diferenças apresentado na tabela 4.9 . . . . . . . . 81

A.1 Gráficos que apresentam a evolução do estado afetivo ao longo das iterações. . . . 91

A.2 Gráficos que apresentam a evolução do estado afetivo ao longo das iterações. . . . 92

A.3 Gráficos que apresentam a evolução do estado afetivo ao longo das iterações. . . . . 93

A.4 Gráficos que apresentam a evolução do estado afetivo ao longo das iterações. . . . . 94

A.5 Gráficos que apresentam a evolução do estado afetivo ao longo das iterações. . . . . 95

B.1 Gráficos que apresentam a evolução do estado afetivo ao longo das iterações. . . . . 99

B.2 Gráficos que apresentam a evolução do estado afetivo ao longo das iterações. . . . 100

B.3 Gráficos que apresentam a evolução do estado afetivo ao longo das iterações. . . . 101

B.4 Gráficos que apresentam a evolução do estado afetivo ao longo das iterações. . . . . 102

B.5 Gráficos que apresentam a evolução do estado afetivo ao longo das iterações. . . . 103 


\section{Lista de Tabelas}

2.1 Os 16 fatores primários propostos por Cattell [de Souza et al., 2007] . . . . . . . . . 16

2.2 Facetas do questionário NEO-PI-R [Garcia, 2006] . . . . . . . . . . . . . . . . 19

2.3 Os oito estados de humor do modelo PAD [Mehrabian, 2009] . . . . . . . . . . . 21

2.4 Os dois componentes da emoção e suas principais atividades [Picard, 1997]. . . . . . 27

3.1 Comparação entre os frameworks pesquisados para desenvolvimento de agentes BDI. 38

3.2 As 22 emoções do modelo OCC [Ortony et al., 1988] . . . . . . . . . . . . . . . . 48

3.3 Mapeamento entre as emoções do modelo OCC e as dimensões de humor do modelo PAD $[$ Gebhard, 2005] . . . . . . . . . . . . . . . . . . . . . . 54

4.1 Matriz de recompensa do Dilema do Prisioneiro. . . . . . . . . . . . . . . . 56

4.2 Os oito estados de humor do modelo PAD [Mehrabian, 1995] . . . . . . . . . . . . 59

4.3 Estratégias para tomada de decisão. . . . . . . . . . . . . . . . . 60

4.4 As dezesseis emoções utilizadas nesse experimento, baseadas no modelo OCC [Ortony

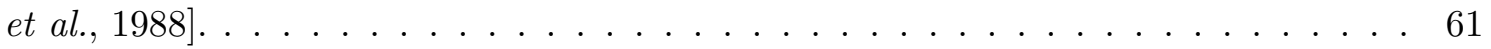

4.5 Mapeamento que relaciona a intensidade das emoções percebidas com os estados de humor. . . . . . . . . . . . . . . . . . . . 6 64

4.6 As dez emoções utilizadas nesse experimento, baseadas no modelo OCC [Ortony

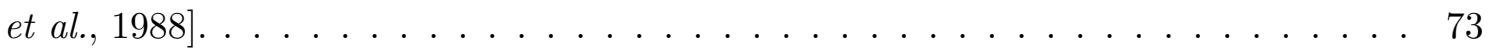

4.7 Mapeamento que relaciona a intensidade das emoções percebidas com os estados de

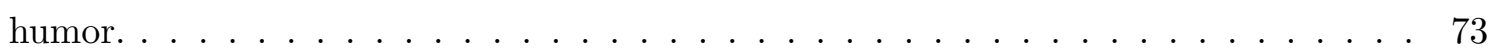

4.8 Estratégias para tomada de decisão. . . . . . . . . . . . . . . . . . . . . 74

4.9 Resultados dos testes realizados no Experimento 2. (continua na próxima página) . . 75

4.9 Resultados dos testes realizados no Experimento 2. (continua na próxima página) . . 76

4.9 Resultados dos testes realizados no Experimento 2 . . . . . . . . . . . . . 77

4.10 Estado de humor dos agentes ao final de cada um dos teste do Experimento 1.A. . . 78

4.11 Estado de humor dos agentes ao final de cada um dos teste do Experimento 1.B. . . 79

4.12 Estado de humor do agente no final dos testes do Experimento 1.A. . . . . . . . . 79

4.13 Estado de humor do agente no final dos testes do Experimento 1.B. . . . . . . . . . 80

4.14 Somatório do número de anos de prisão dos agentes ao final de cada um dos teste do Experimento 1. . . . . . . . . . . . . . . . . . . . . . . . . 82 
A.1 Número de anos de prisão que os agentes receberam em cada um dos testes do Experimento 1.A. . . . . . . . . . . . . . . . . . . . . . 90

B.1 Número de anos de prisão que os agentes receberam em cada um dos testes do Experimento 1.B. . . . . . . . . . . . . . . . . . . . . . . . 98 


\section{Capítulo 1}

\section{Introdução}

A Inteligência Artificial (IA) é uma área da Ciência da Computação, multidisciplinar e que dentre outras atividades e métodos desenvolve pesquisas baseadas em simulações computadorizadas das ações humanas, em especial da inteligência humana e do comportamento inteligente. Tradicionalmente, a IA utiliza sistemas de Entretenimento Digital (por exemplo, os jogos de computador e ambientes virtuais de simulação) como plataforma para desenvolvimento e testes de novas técnicas e algoritmos. Os pesquisadores utilizam esse tipo de sistema em suas investigações, pois fornecem uma alta variedade e escalabilidade de problemas onde o domínio restrito e controlado permite que os resultados sejam, normalmente, simples de serem avaliados [Nareyek, 2001].

As primeiras pesquisas que envolviam as áreas de Inteligência Artificial e Entretenimento Digital, empregavam técnicas de Inteligência Artificial Simbólica nos sistemas de entretenimento, e em especial nos jogos de tabuleiros e de cartas [Miikkulainen, 2006]. Essas técnicas utilizavam-se da grande capacidade que o computador tem de manipular símbolos, scripts e regras, mesmo com ausência de compreensão semântica, para construir oponentes mais difíceis de serem derrotados. O objetivo era fazer a máquina comportar-se de tal forma que fosse chamada de inteligente, caso fosse este o comportamento de um ser humano [McCarthy, 1979]. Alguns dos resultados mais importantes dessas pesquisas foram: o sistema Chinook $^{1}$ que se tornou campeão mundial do jogo de damas em 1994 e o computador Deep Blue ${ }^{2}$ que derrotou o até então campeão mundial de xadrez Garry Kasparov em 1997.

Simultaneamente à realização dessas pesquisas, na década de 1990, a área de Entretenimento Digital atravessou um período de intensa mudança. A popularização dos computadores e o aumento significativo em sua capacidade de processamento tornaram possível a simulação de ambientes mais complexos. Essa nova possibilidade impulsionou o desenvolvimento da indústria do Entretenimento Digital, em especial a dos jogos de vídeo game e de computadores, que passaram de modestas vendas movidas pela curiosidade na década de 1970 a uma arrecadação de mais de 40 bilhões de dólares em todo o mundo no ano de 2007, com uma previsão de ultrapassar os 62 bilhões de dólares em 2012 [Peckham, 2008]. Atualmente, os jogos de computador fazem parte do cotidiano de milhões de pessoas e o mercado continua em plena expansão.

Em virtude da evolução dos computadores, os atuais sistemas de Entretenimento Digital aten-

\footnotetext{
${ }^{1}$ Chinook: http://www.cs.ualberta.ca/ chinook/

${ }^{2}$ Deep Blue: http://www.research.ibm.com/deepblue/
} 
dem demandas diferentes dos sistemas anteriores. Segundo Byl [2004], os sistemas modernos apresentam as seguintes características:

- Acessibilidade: o usuário ou o personagem não tem conhecimento completo do ambiente em que está inserido;

- Mudança: o ambiente não é estático;

- Recursos: o personagem dispõem de recursos que podem ser limitados dentro do ambiente;

- Tempo de processamento: o tempo é limitado para o processamento e raciocínio (tempo real).

Contudo, apesar das mudanças nas necessidades dos sistemas, as pesquisas em IA aplicada ao Entretenimento Digital não acompanharam essa rápida evolução. Mesmo com toda essa demanda, uma das únicas técnicas aplicadas nos jogos modernos é o algoritmo para busca de caminho conhecido como $\mathrm{A}^{*}$ (A estrela) e algumas de suas variações e extensões como, por exemplo, o $\mathrm{D}^{*}$ (D estrela) [Nareyek, 2001] [Miikkulainen, 2006].

Nos últimos anos, algumas técnicas de Inteligência Artificial como os agentes autônomos, planejamento, robótica e aprendizado de máquina (redes neurais e algoritmos evolutivos) foram implementadas em alguns jogos.

Nesse contexto, uma das principais motivações da Inteligência Artificial é criar personagens mais adaptáveis à novas situações, menos previsíveis, com aprendizado rápido, memória de situações passadas e uma grande diversidade de comportamentos consistentes e convincentes ao longo do tempo [Laird e van Lent, 2001]. Essas características são fundamentais para o desenvolvimento tanto de sistemas de software como para a construção de robôs que irão interagir no mundo real.

Uma técnica que atende às necessidades para o desenvolvimento desses personagens é dos agentes inteligentes.

Os agentes inteligentes são sistemas computacionais que têm como principais características atuar de forma autônoma, perceber o ambiente onde estão inseridos, adaptar-se às mudanças e à capacidade de trabalhar em função de objetivos, podendo ser atribuídas aos agentes tarefas normalmente desempenhadas por seres humanos [Russell e Norvig, 2003]. As pesquisas com agentes inteligentes no domínio da Inteligência Artificial normalmente investigam o desenvolvimento desses com o propósito de solucionar problemas específicos e na interação de sistemas multiagentes. No entanto, um dos maiores desafios dessa área é compreender como acontece o processo cognitivo humano, a fim de possibilitar a construção de agentes artificiais "inteligentes" [Konar, 2000].

Os modelos clássicos de raciocínio e tomada de decisão não têm apresentado resultados satisfatórios na tentativa de explicar o processo cognitivo humano e as formas por meio das quais os humanos manipulam os problemas [Oliveira e Sarmento, 2003]. Porém, de acordo com recentes estudos desenvolvidos no campo da Neurociência e da Psicologia, a capacidade de resolução de problemas não está unicamente atrelada à facilidade na manipulação de símbolos, mas também à exploração das características do ambiente e à interação social, que podem ser expressas na forma de fenômenos emocionais. 
Os resultados desses estudos confirmam o papel fundamental que cumprem a personalidade e as emoções do indivíduo na cognição humana, no que se refere à percepção, atenção, planejamento, raciocínio, criatividade, aprendizagem, memória e tomada de decisão.

Um dos principais representantes desses estudos é o livro "O Erro de Descartes: Emoção, Razão e o Cérebro Humano" publicado pelo neurocientista António Damásio [Damásio, 1996]. O livro aborda o papel fundamental que as emoções exercem na vida racional do ser humano. Por meio de experimentos laboratoriais e uma análise sistemática de casos clínicos, o autor mostra como as emoções são imprescindíveis no comportamento das pessoas e em todas as suas atividades fisiológicas e cognitivas.

Os estudos dos sistemas computacionais ou robóticos capazes de reconhecer, sintetizar e expressar emoções deram origem a uma nova área de pesquisa conhecida como Computação Afetiva. A grande referência nesta área é o livro "Affective Computing" da pesquisadora Rosalind W. Picard [Picard, 1997]. Segundo a autora, a simulação da habilidade de manipular emoções é essencial para que os computadores sejam capazes de uma interação mais natural e de maior qualidade com os seres humanos, aumentando assim a possibilidade de aplicações lúdicas, científicas e educativas.

Neste sentido, quando módulos para a manipulação de personalidade e emoções são incorporados à teoria de agentes, é possível a construção de personagens com uma grande riqueza de detalhes, assim como os utilizados em outras mídias (cinema e teatro), e que, ao contrário dessas mídias, permite interação entre o personagem e o espectador. Esse tipo de agente é chamado de Agente com Comportamento Convincente (Believable Agent) [Bates, 1994].

Em outras palavras, um Agente com Comportamento Convincente (ACC) é a união de agentes inteligentes baseados em Inteligência Artificial com os personagens emotivos, como os que aparecem nas artes.

\subsection{Agente com Comportamento Convincente}

Segundo Mateas [2002], "Agente com Comportamento Convincente não são simulações de pessoas, exibindo comportamentos indistinguíveis dos humanos sob condições controladas de laboratório. Ao invés disso, personagens são abstrações artísticas de pessoas, cujo comportamento, motivações e vida interior foram simplificados e exagerados de maneira específica para atrair a audiência na visão do artista".

De acordo com Loyall [1997] e Byl [2004], os requisitos para a construção dos ACCs são: personalidade, emoção, automotivação, mudança, relacionamento social e ilusão de vida.

- Personalidade: característica consistente e duradoura que determina o caráter original e único de cada personagem. A personalidade deve influenciar os processos cognitivos, a expressão emocional para transmitir ao usuário alguma expectativa sobre como ele agirá.

- Emoção: o agente precisa ter uma reação emocional a eventos, agentes e objetos além de apresentá-la de alguma maneira, seja por meio de expressão facial, gesto ou entonação de voz. A emoção no agente deve ser um processo dinâmico e que esteja de acordo com a sua personalidade. 
- Automotivação: no contexto dos agentes, automotivação é um sinônimo para comportamento baseado em objetivos (goal-orientated behavior). O usuário perceberá que, além de reativo, o personagem deve agir por iniciativa própria satisfazendo seus objetivos. Portanto, na expressão emocional, o agente será motivado a realizar tarefas de acordo com a sua personalidade.

- Mudança: com o passar do tempo, tem-se como expectativa que os agentes mudem, não só no aspecto físico, mas também nas suas atitudes e comportamentos de acordo com sua personalidade. Mesmo nos jogos onde o tempo de interação é pequeno, uma mudança consistente deve ocorrer para mostrar que o personagem está inserido em um ambiente e é afetado por ele.

- Relacionamento Social: a maneira como as pessoas interagem e se relacionam apresenta uma visão sobre o seu comportamento. Quando o agente se relaciona com outros agentes e com o usuário cria uma relação que transmite a idéia de que ele possui emoção, e pode influenciar os outros.

- Ilusão de Vida: além das indicações anteriores, o personagem deve possuir características inerentes aos seres humanos para transmitir uma sensação de ilusão de vida. Logo, é importante que os personagens tenham:

- Objetivo: todos os personagens devem ter objetivos e planos para atingi-los;

- Multitarefa: assim como os seres vivos, o agente deve ser capaz de executar várias ações e exercer múltiplas atividades concomitantemente;

- Resposta a estímulos: o agente precisa responder (em tempo razoável) a estímulos para lidar com rápidas mudanças no ambiente, noção de como o ambiente à sua volta está mudando e ter a habilidade de adaptar seus planos de acordo com as mudanças;

- Limites de corpo-mente: é importante que o personagem tenha limites tanto sobre o quanto ele pode pensar, quanto do que é fisicamente capaz de suportar e não ter o completo conhecimento do ambiente. Mesmo personagens como gênios e super-heróis devem ter limites;

- Contexto social: o agente deve compreender as convenções sociais e aspectos culturais do mundo em que está inserido;

- Capacidade: ele precisa ser capaz de agir, pensar, sentir, falar, ouvir, compreender, ter emoções, ou seja, pertencer a um mundo dinâmico;

- Integração: capacidade, conhecimento e comportamentos necessitam de integração para que não aconteçam situações onde o personagem tenha um comportamento que não seja condizente com o conhecimento que possua. 


\subsection{Trabalhos Relacionados}

Os pesquisadores enfrentam grandes desafios para construir personagens utilizando personalidade e emoção. Apesar disso, algumas arquiteturas têm sido desenvolvidas na tentativa de se obter agentes que apresentem comportamento convincente como uma simplificação do comportamento humano.

Essas pesquisas inspiram-se até hoje nos modelos da Psicologia e da Neurociência e nos conceitos da Computação Afetiva. Neste item são apresentadas sete dessas arquiteturas ("Projeto Oz", "A Multilayer Personality Model", "V-PET", "ALMA", "EBDI", "Soar-Emote" e "Making them Remember"). Todos os modelos de personalidade e emoção citados, são descritos no capítulo 2.

\section{Projeto $\mathrm{Oz}$}

O Projeto Oz [Bates et al., 1992] foi um dos primeiros trabalhos a utilizar emoções em sistemas computacionais. Desenvolvido por pesquisadores do Departamento de Ciência da Computação da Universidade Carnegie Mellon nos Estados Unidos, o trabalho tem por objetivo desenvolver uma narrativa interativa. Os personagens foram desenvolvidos utilizando uma arquitetura baseada em objetivos que possui um módulo de emoção baseado no modelo cognitivo de Ortony, Clore e Collins (OCC) que determina sua expressão facial e movimentos. Para construir a história, o usuário interage com os personagens da história por meio de texto e de uma interface gráfica. A figura 1.1 apresenta uma cena da história e seus personagens chamados Woogles.

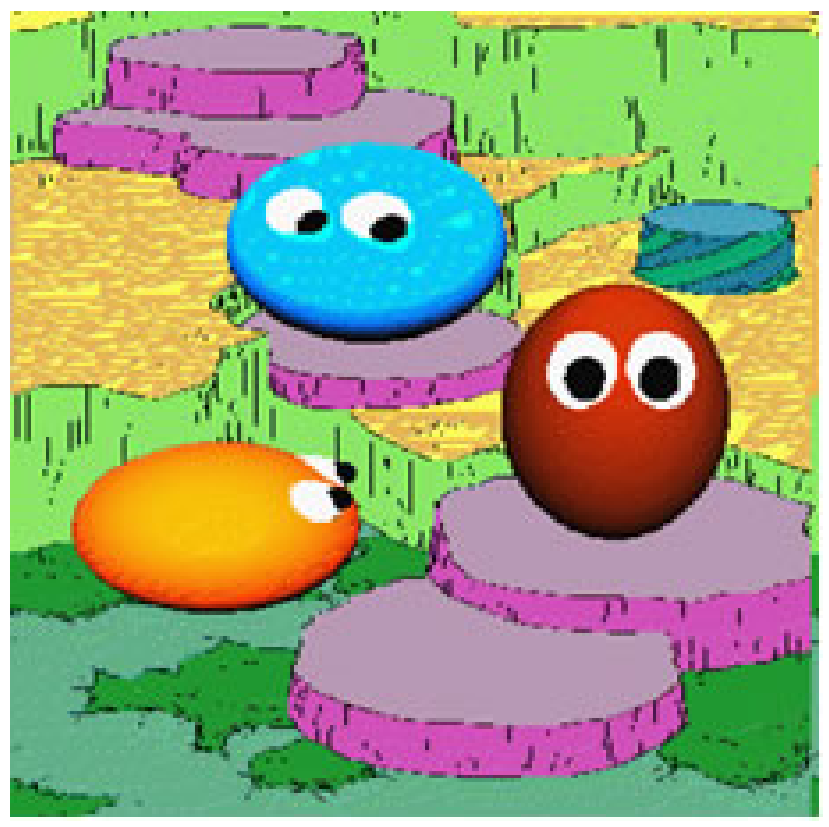

Figura 1.1: Cena da narrativa interativa e os Woogles [Bates et al., 1992]. 


\section{A Multilayer Personality Model}

Esse trabalho [Kshirsagar e Magnenat-Thalmann, 2002] foi desenvolvido por pesquisadores do Miralab (um importante laboratório da Universidade de Genebra na Suíça que atua nas áreas de Ciência da Computação, Matemática, Medicina, Arquitetura, Ciência Cognitiva, Realidade Virtual, entre outras, e que utiliza grupos multidisciplinares para o desenvolvimento de projetos). O Modelo de Personalidade Multicamada discute a criação de simulações de seres humanos virtuais utilizando uma abordagem em camadas para a modelagem de personalidade, humor e emoção. Dessa forma, implementa o Modelo dos Cinco Grandes Fatores de personalidade e uma Rede Bayesiana para a seleção do comportamento. Os estados afetivos determinam a expressão facial, entonação da voz e velocidade de fala do personagem. A figura 1.2 apresenta algumas expressões faciais geradas pelo sistema. As expressões faciais foram integradas com um módulo de bate papo para demonstrar o uso potencial do modelo com um sistema da vida real, permitindo uma comunicação convincente com um humano virtual em linguagem natural.

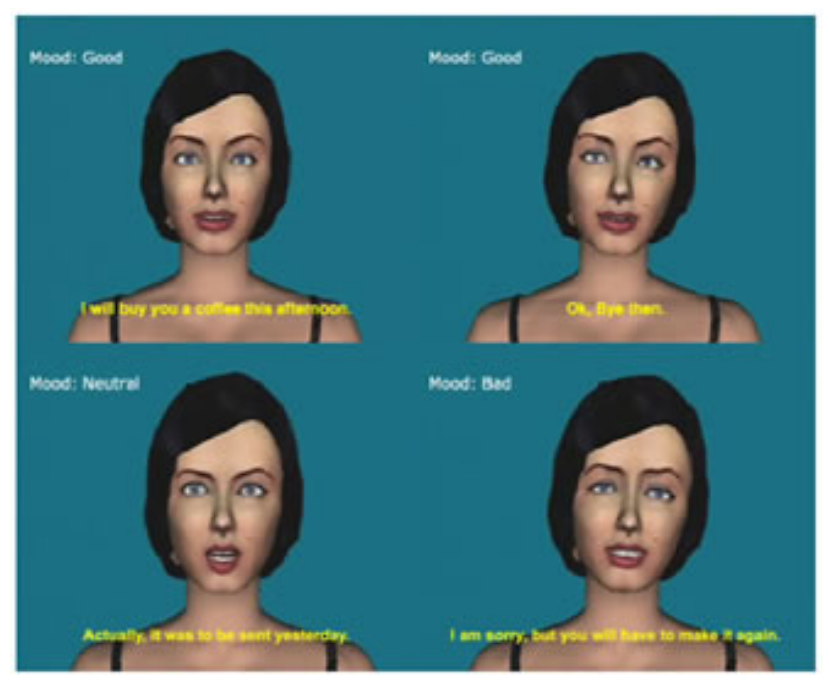

Figura 1.2: Expressões Faciais geradas pelo Modelo de Personalidade de Multicamada [Kshirsagar e Magnenat-Thalmann, 2002].

\section{V-PET}

O V-PET [Yu e Choi, 2005] é um robô virtual que simula um animal de estimação criado por um grupo de pesquisadores da Escola de Engenharia Elétrica da Universidade Nacional de Seul na Coreia. O trabalho estuda aplicações de emoção em robôs. Para a construção da simulação, incorporou-se na arquitetura do agente o modelo dos Cinco Grandes Fatores de personalidade e o modelo das Seis Emoções Básica de Ekman. O sistema apresenta alguns botões rotulados com ações pelos quais os usuários interagem com o robô virtual (Figura 1.3 (a)) e uma interface com uma descrição completa de todo o estado afetivo do personagem (Figura 1.3 (b)). Em seu trabalho, os autores publicaram toda a relação entre personalidade e emoção utilizada na arquitetura e a 
maneira como é realizada a mudança de personalidade. O personagem ainda guarda na memória uma variável (atitude) que indica qual a relação que ele tem com cada usuário. Essa variável também é utilizada para influenciar a intensidade da emoção.

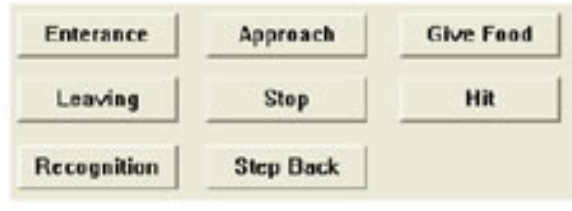

(a)

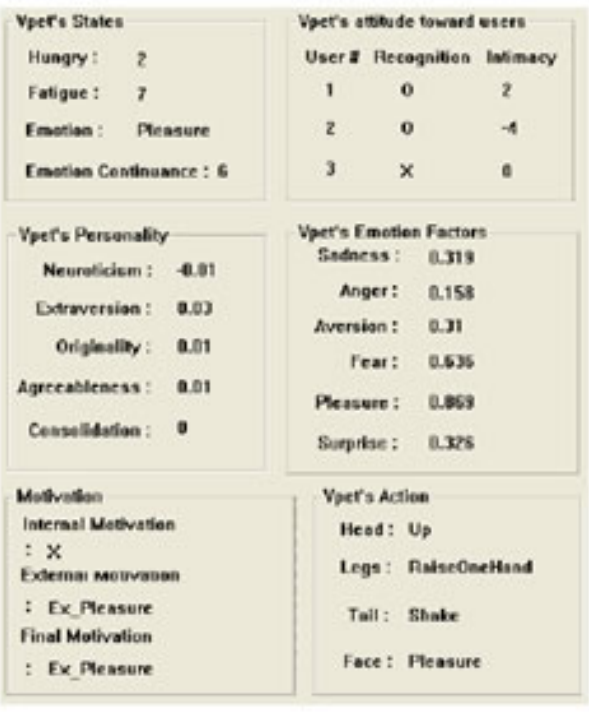

(b)

Figura 1.3: (a) Ações para a interação do usuário com o robô virtual. (b) Estado afetivo atual do personagem [Yu e Choi, 2005].

\section{ALMA - A Layered Model of Affect}

Desenvolvida pelo Centro de Pesquisa Alemão em Inteligência Artificial (DFKI), a arquitetura ALMA [Gebhard, 2005] é uma das principais referências na área de agentes com personalidade e emoção. ALMA implementa modelos de três estados afetivos: emoção (OCC mais as Seis Emoções Básicas de Ekman), humor (PAD) e personalidade (Cinco Grandes Fatores). A arquitetura faz parte de um projeto maior chamado Virtual Human (Figura 1.4), que combina o estado da arte em tecnologia de computação gráfica e geração de diálogos. A Virtual Human é um ambiente 3D de ensino a distância, que utiliza a arquitetura ALMA para controlar, baseado no estado emocional, a expressão facial, seleção de palavras e frases, seleção de estratégias de diálogo e mudança de gestos em função da conversação. Segundo os autores, o controle do comportamento físico dos personagens enriquece a interação com o usuário e aumenta a ilusão de vida dos personagens.

\section{EBDI: An Architecture for Emotional Agents}

O EBDI [Jiang et al., 2007] é uma arquitetura genérica para o desenvolvimento de agentes emocionais que implementa raciocínio prático e mecanismos de manipulação de emoções. Desenvolvida na Universidade de South Carolina (Estados Unidos) os pesquisadores acrescentaram emoções primárias e secundárias a uma arquitetura BDI. Às informações adquiridas pelos agentes são atribuídas emoções primárias que ajustam a lista de prioridades das crenças. Caso não haja 


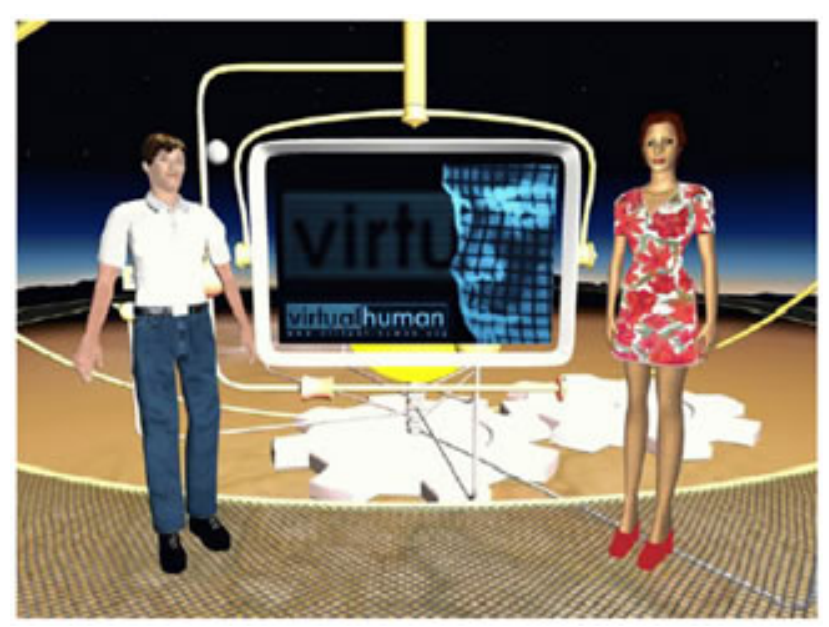

Figura 1.4: Interface do sistema Virtual Human [Gebhard, 2005].

tempo, as informações são processadas dessa maneira. Caso contrário a emoção primária associada à crença é processada resultando em uma emoção secundária que poderá substituí-la. Segundo os autores, a utilização de emoções secundárias refina o processo de decisão do agente.

\section{Soar-Emote}

O Soar ${ }^{3}$ é uma arquitetura cognitiva utilizada no desenvolvimento de sistemas que exibem comportamento inteligente. Criada por John Laird, Allen Newell e Paul Rosenbloom na Universidade Carnegie Mellon e financiada pela Agência de Pesquisas em Projetos Avançados de Defesa do governo dos Estados Unidos, a arquitetura já foi utilizada em diversos sistemas por pesquisadores de Inteligência Artificial e Ciência Cognitiva. Para atender a diferentes áreas do conhecimento, é muito comum o desenvolvimento de extensões dessa arquitetura. Uma recente extensão chamada Soar-Emote [Marinier, 2008], adiciona um módulo com cinco emoções: alegria, esperança, medo, desolação e raiva. Essas emoções foram implementadas para permitir ao agente uma resposta rápida a estímulos no nível fisiológico.

\section{Making them Remember - Emotional Virtual Characters with Memory}

Desenvolvido por pesquisadores do Miralab da Universidade de Genebra, esse trabalho [Kasap et al., 2009] apresenta um modelo de emoção baseado em memória para construir relacionamentos de longo prazo entre personagens virtuais e usuários. O relacionamento é o resultado acumulado da avaliação (positiva ou negativa) que o agente faz do resultado da interação. Essa avaliação é feita por meio de emoções associadas às percepções. Para o desenvolvimento da arquitetura do agente foram utilizados o Modelo dos Cinco Grandes Fatores de personalidade, o modelo PAD de humor e o modelo OCC de emoção. Assim, após uma sessão de interação, o agente armazena na memória sua impressão sobre determinado usuário. Para que a interação seja mais natural, foram implementadas

\footnotetext{
${ }^{3}$ Soar: http://sitemaker.umich.edu/soar/home
} 
técnicas de reconhecimento de faces que permitem ao agente identificar automaticamente cada um dos usuários. Os autores ainda apresentam um exemplo de aplicação: Eva, a professora de geografia (figura 1.5). No exemplo, a professora utiliza as informações armazenadas sobre cada um dos alunos para utilizar diferentes estratégias de diálogo, gestos e expressões faciais.

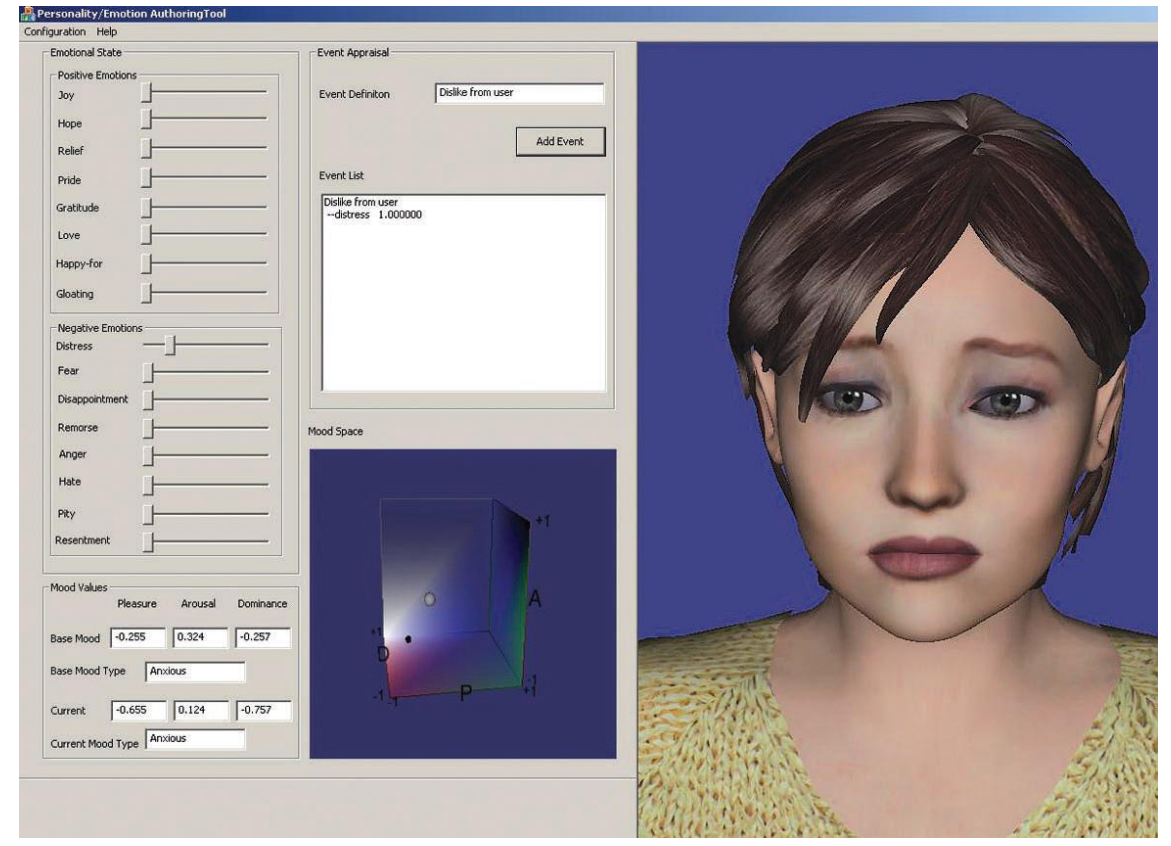

Figura 1.5: Interface de configuração dos estados afetivos da professora virtual [Kasap et al., 2009].

Os sete trabalhos relacionados até agora apresentados revelam que os agentes com personalidade e emoção podem ser aplicados com sucesso em sistemas computacionais, e que a emoção é utilizada como parte importante da arquitetura do agente e tem influência direta no seu comportamento. Entretanto, na maior parte dos trabalhos, a influência da emoção ocorre somente no nível fisiológico.

Conforme será apresentado no capítulo 2, a emoção tem dois componentes [Picard, 1997]: o fisiológico e o cognitivo. Nas arquiteturas descritas, os estados afetivos influenciam a expressão facial, entonação de voz, gestos, seleção de palavras e frases e a resposta reativa a estímulos. No entanto, os trabalhos pouco exploram o componente cognitivo no sentido de investigar como a personalidade e a emoção influenciam processos cognitivos tais como: percepção, motivação, memória e tomada de decisão. Segundo Laird [2008], as pesquisas futuras em computação afetiva deverão explorar como as emoções e sentimentos podem ser utilizados produtivamente com outros módulos (memória, tomada de decisão), assim como na interação com outros agentes.

\subsection{Objetivo}

O objetivo principal deste trabalho é desenvolver e implementar uma arquitetura de agente inteligente para a construção de personagens sintéticos com personalidade e emoção.

Para o desenvolvimento de tal arquitetura utilizou-se o modelo $\mathrm{BDI}^{4}$ como base e aos módulos

\footnotetext{
${ }^{4} \mathrm{O}$ modelo BDI (Beliefs, Desires e Intentions) decompõe a construção de um agente em três principais componentes (Crenças, Desejos e Intenções), além de delinear a interação entre os componentes.
} 
existentes foi incluído um Módulo Afetivo. Esse Módulo Afetivo é constituído por três submódulos (Personalidade, Humor e Emoção) e deve influenciar nas atividades cognitivas de percepção, memória e tomada de decisão do agente.

Por fim, foram construídas duas provas de conceito com a finalidade de mostrar que os agentes desenvolvidos com a arquitetura proposta, apresentam um comportamento coerente e diferente dos agentes tradicionais, pois são influenciados pelo seu estado afetivo.

Este trabalho não pretende discutir se a arquitetura proposta permite a construção de agentes com um comportamento mais convincente do que os demais, mas sim objetiva o estudo da influência dos estados afetivos nos processos cognitivos e as suas consequências no comportamento do personagem.

O objetivo principal pode ser decomposto nos seguinte objetivo específicos:

- Realizar um estudo bibliográfico dos modelos de personalidade e emoção desenvolvidos nas áreas de Psicologia e Neurociência bem como de modelos que associem às atividades cognitivas, personalidade e emoção;

- Identificar, no estudo realizado, quais os modelos adequados e que devem servir de base para o desenvolvimento do modelo conceitual;

- Delinear um modelo conceitual que integre ao modelo BDI um Módulo Afetivo que deve influenciar nas atividades cognitivas do agente;

- Implementar o modelo conceitual proposto utilizando como base um framework de modelo BDI;

- Construir duas provas de conceito (no domínio dos sistemas de Entretenimento Digital) para avaliar e explorar o comportamento dos agentes;

- Validar o comportamento produzido, pelos agentes construídos, utilizando a arquitetura implementada.

\subsection{Estrutura do trabalho}

O primeiro capítulo abordou algumas questões fundamentais que foram utilizadas de motivação e base para o desenvolvimento do trabalho. Primeiramente, destaca-se a importância da Inteligência Artificial nos sistemas de Entretenimento Digital e em especial nos jogos de computador. Em seguida, foram apresentadas definições e características dos agentes inteligentes, computação afetiva e agentes com comportamento convincente. Esse capítulo também explorou alguns projetos correlatos envolvendo agentes e estados afetivos. Por fim, o objetivo geral e os específicos foram delineados bem como as provas de conceito.

Este trabalho foi organizado em cinco capítulos, sendo o restante estruturado da seguinte maneira: 


\section{Capítulo 2: Modelos da Psicologia e Neurociência}

Neste capítulo são descritos alguns modelos de personalidade, humor e emoção, baseados nos estudos da Psicologia e da Neurociência. Além disso, apresenta-se os componentes fisiológico e cognitivo da emoção e também como o estado afetivo influencia o comportamento humano.

\section{Capítulo 3: Arquitetura}

Esse capítulo é dividido em duas partes. Na primeira a base conceitual para a elaboração da arquitetura é discutida envolvendo temas, como por exemplo, agentes inteligentes, tipos de arquiteturas de agentes e frameworks. A segunda parte descreve em detalhes a arquitetura desenvolvida, incluindo seus módulos, filtros e ciclo de iteração.

\section{Capítulo 4: Provas de Conceito}

Esse capítulo inicialmente estabelece os critérios de avaliação que foram considerados para verificar o comportamento produzido pelos agentes criados com a arquitetura desenvolvida. Em seguida são apresentadas as duas provas de conceito utilizadas para a avaliação bem como os resultados. Ao final, esses resultados são analisados considerando os critérios definidos anteriormente.

\section{Capítulo 5: Considerações Finais}

No capítulo 5 são apresentadas as considerações finais do trabalho. Também são descritos alguns

caminhos (experimentos, áreas de aplicação e questões a serem investigadas) que possibilitam a sua continuidade. 


\section{Capítulo 2}

\section{Modelos da Psicologia e Neurociência}

Esse capítulo é dividido em quatro partes. Nas três primeiras são apresentados respectivamente modelos de personalidade, humor e emoção baseados na Psicologia e Neurociência. Na última parte a emoção é dividida em dois componentes: fisiológico e cognitivo. No componente fisiológico, é destacada a influência que a emoção exerce sobre as expressões faciais, gestos e entonação da voz. Já no componente cognitivo, o estudo ressalta a importância da influência dos estados afetivos para a percepção, memória e tomada de decisão.

\subsection{Personalidade}

Uma das investigações mais antigas do campo da Psicologia está em compreender a personalidade de um indivíduo. Nas últimas décadas muitos modelos e definições foram delineados com o objetivo de explicar as diferenças básicas entre os indivíduos [Gazzaniga e Heatherton, 2005]. Desse modo, diversos modelos foram criados, ao longo dos anos, com o intuito de descrever a personalidade de cada ser humano. Esses modelos, em sua maioria, apresentam diferenças quanto à origem da personalidade, metodologias de coletas de dados e a forma como interpretam os dados coletados.

O primeiro autor a publicar um livro sobre personalidade foi Gordon Allport em 1937. Em seu livro intitulado "Personality: A Psychological Interpretation", o autor propõe uma definição funcional onde a personalidade é vista com uma organização dinâmica dos sistemas psicofísicos do indivíduo que determinam seus comportamentos e pensamentos [Matthews et al., 2003]. Apesar de historicamente importante, a definição de Allport não é mais utilizada, pois não inclui muitos conceitos importantes sobre o entendimento contemporâneo da personalidade [Pervin e John, 2003].

Atualmente, a personalidade é compreendida como um sistema no qual um conjunto de padrões inatos da pessoa interage com o ambiente social nas dimensões afetivas, cognitivas e comportamentais para produzir as ações e as experiências de uma vida individual [Garcia, 2006].

Segundo Garcia [2006], a maioria dos teóricos da personalidade concorda com essa definição variando, dependendo da abordagem utilizada, o foco para aspectos mais específicos associados à biologia, à genética, às experiências da infância, à maneira de pensar, ao ambiente, à cultura e ao inconsciente.

As principais abordagens existentes para o estudo da personalidade humana são descritas abaixo [Pervin e John, 2001]: 
Abordagem psicanalítica Essa abordagem explica a personalidade examinando como as forças do inconsciente, desejos, motivos e necessidades físicas e biológicas influenciam os pensamentos, sentimentos e comportamentos. Os principais autores dessa abordagem foram: Sigmund Freud, Carl Jung, Alfred Adler e Erik Erikson.

Abordagem humanista A abordagem humanista enfatiza a experiência pessoal, sentimentos e os valores básicos individuais dos sujeitos. Dessa forma, a personalidade de cada indivíduo é formada pela maneira particular de observar e interpretar o mundo. Os psicólogos humanistas acreditam que a experiência humana é subjetiva e que as pessoas são naturalmente boas. Os dois psicólogos que mais se destacaram nos estudo dessa abordagem foram Abraham Maslow e Carl Rogers.

Abordagem dos traços As palavras utilizadas pelas pessoas para descrever a personalidade das outras (ou delas mesmas) são chamadas de traços de personalidade. A abordagem dos traços procura investigar como as pessoas são diferentes (quais traços melhor as descrevem) e quanto elas diferem (o grau de variação nos traços em relação as outras). Os principais pesquisadores da abordagem dos traços foram: Gordon Allport, Paul Costa Jr., Robert McCrae, Raymond Bernard Cattell e Hans Eysenck.

Abordagem cognitiva A abordagem cognitiva ressalta como as crenças, experiências prévias, aprendizagens anteriores, histórias individuais, interação com o ambiente e a interpretação que é feito dele moldam o comportamento e a personalidade. Os pesquisadores que estudaram a personalidade sob a perspectiva cognitiva foram Kurt Lewin, Jean Piaget, George Kelly, Julian Rotter e Albert Bandura.

Abordagem biológica A abordagem biológica enfatiza como os fatores neuroquímicos e genéticos explicam a predisposição de indivíduos a determinados comportamentos. Dentre os psicólogos e biólogos que defendiam a abordagem biológica destacam-se Charles Darwin, Ivan Pavlov e Hans Eysenck.

Das abordagens descritas, aquela que apresenta as características mais apropriadas à construção de agentes com personalidade, foco de investigação desse estudo, é a abordagem dos traços. Isso se justifica pelo nível de aprofundamento descritivo que tal abordagem se propõe a fazer, e pela semelhança com a maneira intuitiva das pessoas perceberem a personalidade.

Portanto, por ser a abordagem mais apropriada para esse trabalho, a seção a seguir descreve, com um pouco mais de detalhes, a abordagem dos traços e alguns modelos de personalidade. 


\section{Abordagem dos Traços}

Se um indivíduo precisar descrever outro, provavelmente não se aprofundará em questões biológicas, de interpretação do ambiente ou conflitos do inconsciente, mas provavelmente descreverá a pessoa como sendo extrovertida ou introvertida, impulsiva ou conservadora ou utilizando alguma outra característica. No contexto da abordagem dos traços, cada uma dessas características é chamada de traços. Segundo Garcia [2006] os traços são características da personalidade que se tornam estáveis com o tempo e em diferentes situações.

Sendo assim, os pesquisadores da abordagem dos traços definem a personalidade como um modelo matemático da personalidade que representa uma síntese das características básicas, considerando suas propriedades principais e a relação entre elas [Pervin e John, 2003].

Por ser fundamentalmente descritiva, a abordagem dos traços oferece maneiras de quantificar e classificar a personalidade em traços por meio de testes experimentais e observações.

Os primeiros pesquisadores a investigar os traços de personalidade e tentar determinar o número de traços necessários para a descrição de um indivíduo foram os psicólogos norte-americanos Gordon Allport e Henry Obdert da Universidade de Harvard, em 1937. Os cientistas percorreram o dicionário e assinalaram todas as palavras que podiam ser utilizadas para descrever traços de personalidade. Ao final do trabalho aproximadamente 18.000 palavras foram assinaladas. Esse número foi reduzido a pouco mais de 4.500 após a retirada dos sinônimos [Matthews et al., 2003].

O trabalho de Allport e Odbert influenciou muitos pesquisadores de tal maneira que diversos modelos foram construídos com o objetivo de determinar o número de traços necessários para classificar a personalidade de uma pessoa. Abaixo, segue a descrição dos principais modelos desenvolvidos (Modelos dos 16 Fatores de Cattell (16F), Modelo dos três "Superfatores" de Eysenck, Modelo dos Cinco Grandes Fatores).

\subsubsection{Modelo dos 16 Fatores de Cattell (16F)}

Em 1946 o psicólogo britânico Raymond Bernard Cattell iniciou um estudo para analisar a tabela dos descritores de personalidade desenvolvida por Allport e Odbert utilizando análise fatorial. A análise fatorial é um procedimento estatístico baseado no conceito de correlação (coeficiente de correlação) que mede o relacionamento entre dois conjuntos de variáveis. Com a ajuda dos recursos computacionais que estavam emergindo na época, Cattell conseguiu percorrer a extensa base de dados agrupando os descritores de forma objetiva [Gazzaniga e Heatherton, 2005].

Como resultado da análise dessa base, Cattell propôs 16 fatores primários (Tabela 2.1) que descrevem as principais características da personalidade humana. A tabela indica, por exemplo, que pessoas com valores baixos no fator "Disciplina" tendem a ser tolerantes a desordem, flexíveis, ou seja, com pouca disciplina. Já pessoas com altos valores nesse fator, são controladas, perfeccionistas, organizadas e disciplinadas.

Para avaliar a personalidade de um indivíduo em relação aos 16 fatores primários, Cattell desenvolveu um questionário chamado "Questionário de 16 Fatores de Personalidade" lançado em 


\begin{tabular}{|l|l|l|}
\hline Fatores & Valores Baixos & Valores Altos \\
\hline \hline Expansividade & reservado, impessoal, distante & $\begin{array}{l}\text { expansivo, participante, aten- } \\
\text { cioso }\end{array}$ \\
\hline Inteligência & $\begin{array}{l}\text { menos inteligente, pensa- } \\
\text { mento concreto }\end{array}$ & $\begin{array}{l}\text { mais inteligente, pensamento } \\
\text { abstrato }\end{array}$ \\
\hline Estabilidade & $\begin{array}{l}\text { emocional, sensível às im-- } \\
\text { pressões afetivas, emocional- } \\
\text { mente instável }\end{array}$ & $\begin{array}{l}\text { emocionalmente } \\
\text { adaptável, maduro }\end{array}$ \\
\hline Afirmação & $\begin{array}{l}\text { humilde, brando, cooperativo, } \\
\text { avesso a conflitos }\end{array}$ & $\begin{array}{l}\text { afirmativo, dominante, agres- } \\
\text { sivo, assertivo }\end{array}$ \\
\hline Preocupação & $\begin{array}{l}\text { sóbrio, sério, retraído, pru- } \\
\text { dente }\end{array}$ & $\begin{array}{l}\text { despreocupado, alegre, ani- } \\
\text { mado }\end{array}$ \\
\hline Consciência & $\begin{array}{l}\text { evasivo, inconveniente, dissi- } \\
\text { dente }\end{array}$ & $\begin{array}{l}\text { consciencioso, segue valores } \\
\text { culturais, convencionais }\end{array}$ \\
\hline Desenvoltura & acanhado, tímido, sensível & $\begin{array}{l}\text { desenvolto, venturoso, insen- } \\
\text { sível a repressões }\end{array}$ \\
\hline Brandura & prático, objetivo, realista & $\begin{array}{l}\text { sensível, harmonioso, senti- } \\
\text { mental }\end{array}$ \\
\hline Confiança & $\begin{array}{l}\text { confiante, acredita nas pes- } \\
\text { soas }\end{array}$ & $\begin{array}{l}\text { desconfiado, } \\
\text { cauteloso }\end{array}$ \\
\hline Imático, cuidadoso, preciso, \\
formal
\end{tabular}

Tabela 2.1: Os 16 fatores primários propostos por Cattell [de Souza et al., 2007].

1949. Hoje o questionário está na sua quinta versão ${ }^{1}$ (lançada em 1993) que é composto por 185 questões de múltipla escolha com um tempo de aplicação de 50 minutos. Além dessa última versão, existem diversas revisões e alterações que foram criadas para adaptar o instrumento a diferentes contextos, aplicações e culturas.

\subsubsection{Modelo dos três "Superfatores" de Eysenck}

Segundo McCrae [2006], o alemão Hans Jurgen Eysenck é, provavelmente, um dos psicólogos científicos mais importantes da história, não só por suas pesquisas no campo da personalidade, mas

\footnotetext{
${ }^{1}$ http://www.ipat.com
} 
também por suas investigações em outros tantos campos da Psicologia Científica, sobretudo nas áreas relacionadas ao estudo das diferenças individuais.

Diferentemente dos outros modelos apresentados anteriormente, Eysenck fundamenta sua pesquisa nas bases biológicas dos traços, e não de um ponto de vista léxico da linguagem. Dessa maneira, uma dimensão da personalidade não é considerada como um traço de temperamento básico se não dispõe de uma base biológica contrastada por meio de estudos correlacionais e experimentais. Por apresentar uma validação experimental das propriedades dos traços, o modelo de Eysenck é considerado uma verdadeira teoria da personalidade [Garcia, 2006].

Em 1970, por meio de uma análise fatorial do histórico clínico de pacientes internados em hospitais psiquiátricos, Eysenck extraiu duas dimensões de personalidade (descritas abaixo): Extroversão e Neuroticismo [Gazzaniga e Heatherton, 2005].

Neuroticismo: Pessoas com alto neuroticismo normalmente são ansiosas, deprimidas e apresentam frequente mudanças no humor (especialmente quando as emoções são negativas). Já os indivíduos mais calmos e equilibrados apresentam baixo neuroticismo.

Extroversão: Alta extroversão refere-se à pessoas sociáveis, expansivas e ousadas e baixa extroversão à pessoas tímidas, reservadas e tranquilas.

A análise dos valores das duas primeiras dimensões são as mesmas que aparecem no modelo dos Cinco Grandes Fatores (descrito na próxima seção). Todos os modelos desenvolvidos posteriormente adicionaram as dimensões Neuroticismo e Extroversão devido à reconhecida fundamentação empírica dos trabalhos de Eysenck [McCrae, 2006].

Para classificar a personalidade de uma pessoa, o autor descreveu quatro subtipos de personalidade (melancólico, colérico, fleumático e sanguíneo) que operam sobre os eixos da Figura 2.1. A figura mostra dois eixos representados pelos traços extroversão e neuroticismo, bem como um conjunto de adjetivos que podem descrever cada subtipo.

A figura indica, por exemplo, que um indivíduo com baixo escore em neuroticismo (instável) e baixo escore em extroversão (introvertido) se encaixa no subtipo de personalidade melancólico, tendo como características ser um sujeito quieto, antissocial, reservado, pessimista, sóbrio, rígido, ansioso e mal-humorado.

Após estudos iniciais abordando a personalidade com somente dois fatores, Eysenck adiciona mais um fator chamado psicoticismo [Pervin e John, 2003].

Psicoticismo: Pessoas com alto escore em Psicoticismo tendem a ser impulsivas e respondem de maneira agressiva e hostil as consequências de seus atos. São consideradas frias, cruéis e insensíveis. Baixos escores indicam pessoas carinhosas, amáveis e que sabem controlar melhor seus impulsos.

Para medir o escore dos indivíduos em cada um dos fatores, Eysenck desenvolveu diversos questionários - Maudsley Personality Inventory, Eysenck Personality Inventory e Eysenck Personality 


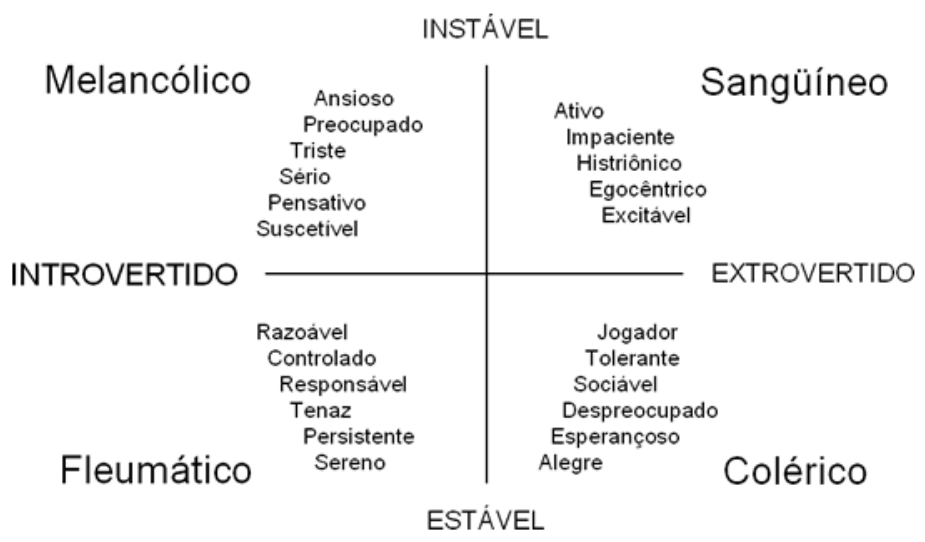

Figura 2.1: Classificação de personalidade no modelo de Eysenck [Garcia, 2006].

Questionnaire. A exemplo do que acontece com o "Questionário de 16 Fatores de Personalidade", os questionários criados por Eysenck já foram revisados e adaptados, podendo variar quanto ao número e tipo de questões (múltipla escolha ou verdadeiro e falso) dependendo da versão.

\subsubsection{O modelo dos Cinco Grandes Fatores}

O modelo dos Cinco Grandes Fatores começou a ser delineado na década de 1930 pelo psicólogo britânico William McDougall que sugeriu analisar a personalidade a partir de cinco fatores [Gazzaniga e Heatherton, 2005]. No entanto, esse modelo só ganhou impulso a partir da década de 1980 quando as pesquisas começaram a comprovar a existência de cinco traços básicos de personalidade em indivíduos de diferentes culturas e faixas etárias. Assim, nos últimos 30 anos, muitos psicólogos da personalidade concordam com o modelo dos Cinco Grandes Fatores [McCrae e Costa, 1999].

Por meio de uma abordagem léxica em linguagem natural foi desenvolvido o modelo que descreve e classifica a personalidade humana em cinco fatores (Neuroticismo, Extroversão, Abertura à Experiência, Cordialidade e Responsabilidade), onde cada fator reune uma variedade de traços psicológicos [Fioravanti, 2006]. A abordagem utilizada para descobrir esses fatores partiu do pressuposto que todos os descritores da personalidade humana, que tem alguma relevância, interesse, utilidade ou importância estão registrados na linguagem natural [Garcia, 2006]. Os cinco fatores são descritos a seguir.

Neuroticismo: Indivíduos com escores altos apresentam hipersensibilidade emocional, reações muito intensas a todo tipo de estímulo e têm dificuldades para retornar a normalidade depois de experiências fortes. Geralmente são ansiosos, preocupados, depressivos, com mudança de humor e propensos a sofrimento psicológico. Já os indivíduos mais equilibrados, calmos, controlados e que respondem a estímulos emocionais de maneira mais controlada e proporcionada apresentam baixo escores nesse fator.

Extroversão: Altos escores em extroversão revelam pessoas sociáveis, otimistas, ativas, que gostam de situações excitantes e de se arriscar. Adoram brincadeiras e mudanças. Baixos escores reve- 
lam pessoas socialmente reservadas, distantes, previdentes, desconfiadas de impulsos súbitos, independentes e quietas.

Abertura à Experiência: As pessoas com altos escores nesse fator são liberais, criativas, curiosas, imaginativas e tolerantes. Tendem a ter fantasias, emoções, idéias e valores não convencionais. Já as pessoas com baixo escore em abertura à experiência são essencialmente conservadoras e convencionais em suas crenças e atitudes. Não gostam de idéias que provoquem mudanças profundas.

Cordialidade: Pessoas com alta cordialidade tendem a ser amáveis, agradáveis, cordiais, prestativas, altruístas, confiantes. Percebem e interpretam adequadamente tanto as próprias emoções quanto as dos outros. No outro extremo, temos as pessoas frias, egocêntricas, não cooperativas, cínicas, rudes e irritáveis.

Responsabilidade: Altos escores em responsabilidades indicam uma pessoa metódica, reflexiva, organizada e persistente. Pensam muito antes de tomar alguma decisão e gostam de ter tudo planejado. Possuem forte sentido do dever, respeitam regras sociais e controlam seus impulsos. Baixos escores sinalizam uma pessoa pouco capaz de controlar seus impulsos. Não tem objetivos claros, e tende a ser desorganizada, irresponsável, preguiçosa, e não respeita obrigações pessoais ou sociais.

As descrições apresentadas acima são baseadas apenas em um único traço, contudo, segundo o modelo das Cinco Grandes Fatores, é preciso conhecer a pessoa nos cinco traços para obter-se um perfil adequado da personalidade. Para tanto, alguns questionários foram criados e o principal deles é o NEO-PI-R (Revised NEO Personality Inventory) criado em 1992 pelos pesquisadores americanos Paul Costa e Robert McCrae.

O NEO-PI-R é um questionário com 240 questões de múltipla escolha (possui também uma versão reduzida com 60 questões) que avalia a personalidade de uma pessoa nos cinco grandes fatores. Para um melhor entendimento de cada um dos fatores, os autores dividiram cada um dos cinco fatores em seis facetas (conforme a Tabela 2.2) [Garcia, 2006].

\begin{tabular}{|c|c|c|c|c|}
\hline Neuroticismo & Extroversão & Abertura & Cordialidade & Responsabilidade \\
\hline \hline Ansiedade & Acolhimento & Fantasia & Confiança & Competência \\
Agressividade-hostilidade & Gregarismo & Estética & Retidão & Ordem \\
Depressão & Assertividade & Sentimentos & Altruísmo & Cumprimento do dever \\
Constrangimento & Atividade & Ações & Complacência & Esforço por realizações \\
Impulsividade & Busca de sensações & Idéias & Modéstia & Autodisciplina \\
Vulnerabilidade ao estresse & Emoções positivas & Valores & Sensibilidade & Deliberação \\
\hline
\end{tabular}

Tabela 2.2: Facetas do questionário NEO-PI-R [Garcia, 2006].

Os autores descrevem que todas as facetas de cada um dos traços são relacionadas entre si. Dessa maneira cada uma das seis facetas representa um fator primário do traço em questão. Por 
exemplo: o questionário define que existem tendências a que todas as pessoas com alto escore em responsabilidade sejam organizadas, tenham autodisciplina, cumpram seus deveres e que façam esforço para as suas realizações. Um raciocínio análogo pode ser feito para os outros quatro traços. Essa hipótese pode ser comprovada empiricamente: analisando conjuntamente as 30 facetas do questionário avaliativo NEO-PI-R, provavelmente cada faceta se agrupa em seu fator correspondente descrevendo cinco fatores claramente identificáveis como as cinco dimensões de temperamento da personalidade [McCrae, 2006].

Outro exemplo de questionário é o Inventário de Traços Bipolares proposto por Goldberg [1992]. Uma versão reduzida do inventário descrita por Pervin e John [2003] é apresentada abaixo na figura 2.2 .

\begin{tabular}{|c|c|c|c|c|c|c|c|c|c|c|}
\hline & Muito & \multicolumn{3}{|c|}{ Moderadamente } & Nenhum & \multicolumn{3}{|c|}{ Moderadamente } & Muito & \\
\hline \multicolumn{11}{|c|}{ Introversão versus Extroversão } \\
\hline Silencioso & 1 & 2 & 3 & 4 & 5 & 6 & 7 & 8 & 9 & Falante \\
\hline Não-assertivo & 1 & 2 & 3 & 4 & 5 & 6 & 7 & 8 & 9 & Assertivo \\
\hline Não-ousado & 1 & 2 & 3 & 4 & 5 & 6 & 7 & 8 & 9 & Ousado \\
\hline Não-enérgico & 1 & 2 & 3 & 4 & 5 & 6 & 7 & 8 & 9 & Enérgico \\
\hline Tímido & 1 & 2 & 3 & 4 & 5 & 6 & 7 & 8 & 9 & Destemido \\
\hline \multicolumn{11}{|c|}{ Antagonismo versus Amabilidade } \\
\hline Indelicado & 1 & 2 & 3 & 4 & 5 & 6 & 7 & 8 & 9 & Bondoso \\
\hline Não-cooperativo & 1 & 2 & 3 & 4 & 5 & 6 & 7 & 8 & 9 & Cooperativo \\
\hline Egoísta & 1 & 2 & 3 & 4 & 5 & 6 & 7 & 8 & 9 & Altruísta \\
\hline Desconfiado & 1 & 2 & 3 & 4 & 5 & 6 & 7 & 8 & 9 & Confiante \\
\hline Mesquinho & 1 & 2 & 3 & 4 & 5 & 6 & 7 & 8 & 9 & Generoso \\
\hline \multicolumn{11}{|c|}{ Falta de Direção versus Consciência } \\
\hline Desorganizado & 1 & 2 & 3 & 4 & 5 & 6 & 7 & 8 & 9 & Organizado \\
\hline Irresponsável & 1 & 2 & 3 & 4 & 5 & 6 & 7 & 8 & 9 & Responsável \\
\hline Não-prático & 1 & 2 & 3 & 4 & 5 & 6 & 7 & 8 & 9 & Prático \\
\hline Descuidado & 1 & 2 & 3 & 4 & 5 & 6 & 7 & 8 & 9 & Detalhista \\
\hline Preguiçoso & 1 & 2 & 3 & 4 & 5 & 6 & 7 & 8 & 9 & Trabalhador \\
\hline \multicolumn{11}{|c|}{ Estabilidade Emocional versus Neuroticismo } \\
\hline Descontraido & 1 & 2 & 3 & 4 & 5 & 6 & 7 & 8 & 9 & Tenso \\
\hline Tranqüilo & 1 & 2 & 3 & 4 & 5 & 6 & 7 & 8 & 9 & Nervoso \\
\hline Estável & 1 & 2 & 3 & 4 & 5 & 6 & 7 & 8 & 9 & Instável \\
\hline Satisfeito & 1 & 2 & 3 & 4 & 5 & 6 & 7 & 8 & 9 & Insatisfeito \\
\hline Não-emotivo & 1 & 2 & 3 & 4 & 5 & 6 & 7 & 8 & 9 & Emotivo \\
\hline \multicolumn{11}{|c|}{ Fechamento versus Abertura à Novas Experiências } \\
\hline Não-imaginativo & 1 & 2 & 3 & 4 & 5 & 6 & 7 & 8 & 9 & Imaginativo \\
\hline Não-criativo & 1 & 2 & 3 & 4 & 5 & 6 & 7 & 8 & 9 & Criativo \\
\hline Não-inquisitivo & 1 & 2 & 3 & 4 & 5 & 6 & 7 & 8 & 9 & Curioso \\
\hline Não-reflexivo & 1 & 2 & 3 & 4 & 5 & 6 & 7 & 8 & 9 & Reflexivo \\
\hline Não-sofisticado & 1 & 2 & 3 & 4 & 5 & 6 & 7 & 8 & 9 & Sofisticado \\
\hline
\end{tabular}

Figura 2.2: Uma versão reduzida do Inventário de Traços Bipolares [Pervin e John, 2003].

Segundo Pervin e John [2003] o inventário apresentado na figura 2.2 não é uma avaliação formal, mas sim um exercício que exemplifica uma possível maneira de medir a personalidade. Para obter o resultado final, basta fazer a média dos resultados de cada um dos traços. 


\subsection{Humor}

As pessoas tendem a empregar as palavras humor e emoção de maneira equivalente na linguagem do cotidiano. Humor e emoção se distinguem em termos de intensidade e em termos de duração [Vinayagamoorthy et al., 2006]. O humor é um estado emocional difuso e duradouro que influencia as atividades cognitivas humanas [Gazzaniga e Heatherton, 2005]. Além disso, o humor, normalmente é resultado de pequenos acontecimentos, enquanto as emoções são causadas por um único estímulo. Segundo Morris [1992], o humor é a percepção que as pessoas têm de possuir recursos, ou não, necessários para atender às demandas do ambiente onde estão inseridas.

Tradicionalmente, o humor é representado de forma unidimensional onde nos extremos estão o "bom humor" e o "mau humor" [Picard, 1997]. O ponto central dessa dimensão é chamado de humor neutro.

Outra representação do humor utilizada recentemente é o modelo PAD (pleasure, arousal, e dominance) [Mehrabian, 1995]. Inicialmente, esse modelo foi desenvolvido para verificar a satisfação de consumidores após a compra de um produto. O modelo consiste de três dimensões independentes que são utilizadas para descrever e avaliar estados de humor: prazer/desprazer, excitação/tranquilidade, e dominância/submissão. O prazer/desprazer mede a qualidade afetiva dos estados emocionais, excitação/tranquilidade descreve uma composição de atividade física e atenção, e dominância/submissão é definida em termos de controle e falta de controle [Mehrabian, 2009].

Um ponto nesse espaço tridimensional representa o humor de uma pessoa. Como em termos numéricos cada uma das dimensões varia de -1.0 até 1.0, existem oito estados de humor definidos pelo modelo. Os oito estados são apresentados na tabela 2.3 e o espaço tridimensional do modelo PAD pode ser visualizado na figura 2.3:

\begin{tabular}{|c|c|}
\hline Dimensão & Humor \\
\hline \hline$+\mathrm{P}+\mathrm{A}+\mathrm{D}$ & exuberante \\
$+\mathrm{P}+\mathrm{A}-\mathrm{D}$ & dependente \\
$+\mathrm{P}-\mathrm{A}+\mathrm{D}$ & relaxado \\
$+\mathrm{P}-\mathrm{A}-\mathrm{D}$ & dócil \\
$-\mathrm{P}-\mathrm{A}-\mathrm{D}$ & entediado \\
$-\mathrm{P}-\mathrm{A}+\mathrm{D}$ & arrogante \\
$-\mathrm{P}+\mathrm{A}-\mathrm{D}$ & ansioso \\
$-\mathrm{P}+\mathrm{A}+\mathrm{D}$ & hostil \\
\hline
\end{tabular}

Tabela 2.3: Os oito estados de humor do modelo PAD [Mehrabian, 2009].

\subsection{Emoção}

A emoção tem sido objeto de estudo em diversas áreas do conhecimento tais como Psicologia, Neurociência, Filosofia e Inteligência Artificial. Entretanto, não existe um consenso sobre a definição de emoção, devido a sua natureza subjetiva, a divergência dos pesquisadores quanto a sua origem e pelo termo ser empregado para descrever uma ampla gama de estados cognitivos e fisiológicos [Gazzaniga e Heatherton, 2005]. Segundo Fehr e Russell [1984], todas as pessoas sabem 


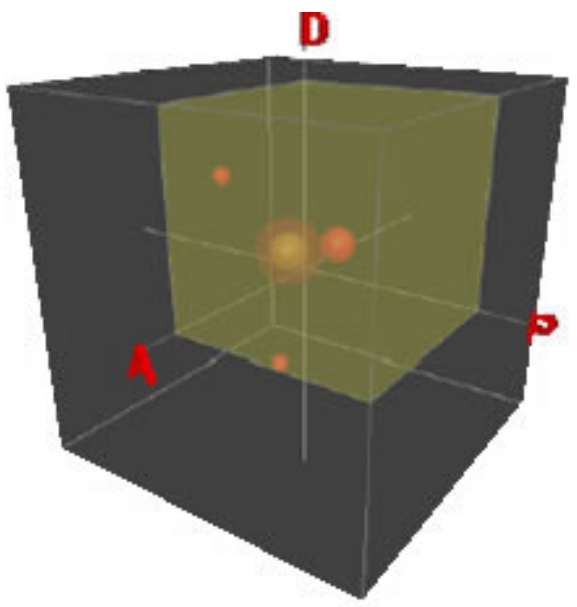

Figura 2.3: Espaço tridimensional do modelo PAD [Gebhard, 2005].

o que é emoção, até pedirem para defini-la. A emoção é muitas vezes utilizada para descrever não somente sentimentos (felicidade e tristeza), mas também desejos de motivação biológicos (fome e sede). Assim, também podem ser definidas como sendo os estados mentais fortemente influenciados pelos sentimentos gerados por alterações fisiológicas.

Os filósofos da Grécia Antiga foram os primeiros a tratarem o assunto. Platão dizia que a emoção é algo que confunde, interrompe e distrai a razão humana. Entretanto, para Aristóteles a emoção é uma mistura envolvendo em grande parte a vida cognitiva e em pequena parte da vida fisiológica. Ainda segundo Aristóteles, a emoção é a faceta mais interessante da existência humana [Strongman, 2003].

O pensador René Descartes promoveu a primeira teoria influente de que a mente e o corpo eram separados, mas interligados (Teoria do Dualismo). Dentro dessa teoria, o corpo funcionava apenas como uma unidade de ação mecânica, previsível e determinística, enquanto que a mente controlava a ação, memória, imaginação e emoção [Damásio, 1996]. Já o cientista Charles Darwin publicou em 1872 o livro "A Expressão da Emoção em Homens e Animais" onde destacou o papel fundamental das emoções no processo de adaptação dos seres vivos. Segundo o cientista, a expressão facial indicando estados emocionais é uma forma de comunicação eficiente e compreensível para as pessoas, independente da cultura e essas características expressivas são adaptativas em todas as formas de vida.

Atualmente, os pesquisadores dividem os estudos sobre emoção em três áreas descritas a seguir: Emoções Básicas, Emoções na Teoria da Avaliação e Emoções Primárias, Secundárias e Terciárias.

\subsubsection{Emoções Básicas}

O conceito de Emoção Básica (ou Emoção Pura) foi proposto pelos psicólogos norte-americanos Paul Ekman e Wallace Friesen e frequentemente é associado a simulação de expressões faciais. Essas emoções, segundo os autores, são inatas, evolutivamente adaptativas, compartilhadas por todas as culturas e associadas a estados fisiológicos específicos.

Apesar de não haver um consenso entre os pesquisadores sobre quantas e quais são as emoções 
básicas, Ekman e Friesen Ekman e Friesen [1978] propuseram um modelo de seis emoções básicas: tristeza, raiva, alegria, medo, desagrado e surpresa. Para testar a validade dos resultados da pesquisa, os autores foram à Argentina, ao Brasil, ao Chile, ao Japão, à Nova Guiné e aos Estados Unidos, onde pediram para que pessoas identificassem respostas emocionais apresentadas em fotografias de expressões faciais e descobriram que em todos esses países as pessoas reconheciam as seis emoções básicas.

As principais críticas a esse modelo é o número insuficiente de rótulos para descrever a riqueza das expressões emocionais e a diferenças entre o número de emoções positivas e negativas dentre as seis básicas.

Outro modelo baseado em Emoções Básicas é o modelo de Plutchik [1980] chamado de "Teoria Psicoevolutiva das Emoções". Esse modelo desenvolvido pelo pesquisador Robert Plutchik representa oito emoções básicas (alegria, confiança, antecipação, raiva, tristeza, repugnância, surpresa e medo) em um círculo colorido. A figura 2.4 apresenta as oito emoções básicas em três dimensões: similaridade (corresponde à proximidade das emoções), polaridade negativa e positiva (as oito emoções são agrupadas em quatro pares de pólos opostos) e intensidade (quanto mais intensa a emoção, mas intensa a cor). Segundo o autor, cada uma das oito emoções corresponde a um processo adaptativo que pode estar associado a segurança, reprodução e socialização.

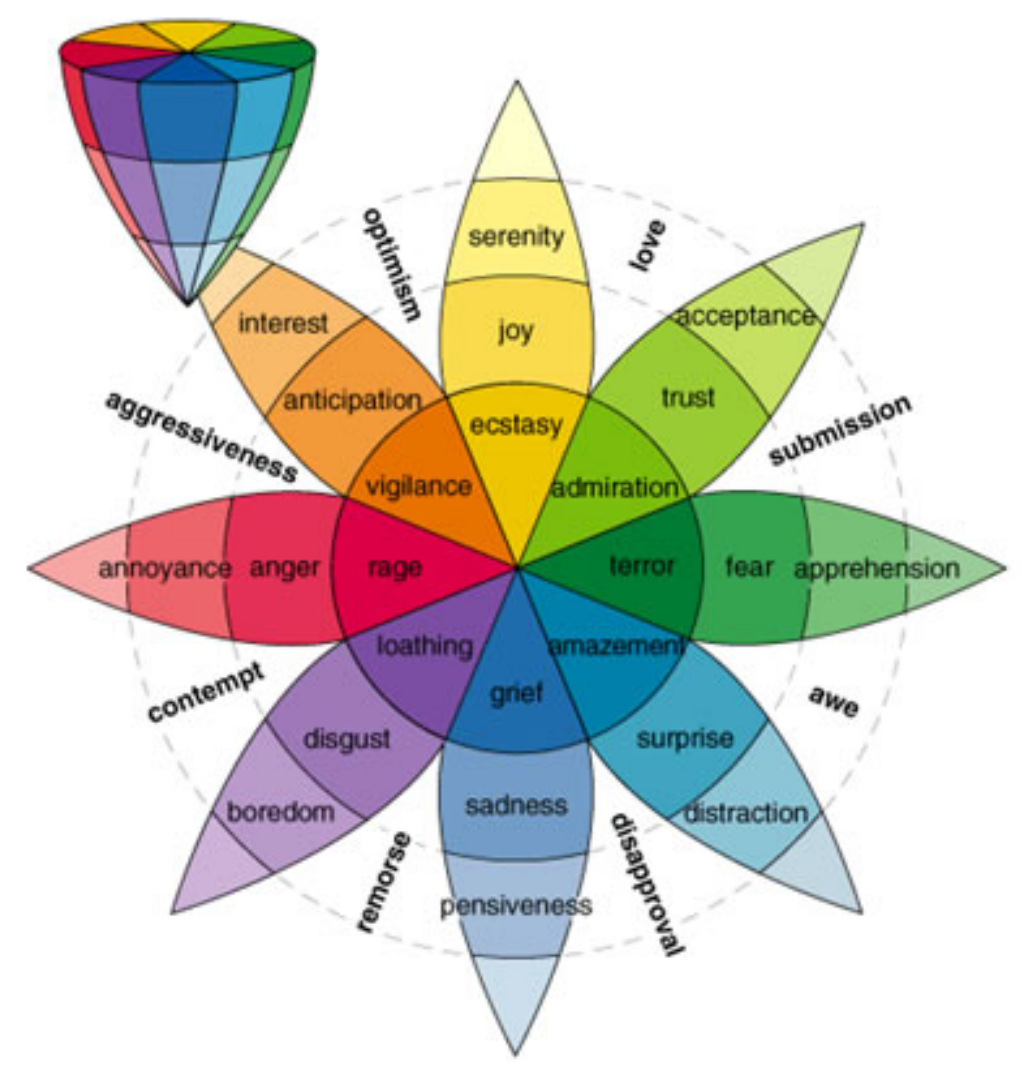

Figura 2.4: Representação gráfica do modelo de Plutchik [Plutchik, 2002]. 


\subsubsection{Emoções na Teoria da Avaliação}

Outra abordagem comum são os modelos avaliativos da emoção. Nessa abordagem, a emoção é uma reação que resulta da avaliação de eventos, indivíduos e objetos do ambiente. Durante o processo de avaliação, os eventos emocionais são classificados e sua intensidade é determinada em função dos objetivos, crenças, riscos e atitudes da pessoa ou agente [Strongman, 2003]. A seguir são apresentados dois dos principais modelos de emoção na teoria da avaliação: o Modelo Cognitivo de Ortony, Clore e Collins (OCC) e o Modelo Cognitivo de Roseman.

\section{O Modelo Cognitivo de Ortony, Clore e Collins (OCC)}

Em 1988 os pesquisadores Andrew Ortony, Gerald Clore e Allan Collins no livro "The Cognitive Structure of Emotions" estabeleceram um modelo cognitivo de emoções que ficou conhecido como o modelo OCC. Segundo os autores, sistemas de Inteligência Artificial devem ser capazes de raciocinar sobre emoções, especialmente para compreensão de linguagem natural, solução cooperativa de problemas e de planejamento [Ortony et al., 1988].

O modelo não aborda o problema da representação das emoções utilizando conjuntos de emoções básicas, ou usando um espaço explicitamente dimensionado, mas sim, por agrupamento, de acordo com o tipo de estímulo recebido do ambiente. Esse modelo descreve 22 tipos de emoções (correspondem às caixas presentes na parte inferior da Figura 2.5), que são valoradas em positivas e negativas, e são resultantes de três tipos de estímulos: eventos que acontecem no ambiente, interação do agente com os objetos do cenário e interação com outros agentes [Picard, 1997]. Um exemplo de funcionamento do diagrama da figura 2.5 é a resposta a um evento, que terá consequências em outro indivíduo. Se esse evento for desejável, pode provocar no agente as emoções "feliz por" ou "ressentimento" dependendo do contexto.

Além da estruturação, esse foi o primeiro modelo que apresentou, aos pesquisadores, um conjunto definido de regras que podem ser implementadas em uma linguagem de programação. Apesar abordar somente a geração cognitiva da emoção, o modelo tornou-se o padrão para sintetizar emoções em máquinas [Kasap e Magnenat-Thalmann, 2007].

O OCC não é um modelo apenas utilizado para o raciocínio empregando estados afetivos e para a geração cognitiva de emoção, mas também pode ser utilizado para acionar outras importantes consequências emocionais por meio de gatilhos.

\section{O Modelo Cognitivo de Roseman}

O outro modelo cognitivo apresentado para a síntese de emoções é o de Roseman [Roseman et al., 1996]. Os pesquisadores Ira Roseman, Ann Aliki Antoniou e Paul Jose, em 1996, desenvolveram uma categorização de como as pessoas fazem avaliações sobre eventos que causam emoções. Para tanto, os autores realizaram estudos envolvendo as recordações de experiências emocionais e as respostas fornecidas pelos indivíduos participantes às perguntas, que foram projetadas para avaliar os eventos que conduziram às emoções. 


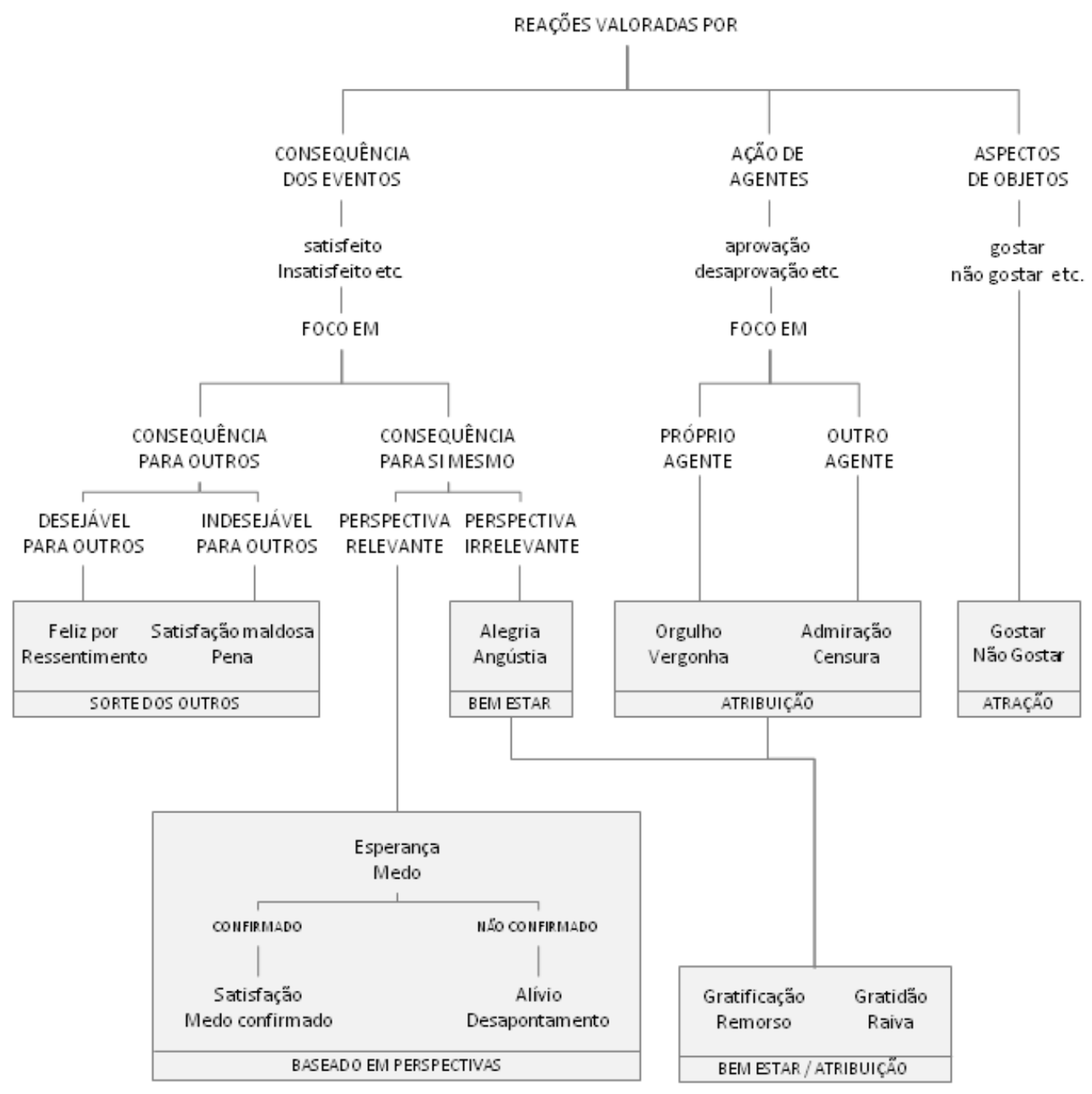

Figura 2.5: A estrutura cognitiva do modelo OCC [Ortony et al., 1988].

A partir dos estudos, os autores construíram um modelo em que um pequeno número de avaliações interagem para dar origem a dezessete emoções. As seis avaliações e as dezessete emoções são apresentadas na Figura 2.6 que indica, por exemplo, que um estímulo de baixo potencial de controle causado pelo próprio indivíduo pode produzir orgulho ou pesar.

Apesar da aparente simplicidade, o modelo de Roseman é bem fundamentado em estudos de avaliações humanas. Assim, mostra-se promissor para aplicações em sistemas computacionais tanto para o raciocínio empregando emoções, quanto para a geração de emoções com base em avaliações cognitivas [Picard, 1997].

\subsubsection{Emoções Primárias, Secundárias e Terciárias}

Os estudos realizados por Damásio [1996] e Sloman [2001] dividiram a emoção em três categorias: emoções primárias, secundárias e terciárias. Assim como as emoções básicas, as emoções primárias 


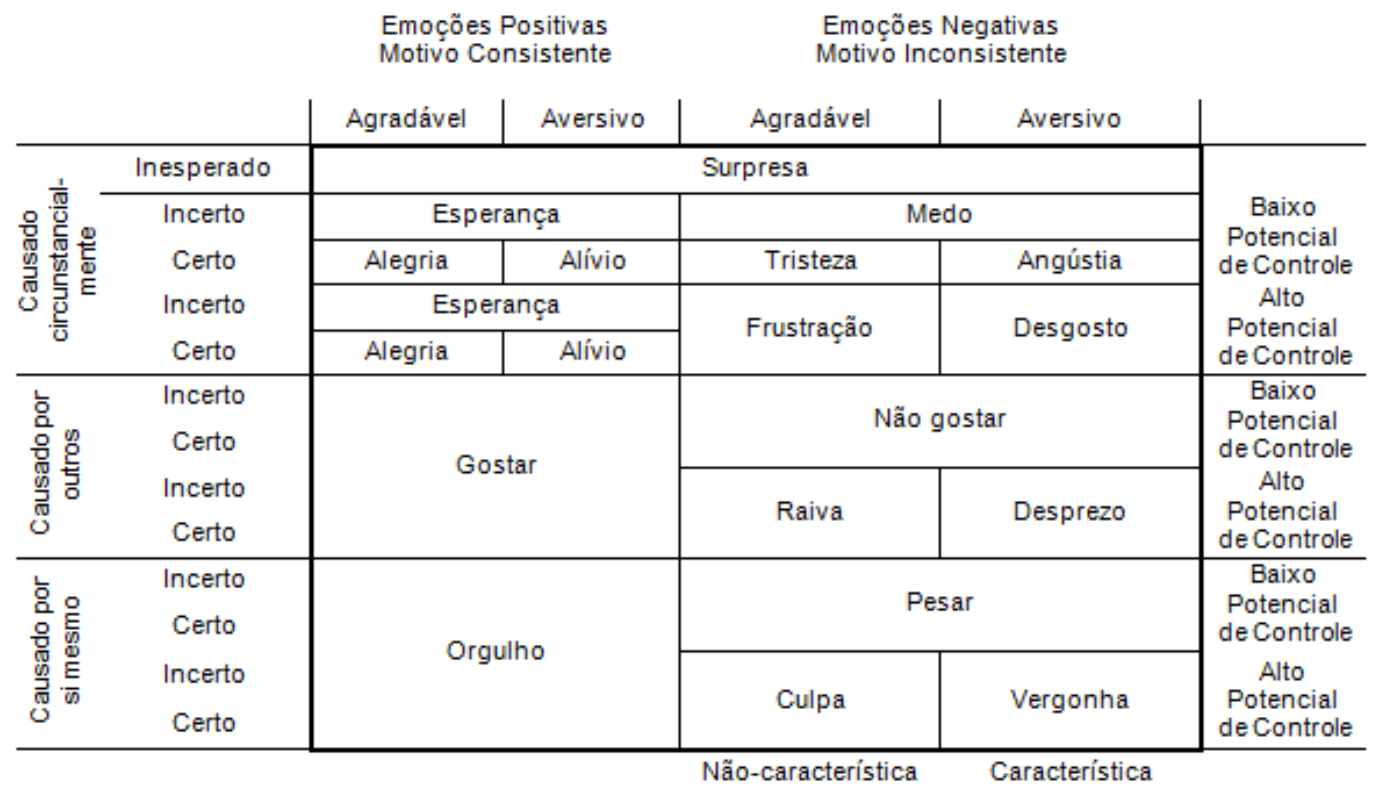

Figura 2.6: A estrutura cognitiva do modelo Roseman [Picard, 1997].

são inatas, evolutivamente adaptativas, compartilhadas por todas as culturas e associadas a estados fisiológicos específicos. Essas emoções são produzidas por mecanismos reativos que expressam comportamento em função do mapeamento de estímulos externos [Gazzaniga e Heatherton, 2005].

As emoções secundárias são compreendidas como o resultado da união do mapeamento de estímulos externos, realizado pelas emoções primárias, com uma análise das circunstâncias onde ocorreram essas emoções. Já as emoções terciárias surgem da interação da emoção com outros processos cognitivos (por exemplo a motivação) [Vinayagamoorthy et al., 2006].

\subsection{Componentes da Emoção}

As teorias sobre emoção podem ser amplamente analisadas em termos de dois componentes [Picard, 1997]: fisiológico e cognitivo.

No componente fisiológico as emoções preparam o corpo para responder de forma rápida qualquer estímulo exterior. Esse componente normalmente influencia os principais meios de comunicação não verbal dos seres humanos tais como expressão facial, gestos e entonação da voz.

No componente cognitivo, as emoções alteram as prioridades do indivíduo, servindo assim para alocar recursos limitados em múltiplos planos e objetivos [Oatley e Johnson-Laird, 1987]. Durante muitos anos, os pesquisadores investigaram os processos cognitivos sem considerar os processos emocionais, e portanto as atividades de tomada de decisão e memória eram estudadas como se as pessoas avaliassem a informação sempre de uma perspectiva racional. Entretanto, as respostas afetivas imediatas surgem rápida e automaticamente influenciando a percepção dos seres humanos no momento em que um objeto é visualizado. Essas avaliações instantâneas subsequentemente 
orientam a tomada de decisão, a memória e o comportamento [Gazzaniga e Heatherton, 2005].

A tabela 2.4, a seguir, apresenta as principais atividades influenciadas por cada componente.

\begin{tabular}{|c|c|}
\hline Componente Fisiológico & Componente Cognitivo \\
\hline \hline Expressão facial & Memória \\
Entonação de voz & Percepção \\
Movimentos, gestos & Tomada de decisão \\
Postura & Aprendizado \\
Dilatação da pupila & Objetivo, motivação \\
Ritmo da respiração & Atenção \\
Taxa de batimentos cardíacos & Prioridade \\
Temperatura & Planejamento \\
Pressão arterial & Criatividade \\
\hline
\end{tabular}

Tabela 2.4: Os dois componentes da emoção e suas principais atividades [Picard, 1997].

Para o desenvolvimento de sistemas computacionais capazes de manipular emoções, exige-se a compreensão de ambos componentes. A seguir, são descritas principais atividades do componente fisiológico (expressão facial, gestos e entonação de voz) e do componente cognitivo (percepção, memória e tomada de decisão).

\subsubsection{Expressão Facial}

A expressão facial é um aspecto fundamental da interação social. Segundo Ekman [1992], existe um conjunto de emoções básicas que são consideradas fundamentais, pois dependendo do contexto, desempenham uma função específica (normalmente biológica ou social) que estão relacionadas com eventos fundamentais da vida diária. Essas emoções podem ser facilmente mapeadas nas expressões faciais.

Recentes pesquisas indicam que 46 músculos com ação isolada são envolvidos para a formação das expressões faciais [Davidson, 1999]. A figura 2.7 mostra a ação de algumas unidades identificadas para a sobrancelha e a testa. Combinações específicas de atuação desses músculos levam as pessoas a dizerem que uma particular emoção está sendo expressa. Por exemplo, a combinação de ação das unidades 1 e 2 leva a um rótulo de "surpresa".

De acordo com Ekman [1992], combinações da utilização dos músculos faciais expressam seis emoções básicas (descritas abaixo e representadas na Figura 2.8): raiva, medo, desagrado, surpresa, alegria e tristeza. Essas seis emoções são ditas básicas ou primárias, pois servem de base evolutiva para estudos multiculturais e de desenvolvimento.

1. Raiva: ódio;

2. Medo: ansiedade, terror, pânico, timidez;

3. Desagrado: aversão, desgosto;

4. Surpresa: espanto; 


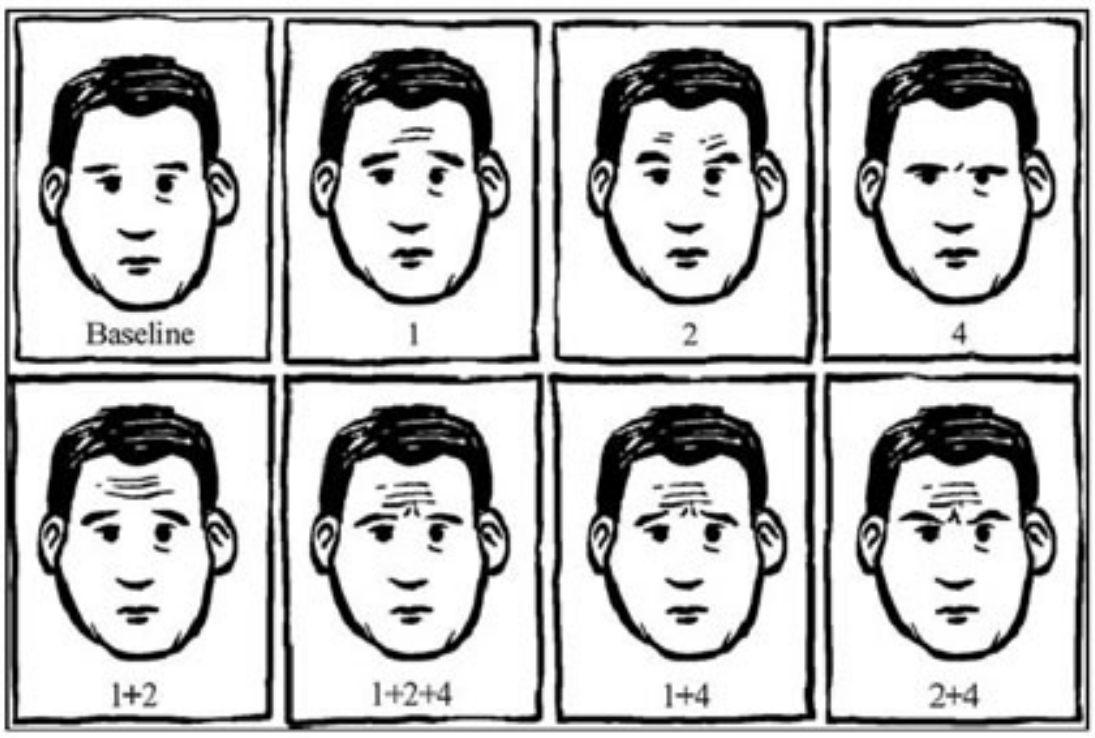

Figura 2.7: Unidades identificadas nas sobrancelhas e testa em ação [Isbister, 2006].

5. Alegria: prazer, euforia, êxtase, amor, devoção;

6. Tristeza: tristeza, melancolia, desespero.

Na figura 2.8 essas seis emoções são visualizadas por meio de expressões faciais.

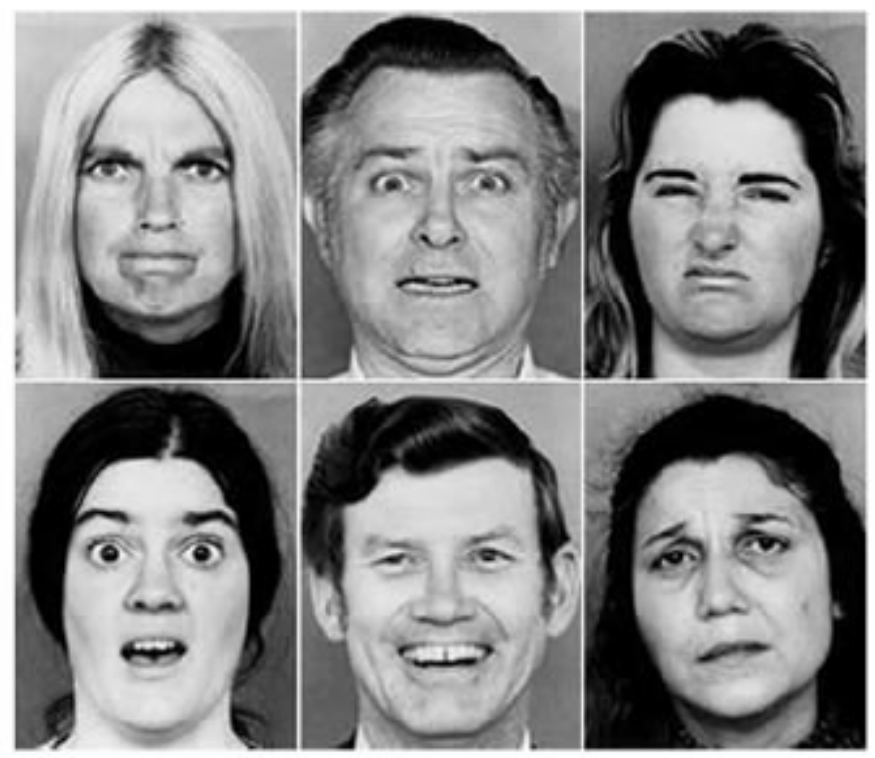

Figura 2.8: Expressão facial das seis emoções básicas de Ekman. Da esquerda para a direita e de cima para baixo: raiva, medo, desagrado, surpresa, alegria e tristeza [Rodrigues, 2007]. 


\subsubsection{Gestos}

Depois da expressão facial, a maneira de comunicação não verbal mais utilizada são os gestos que podem ser chamados de emblemas quando têm significado (por exemplo o símbolo da paz) e ilustradores quando aplicam ou explicam a comunicação verbal (quando uma pessoa aponta uma direção à outra). Os gestos têm por objetivo complementar o discurso e possuem uma semântica associada que depende do contexto, cultura e relação interpessoal [Gazzaniga e Heatherton, 2005].

Além dos gestos, o movimento do corpo pode ser utilizado para expressar emoção pela postura, distância das outras pessoas, modo de caminhar e olhar. Segundo Ekman e Friesen [1967] a expressão facial é responsável por demonstrar uma determinada emoção, enquanto que o corpo demonstra a sua intensidade. Entretanto, outros pesquisadores argumentam que a postura é a fonte dominante de percepção das emoções em um indivíduo [Isbister, 2006].

\subsubsection{Entonação de Voz}

Outra maneira de comunicação, muito utilizada pelos seres humanos, é a entonação da voz. A emoção que é expressa em um discurso pode ser entendida até mesmo por pessoas que não sabem o que está sendo dito. Por exemplo, crianças e animais de estimação não entendem o que os adultos falam, mas identificam, pela entonação da voz, a mensagem que os outros lhes querem transmitir [Isbister, 2006].

Durante uma fala, existem algumas características físicas que podem ser identificadas, além da entonação da voz, para expressar emoção: intensidade, volume, frequência, duração, distribuição, qualidade de som entre outras [Picard, 1997]. Entretanto, é difícil encontrar um modelo que relacione todas essas dimensões e o estado afetivo, uma vez que as pessoas expressam emoções de maneiras diferentes.

Atualmente, pesquisadores da área de processamento de linguagem natural estão utilizando conceitos de Computação Afetiva para a construção de sistemas capazes de interpretar, em uma conversa, o que está sendo dito e de que forma.

\subsubsection{Percepção}

Os psicólogos tradicionalmente dividem a maneira pela qual percebemos o mundo em três dimensões distintas: sensação, percepção e atenção [Gazzaniga e Heatherton, 2005]. Essas dimensões formam um conjunto de processos pelos quais as pessoas recebem, organizam e entendem os estímulos ambientais [Stenberg, 2000], ligando os mundos físicos e psicológicos.

As pesquisas sobre a sensação identificam como os cinco sentidos respondem a estímulos externos (luzes, sons, cheiros) e como as respostas são enviadas ao cérebro.

Quando os sinais sensoriais chegam ao cérebro, é realizado um processamento adicional que resulta em uma representação interna dos estímulos [Gazzaniga e Heatherton, 2005]. Esse processamento cerebral é chamado de percepção. Desta forma, a sensação está relacionada ao nível fisiológico e a percepção ao nível psicológico. Já a atenção é responsável por processar uma quantidade limitada de informações do enorme montante disponíveis pelos sensores, e armazená-las na memória ou distribuí-las para outros processos cognitivos [Stenberg, 2000]. 
Existem algumas evidências de que o estado de humor atual da pessoa influencia na sua percepção [Niedenthal et al., 2000]. Por meio de pesquisas laboratoriais, alguns pesquisadores demonstraram que indivíduos em um estado de humor negativo, tendem a perceber eventos negativos com maior frequência do que eventos positivos, e o contrário também verdadeiro para indivíduos com estado de humor positivo [Izard, 1993]. Em outras palavras, esses estudos mostram que os indivíduos tendem a perceber um estímulo de maneira congruente com seu estado afetivo de modo mais eficiente [Niedenthal e Setterlund, 1994].

Outro resultado produzido recentemente mostra a relação entre estado afetivo e atenção [Phelps et al., 2006], por meio de um experimento onde imagens de pessoas expressando emoções são colocadas ao lado de imagens com pequenos ruídos. O estudo revela que os ruídos são percebidos mais facilmente quando colocado juntos a imagens de pessoas expressando emoções de maneira intensa. Segundo os autores, a emoção facilita a percepção e potencializa a atenção, e a magnitude desse efeito pode variar do tipo e intensidade da emoção percebida.

\subsubsection{Memória}

Durante muitos anos, os psicólogos utilizavam o funcionamento de um computador como metáfora para o estudo da memória. O computador recebe as informações por meio dos dispositivos de entrada, essas informações vão até o processador onde depois de processá-las, as armazena em um disco rígido para futura recuperação e utilização.

Em 1968, Richard Atkinson e Richard Shiffrin propuseram um modelo que divide a memória em três sistemas que são diferenciados quanto a sua capacidade e duração [Gazzaniga e Heatherton, 2005]:

Memória sensorial: memória que fica no cérebro por frações de segundo e depois desaparece. Exemplo: luzes, sons, cheiros.

Memória de curto prazo: memória de capacidade limitada que armazena informações (no máximo sete itens) por um curto espaço de tempo (aproximadamente 20 segundos) e depois desaparecem a não ser que sejam repetidas. Pesquisadores acreditam que é na memória de curto prazo que ficam os pensamentos e impressões sobre o ambiente.

Memória de longo prazo: memória com grande capacidade e relativamente permanente que pode armazenar lembranças durante anos.

Um diagrama do funcionamento do modelo de Atkinson e Shiffrin é apresentado na figura 2.9. Apesar de abrangente, o modelo é considerado por alguns pesquisadores como inexato. Atualmente acredita-se que a memória possua mais de três sistemas, embora não exista uma concordância sobre o número de sistemas existentes. Entretanto, esse modelo continua sendo muito utilizado em pesquisas sobre memória [Gazzaniga e Heatherton, 2005].

Recentes estudos mostram que o armazenamento e recuperação das informações são fortemente influenciados pelo contexto cognitivo do indivíduo [Stenberg, 2000]. Desta forma, os estados afetivos 


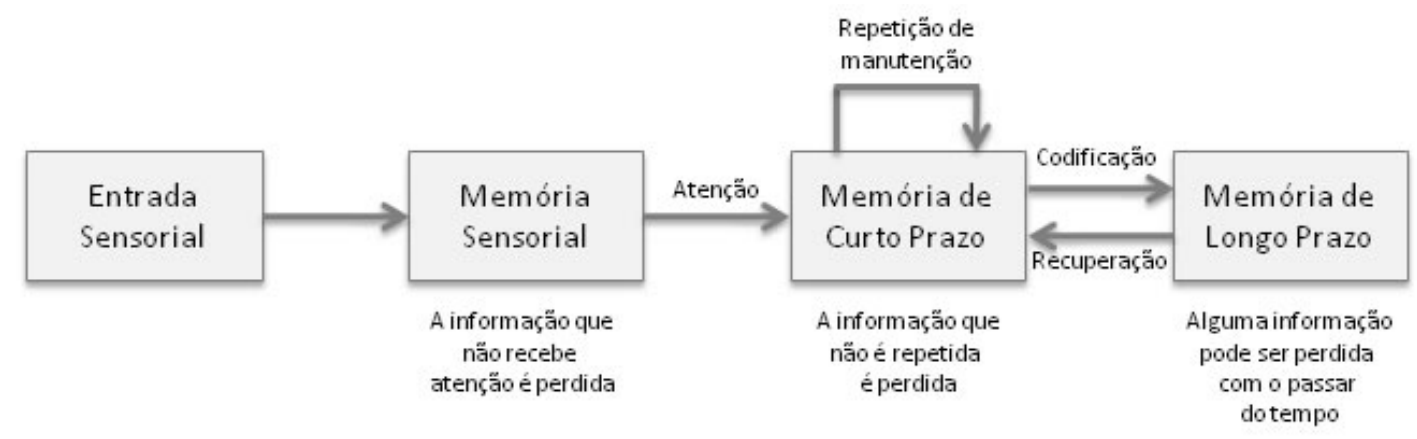

Figura 2.9: Diagrama do modelo de Atkinson e Shiffrin de memória [Gazzaniga e Heatherton, 2005].

e suas intensidades podem propiciar um contexto que afeta a recuperação posterior da informação, isto é, quando a informação é armazenada durante um determinado estado de humor, será recuperada com maior facilidade quando o indivíduo encontrar-se novamente naquele estado [Bower, 1981].

Segundo Bower [1981], existem quatro teorias que relacionam estados afetivos e processos cognitivos: (1) as memórias são mais facilmente recuperadas quando o indivíduo está com o mesmo humor de quando foram armazenadas, (2) o estado afetivo atual influencia pensamentos e interpretação de eventos, (3) memórias associadas com estado afetivo similar ao atual são facilmente recuperadas, (4) as memórias associadas a emoções mais intensas são prontamente recuperadas.

\subsubsection{Tomada de Decisão}

A tomada de decisão é um processo cognitivo que avalia as informações recebidas e escolhe o plano de ação mais apropriado para atingir determinado objetivo. Essa avaliação é baseada nas informações recebidas pelos sensores, e em algumas propriedades internas tais como motivação, experiências passadas, estados afetivos entre outros [Stenberg, 2000].

A influência que os estados afetivos exercem sobre a tomada de decisão, é um assunto ainda muito discutido. Durante séculos, a emoção foi vista como uma barreira que poderia anular o pensamento racional, e normalmente era considerada uma influência negativa ao comportamento das pessoas. Platão afirmava que os sentimentos, desejos e emoções tornavam impossível o pensamento racional [Ledoux, 1996]. No século XVI, Descartes defendia a idéia da separação do corpo e da mente, onde as emoções eram respostas a estímulos e necessidades provocadas pelo corpo e a mente era responsável pelo raciocínio e tomada de decisão.

Recentes pesquisas na área da Neurociência revelam a importância das emoções no processo de tomada de decisão [Damásio, 1996]. Por meio de análises clínicas em pacientes, António Damásio traçou um paralelo entre lesões cerebrais específicas e incapacidade emocional [Marreiros, 2007]. Os pacientes que apresentaram esse tipo de lesão, continuavam com sua memória, capacidade léxica e matemática intactas, entretanto havia uma mudança significativa de postura e atitudes que provocavam problemas nas relações sociais, estabelecimento de planos futuros e tomada de decisão simples do dia-a-dia. A perda dessas capacidades e o local da lesão indicam a existência de uma 
relação entre emoção e tomada de decisão [Damásio, 1996].

Para concretizar essa relação, Damásio [1996], criou a teoria dos marcadores somáticos. Os marcadores somáticos são marcas atribuídas a cada uma das ações executadas pelo indivíduo contendo a avaliação emocional das reações corporais obtidas como resposta àquela ação. Portanto, torna-se possível, posteriormente, analisar qual será o estado afetivo produzido por cada ação, evitando aquelas que produzem estados afetivos negativos e motivando situações que produzem estados afetivos positivos.

Essa teoria ajuda a explicar as funções de adaptação e motivação que os estados afetivos exercem nos seres vivos, pois contribuem para a escolha de ações que promovam a sobrevivência e bem-estar do indivíduo. Dessa forma, os marcadores somáticos podem orientar os indivíduos a realizarem um comportamento adaptativo [Gazzaniga e Heatherton, 2005].

Neste capítulo foram delineados alguns dos principais modelos de personalidade, humor e emoção desenvolvidos nas áreas da Psicologia e Neurociência. No início foi introduzido o conceito de personalidade bem como suas cinco principais abordagens. Dessas, a abordagem dos traços foi explorada com maiores detalhes porque se assemelha à maneira intuitiva de como as pessoas percebem a personalidade e tem foco na descrição e não na explicação de como ela é desenvolvida. Dentro dessa abordagem três modelos foram descritos e comparados. Depois, foram discutidos o conceito de humor e dois possíveis modelos de representação e também o conceito de emoção sob três diferentes abordagens. Depois, a emoção foi analisada em termos de dois componentes: fisiológico e cognitivo. Para cada um dos componentes foram descritas três atividades e discutido a influência que o estado afetivo exerce sobre cada uma. Os conceitos, discussões e modelos introduzidos nesse capítulo servem de base para a elaboração da arquitetura que é apresentada a seguir. 


\section{Capítulo 3}

\section{Arquitetura}

Depois de explorar os estados afetivos no domínio da Psicologia e da Neurociência, esse capítulo apresenta um modelo conceitual e detalhes da implementação da arquitetura para a construção de agentes inteligentes com personalidade e emoção. Na primeira seção são introduzidas as bases conceituais dos agentes inteligentes e de arquiteturas de agentes. Em seguida, são descritos algumas implementações (frameworks) existentes de modelo BDI. Na segunda seção, é delineado o modelo conceitual da arquitetura, todos os seus módulos e filtros. Depois, apresentam-se os detalhes da implementação de cada um desses módulos (em especial o Módulo Afetivo) e filtros, bem como o seu ciclo de iteração.

\subsection{Bases Conceituais}

Para construir personagens com características afetivas, foram empregadas técnicas de agentes inteligentes. Segundo Wooldridge [2002] agentes são sistemas computacionais situados em algum ambiente onde são capazes de realizar atividades de maneira autônoma para atingir seus objetivos, ou seja, ele deve existir dentro de um ambiente, agir de maneira independente e tomar suas próprias decisões. Ainda segundo o autor, para que um agente seja considerado "inteligente" além das características definidas anteriormente, ele deve ser reativo, pró-ativo e possuir habilidade social. Ele é reativo quando percebe, processa e responde (em tempo hábil) as alterações do ambiente, é pró-ativo se exibe um comportamento motivado por seus objetivos e finalmente, é social quando interage com outros agentes do ambiente.

Tradicionalmente os agentes são especificados por meio de um diagrama onde os retângulos indicam os módulos e as setas o fluxo de dados entre as partes. Essa representação recebe o nome de "arquitetura do agente". Wooldridge [2002] define "arquitetura de um agente" como uma metodologia particular para a construção de agentes que especifica como ele pode ser decomposto em módulos e como esses módulos interagem, além de um mapeamento que relaciona as percepções recebidas com as ações à serem executadas.

\subsubsection{Arquiteturas dos Agentes Inteligentes}

As arquiteturas dos agentes inteligentes podem ser abstratas (representações) ou concretas quando são efetivamente implementadas em uma linguagem de programação. Segundo Weiss [2001] existem basicamente quatro tipos diferentes de arquiteturas para agentes inteligentes: Agentes 
Baseados em Lógica, Agentes Reativos, Agentes BDI (Beliefs, Desires e Intentions) e Agentes com Arquitetura em Camadas. Cada um dos quatro tipos de arquitetura são explicados abaixo.

Agentes Baseados em Lógica: também conhecida como Inteligência Artificial Simbólica, essa abordagem clássica sugere que o comportamento inteligente do agente pode ser alcançado com um sistema de representação simbólica tanto do comportamento desejado do agente quanto do ambiente onde está inserido, além de um conjunto de regras para a manipulação desses símbolos. Essa representação simbólica é constituída de fórmulas lógica e sua manipulação corresponde à dedução lógica.

Agentes Reativos: para o desenvolvimento de agentes reativos, é realizado um mapeamento direto relacionando as possíveis informações de entrada (percepções) que o agente pode ter com cada uma das ações que ele poderá realizar no ambiente. Esses agentes selecionam ações com base na percepção atual, ignorando o restante do histórico de percepções. Apesar de simples, econômica e robusta, essa abordagem apresenta problemas porque não é projetada para aprender com a experiência e, consequentemente, melhorar o seu desempenho ao longo do tempo.

Agentes BDI: criada pelo filósofo Michael Bratman, esse tipo de arquitetura tem por objetivo descrever o processo prático do raciocínio humano. Os agentes BDI implementam e manipulam uma estrutura que divide sua arquitetura em três módulos principais: crenças, desejos e intenções. Inicialmente as informações do ambiente externo são capturadas pela percepção, e a base de conhecimento é atualizada. O processamento da arquitetura decide qual objetivo quer alcançar e em função dessa decisão, escolhe um plano da biblioteca para executar.

Agente com Arquitetura em Camadas: essa abordagem divide o processo de tomada de decisão de um agente em diversas camadas. Essa idéia separa a maneira como diferentes tipos de comportamento são gerados (por exemplo comportamentos pró-ativos e reativos). Os agentes que implementam essa abordagem podem escolher uma estrutura de camadas horizontais ou verticais, onde na estrutura de camadas horizontais todas elas manipulam os dados de entrada e saída e na vertical, apenas a primeira manipula dados de entrada e apenas a última manipula dados de saída.

Das quatro arquiteturas descritas, a mais adequada a esse trabalho é a BDI, pois apresenta uma estrutura capaz de produzir comportamentos adaptativos, oferece um conjunto de regras que delimitam a compreensão do raciocínio e possui um grande número de implementações já existentes (frameworks). 


\subsubsection{Frameworks do modelo BDI}

A possibilidade de utilização de implementações existentes da arquitetura BDI é especialmente interessante, pois alguns desses frameworks já foram amplamente utilizados e testados em diversos projetos e podem reduzir significativamente o trabalho de implementação. Assim, para escolher qual o framework mais apropriado a esse trabalho foi realizado um estudo comparativo entre seis implementações existentes: AgentBuilder, Jack, Jadex, JAM, UMPRS e Jason. Segue abaixo uma descrição de cada uma das implementações pesquisadas.

\section{AgentBuilder}

O AgentBuilder ${ }^{1}$ é um pacote de ferramentas integradas para construção de agentes inteligentes em Java desenvolvido pela Acronymics Inc. O objetivo do AgentBuilder é reduzir o tempo necessário para a implementação de sistemas inteligentes que utilizam agentes, simplificando as ferramentas de desenvolvimento. Por meio de uma interface gráfica e ferramentas de geração automática de código, o desenvolvedor pode especificar ontologias, mapas de conceito, comportamentos e protocolos de comunicação. O sistema ainda fornece ferramentas para teste e depuração de código do programa agente, e funcionalidades para a análise de desempenho e comportamento dos agentes em tempo de execução. O AgentBuilder possui dois tipos de licença (acadêmica e comercial), oferece uma documentação junto com o sistema, sua última versão é de 2003 e apesar de não permitir a customização do produto, permite a integração do sistema com outras bibliotecas de software desenvolvidas em Java, $\mathrm{C}$ ou $\mathrm{C}++$.

\section{Jack}

O Jack Autonomous Software ${ }^{2}$ é um framework para o desenvolvimento de sistemas multiagentes em Java. Desenvolvido pela Agent Oriented Software Pty. Ltd., o sistema tem por objetivo transferir a tecnologia dos agentes inteligentes de maneira fácil e rápida das pesquisas acadêmicas para aplicações industriais. Por meio de um ambiente de desenvolvimento próprio, o programador pode analisar, especificar e implementar aplicações pro-ativas, reativas, sociais e distribuídas com agentes (baseados no modelo BDI) simplesmente arrastando funções e elementos gráficos para a área de desenvolvimento. Com o Jack é possível construir aplicações multiplataformas e robustas o suficiente para serem executadas em hardwares de baixo processamento como, por exemplo, um PDA (Personal Digital Assistants). Registrado sob uma licença comercial ou uma licença acadêmica, o Jack disponibiliza gratuitamente um abrangente manual e outros manuais menores sobre partes mais específicas do sistema. Extensões e bibliotecas externas podem incorporadas ao sistema por meio de plug-ins.

\footnotetext{
${ }^{1}$ AgentBuilder: http://www.agentbuilder.com

${ }^{2}$ Jack: http://www.agent-software.com.au
} 


\section{Jadex}

O Jadex ${ }^{3}$ é um framework para a criação de agentes BDI inteligentes em Java. Desenvolvido pelo grupo de pesquisa de Sistemas Distribuídos e Sistemas de Informação da Universidade de Hamburgo na Alemanha, o framework busca diminuir o trabalho de implementação de sistemas que utilizam agentes sem abrir mão da fundamentação teórica do modelo BDI. Para tanto, divide o sistema como um todo em camadas (utilizando fundamentos de engenharia de software) onde o framework funciona como uma camada intermediária (middleware) entre a arquitetura BDI e o programa agente. A comunicação entre as diversas camadas do sistema é realizada utilizando-se de tecnologia como Java e XML e conceitos de orientação à objetos. O Jadex é um projeto em contínuo desenvolvimento (última atualização em 2009), que possui licença GNU LGPL e uma boa documentação. Como seu código fonte é aberto e disponível para download, extensões podem ser realizadas diretamente no código fonte.

\section{JAM / UMPRS}

O $\mathrm{JAM}^{4}$ e o $\mathrm{UMPRS}^{5}$ são ambos arquiteturas para o desenvolvimento de agentes baseados no modelo BDI. A diferença básica entre os dois é que o JAM é implementado em Java enquanto que o UMPRS utiliza $\mathrm{C}++$. Desenvolvidos por pesquisadores da Universidade de Michigan (Estados Unidos), os sistemas são compostos basicamente por quatro componentes: "World Model" que armazena todas as crenças do agente funcionando como uma representação interna do ambiente externo; "Intention Structure" que contém os objetivos e intenções do agente; "Plan Library" que armazena a coleção de planos e o "Agent Interpreter" que seleciona e executa os planos. Ambas as arquiteturas possuem licenças livre para uso sem fins lucrativos e o UMPRS ainda possui uma licença comercial. O código fonte das arquiteturas está disponível para download bem como uma pequena documentação. Ainda que segundo o site oficial informe que as arquiteturas são trabalhos em andamento, a última versão de ambos os sistemas são de 2001.

\section{Jason}

O Jason ${ }^{6}$ é um framework para o desenvolvimento de agentes inteligentes BDI baseado em uma linguagem de programação orientada a agentes chamada AgentSpeak. Essa linguagem implementa uma extensão de programação lógica para agentes BDI. Desenvolvido por uma rede de vários pesquisadores, o Jason é composto por quatro componentes principais: Base de Conhecimento, Biblioteca de Planos, Conjunto de Eventos e Conjunto de Intenções. Com a utilização do framework é possível controlar todo o ciclo de vida do agente (criação, execução e destruição) bem como a comunicação entre eles. Em ambientes multiagentes o sistema pode ser facilmente configurado para ser executado de maneira centralizada ou em diferentes servidores (utilizando infraestruturas

\footnotetext{
${ }^{3}$ Jadex: http://jadex.informatik.uni-hamburg.de

${ }^{4}$ JAM: http://www.marcush.net/IRS/irsdownloads.html

${ }^{5}$ UMPRS: http://www.marcush.net/IRS/irsdownloads.html

${ }^{6}$ Jason: http://jason.sourceforge.net
} 
de comunicação tais como $\mathrm{JADE}^{7}$ e $\mathrm{SACI}^{8}$ ). O Jason está disponível para download sob a licença GNU LGPL. Possui uma boa documentação (tanto do funcionamento e operação do sistema quanto do código fonte). O projeto possui mais de cinco anos e sua última versão foi lançada em 2009.

As implementações foram comparadas seguindo os seguintes critérios: tipo de licença, linguagem de programação utilizada, atividade do projeto, documentação disponível, existência de um ambiente de desenvolvimento (IDE), existência de uma ferramenta para depuração de código (Debug)e possibilidade de extensão. O resultado desse estudo comparativo é apresentado na tabela 3.1.

Após o levantamento dessas informações foi realizada uma análise sobre a tabela 3.1 tendo como foco o desenvolvimento de personagens com personalidade e emoção. Por tratar-se de um projeto acadêmico que a ideia é utilizar um software existente, para customizá-lo e estende-lo, fica evidente que uma solução baseada em software livre seria mais adequada. Dessa maneira, o AgentBuilder e o Jack foram descartados. Em seguida, foram descartados o JAM e o UMPRS, pois são projetos já extintos e com pouca documentação. Assim, das seis implementações iniciais, restaram apenas duas.

Testes iniciais foram realizados com o Jadex e o Jason com o objetivo de identificar qual o mais apropriado para o desenvolvimento desse trabalho. Uma análise mais aprofundada das características e a criação de alguns exemplos em ambas as implementações revelaram o Jason como o framework mais apropriado. A característica fundamental que essas implementações devem apresentar para auxiliar na realização desse trabalho é a possibilidade de customização de alguns módulos e funções de seleção. Além de apresentar uma implementação padrão, as funções de seleção do Jason foram projetadas para ser estendidas ou customizadas pelos desenvolvedores. Além disso, o Jason implementa uma classe chamada "environment" que é responsável pela comunicação do agente com o ambiente externo. Com essa classe, é possível desenvolver ambientes em Java de maneira fácil e independente da arquitetura. Por essas razões, o Jason foi escolhido.

\subsubsection{Framework Jason}

Para construir um agente BDI utilizando AgentSpeak em Jason, é necessário inicialmente especificar (1) um conjunto de informaçãoes que formam a base de crenças inicial, (2) um conjunto de objetivos (estados do ambiente) e (3) um conjunto de planos que compõem a biblioteca de planos.

\section{Crenças}

As crenças são todas as informações que o agente tem sobre o ambiente onde está inserido e sobre os outros agentes. Inicialmente um conjunto de crenças é atribuído ao agente em seu código fonte. Esse conjunto inicial de crenças recebe o nome de base de conhecimento. Além das crenças iniciais, a cada nova percepção que o agente tem do ambiente, essa base de conhecimento é atualizada e novas crenças são inseridas.

Em AgentSpeak, uma crença é escrita como uma coleção de literais onde a informação é representada de maneira simbólica por meio de predicados que podem expressar uma característica de

\footnotetext{
${ }^{7}$ Jade: http://jade.tilab.com

${ }^{8}$ SACI: http://www.lti.pcs.usp.br/saci
} 


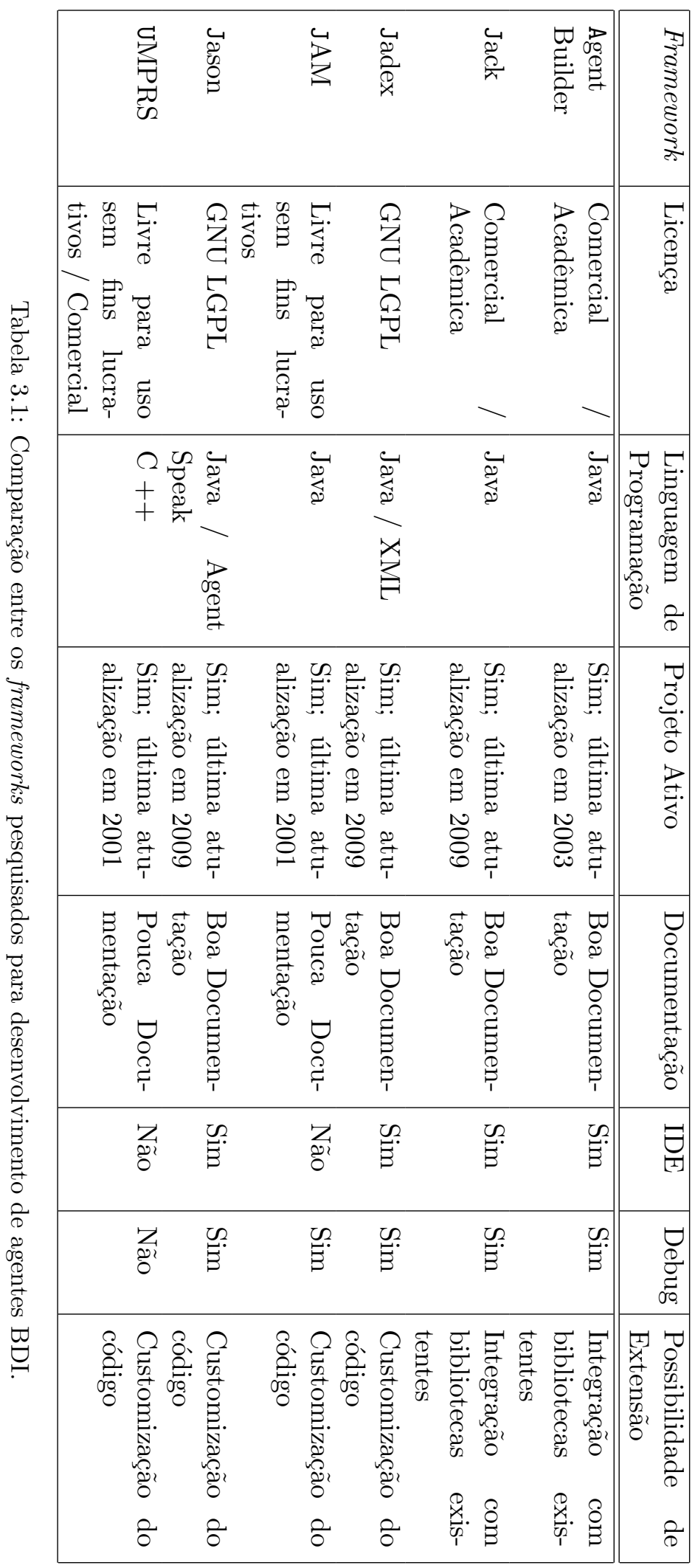


um objeto ou o relacionamento entre dois ou mais objetos. Os argumentos dos predicados podem ser números inteiros, números com ponto flutuante, objetos e listas. Segue abaixo alguns exemplos de crenças:

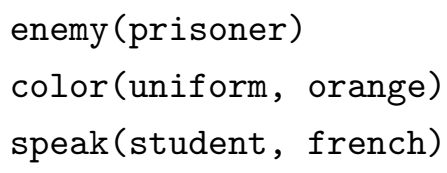

\section{Objetivos}

Objetivos, ou desejos, são alguns estados do ambiente que o agente quer alcançar. Os objetivos são responsáveis pela propriedade pró-ativo dos agentes, pois um agente deve interagir e modificar o ambiente (por meio de ações) de tal maneira a deixá-lo com o estado desejado. Em linguagem AgentSpeak existem dois tipos de objetivos: realização e teste. A realização é responsável pela característica pró-ativa do agente, como descrita anteriormente. Assim como uma crença, esse tipo de objetivo é construído como uma coleção de literais que formam um predicado e parâmetros que podem ser números inteiros, números com ponto flutuante, objetos e listas, no entanto, o objetivo é precedido do operador "!". Abaixo alguns exemplos de objetivos de realização.

! go (home)

! buybook(10)

O outro tipo de objetivo são os objetivos de testes. Os testes são utilizados para pesquisar informações da base de conhecimento. Quanto à sua construção, ele se difere do objetivo de realização pois é precedido do operador "?", por exemplo:

?books (N)

?money $(\mathrm{R})$

Assim como as crenças, os objetivos iniciais são determinados no código fonte do agente. Porém, esses objetivos definidos podem ser alterados pelos planos executados pelo agente.

\section{Planos}

Para alcançar os objetivos, a arquitetura executa alguns planos (também chamado de ações) que o agente é capaz de realizar no ambiente. Em AgentSpeak, os planos iniciais também são definidos no código fonte do agente e o conjunto desses planos iniciais recebe o nome de biblioteca de planos. Sobre a sua construção, ele é dividido em três partes:

triggeringevent : context <- body 
O "triggeringevent" é o nome do evento que identifica internamente o plano. O "context" indica as condições que precisam ser verdadeiras para que o plano seja executado. Ele é especialmente importante, pois a sua estrutura permite que o agente escolha qual plano executará dependendo do estado atual do ambiente, o que permite a construção de comportamentos adaptativos. No "body" é descrita a sequência de ações que o agente seguirá para realizar o plano. Essas ações podem ter efeito direto no ambiente, ou podem modificar (ou inserir) crenças e objetivos do agente. Segue abaixo um exemplo de plano:

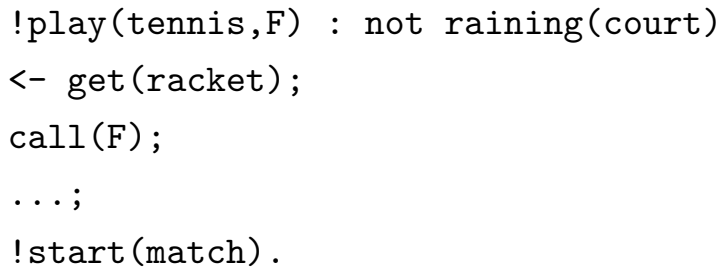

Depois da criação do código fonte com a base de conhecimento, os objetivos e a biblioteca de planos, o Jason inicia a execução do ciclo de iteração da arquitetura. A operação e os módulos da arquitetura são apresentados na figura 3.1 [Bordini et al., 2007] onde os retângulos representam os principais módulos (base de conhecimento, conjunto de eventos, conjunto de intenções e biblioteca de planos), os retângulos com cantos arredondados e os losangos representam funções utilizadas que podem ser customizadas pelos desenvolvedores. Os círculos indicam processos internos que não podem ser customizados e as setas direcionadas para dentro e fora do agente, representam as ações de entrada e saída da arquitetura.

Após as definições iniciais, o ciclo de iteração é iniciado. Segundo Bordini et al. [2007] o ciclo de iteração pode ser divido em 10 passos, onde cada um é representado, na figura 3.1, pelos números de 1 a 10. Os quatro primeiros são responsáveis pela percepção de informações do ambiente e os outros seis pelo processamento dessas informações recebidas. Os dez passos descritos por Bordini et al. [2007] são:

\section{Passo 1 - Percebendo o Ambiente:}

A primeira atividade do ciclo de iteração é capturar informações do ambiente externo por meio de sensores. O módulo responsável por essa atividade é a "Percepção".

\section{Passo 2 - Atualizando a Base de Conhecimento}

Depois de obtidas as informações do módulo "Percepção", uma função que atualiza a base de conhecimento é executada. Essa função verifica se as informações já estão armazenadas e caso não estejam as inserem. Caso contrário, as atualiza. Após essas operações, a função de revisão de crença é executada para garantir a consistência dos dados. Todas as operações de inserção e atualização na base de conhecimento geram um evento indicando, nesse caso, que um evento externo aconteceu. Esse evento gerado informa ao agente que houve uma mudança no seu estado atual. 


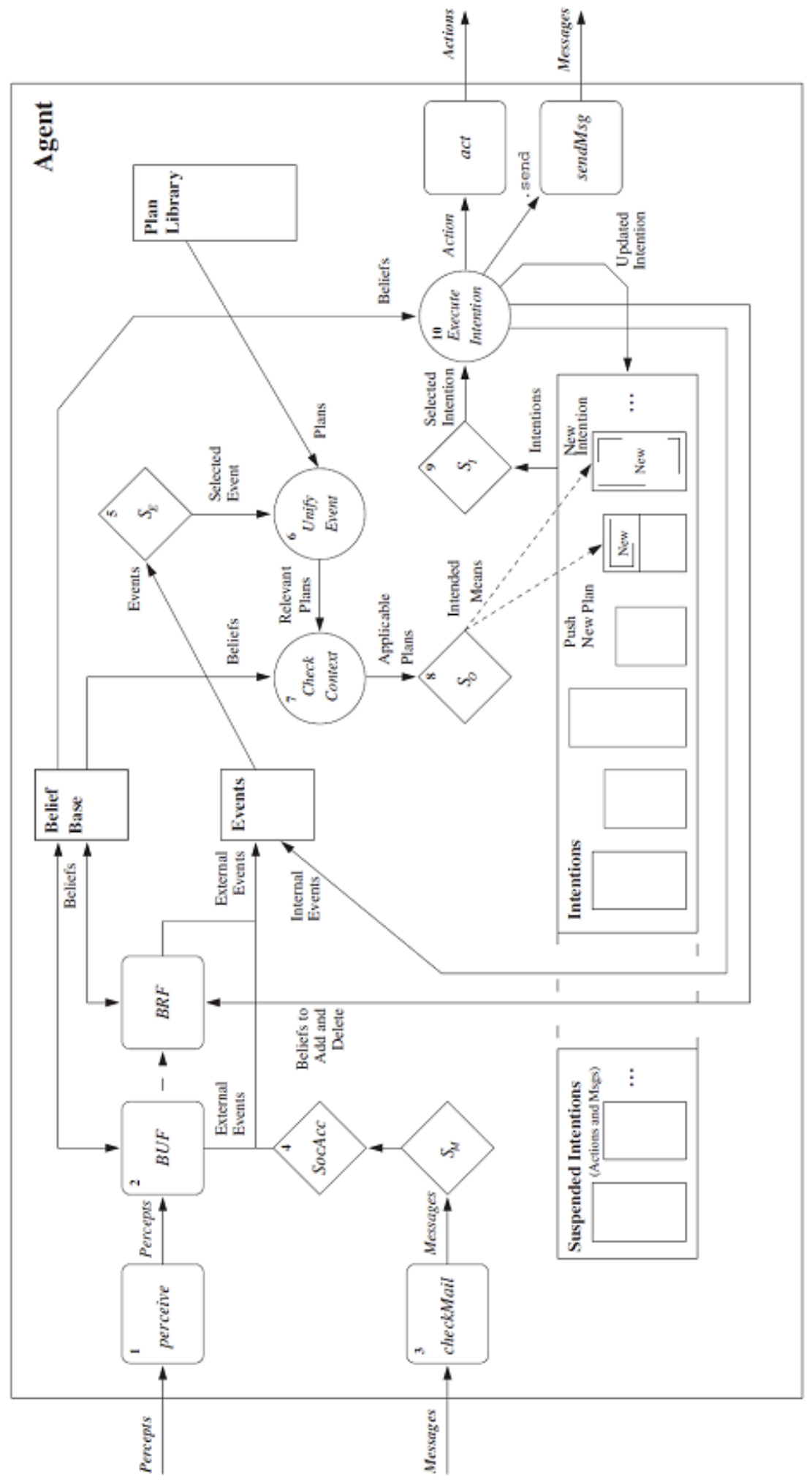

Figura 3.1: Diagrama de funcionamento da arquitetura do Jason [Bordini et al., 2007]. 


\section{Passo 3 - Recebendo a Comunicação de Outros Agentes}

Outra maneira do agente capturar informações do ambiente é na troca de mensagens com outros agentes. A troca de mensagens é uma tarefa fundamental nos sistemas multiagentes. Um agente em Jason verifica sua caixa de entrada de mensagens por meio da função "checkMail". Caso encontre uma ou mais mensagens, todas elas são enviadas para a "Função de Seleção de Mensagens". Essa função de seleção pode ser customizada pelo desenvolvedor com o intuito de reordenar as mensagens seguindo algum critério. Caso isso não aconteça, o Jason, por padrão, respeita a ordem de chegada das mensagens.

\section{Passo 4 - Selecionando Mensagens "Socialmente Aceitáveis"}

Após o recebimento e ordenação das mensagens a função "SocAcc" é executada. Essa função tem por objetivo interpretar, processar e selecionar quais mensagens o agente deve ou não receber. Por padrão, o agente deve receber todas as mensagens, porém, a função "SocAcc" pode ser implementada novamente especificando novos critérios para a seleção dessas mensagens.

\section{Passo 5 - Selecionando um Evento}

Terminada a fase que reúne a percepção do ambiente externo e a atualização da base de conhecimento, inicia-se a fase de processamento das informações. O módulo "Eventos" recebe uma lista de eventos externos vindos da atualização da base de conhecimento e uma lista de eventos internos vindos da função que executa ações no ambiente. Essas duas listas são reunidas em uma única que passa pela "Função de Seleção de Eventos". Essa função seleciona um evento seguindo alguns critérios que podem ser definidos pelo desenvolvedor. Em sua implementação padrão, a função seleciona os eventos por ordem de entrada como em uma fila (o primeiro a entrar é o primeiro a sair).

\section{Passo 6 - Recuperando todos os Planos Relevantes}

O evento selecionado é enviado à função de "Unificar o Evento". Essa função recupera, do componente "Biblioteca de Planos", um conjunto com todos os planos relacionados com aquele evento.

\section{Passo 7 - Determinando os Planos Aplicáveis}

O evento e o conjunto com todos os planos relacionados são direcionados para a função "Verificar Contexto". A função inicialmente faz uma pesquisa na "Base de Conhecimento" identificando qual o estado atual do agente e depois verifica quais dos planos relacionados têm seus contextos satisfeitos com esse estado. Dessa maneira é possível definir os planos que podem ser aplicáveis em um determinado momento. 


\section{Passo 8 - Selecionando um Plano Aplicável}

Com a lista reduzida para o número de planos aplicáveis, a função de "Seleção de Opções" é executada. Também conhecida como função de "Seleção de Planos Aplicáveis", ela faz uma consulta ao conjunto de objetivos do agente, e baseado nessa consulta, determina qual dos planos aplicáveis deve ser escolhido. Uma chamada para o plano aplicável é inserida no conjunto de intenções do agente para futura execução. Assim, como as outras funções de seleção, essa função pode ser customizada, e por padrão, escolhe os planos na ordem em que eles aparecem.

\section{Passo 9 - Selecionando uma Intenção para Futura Execução}

Normalmente um agente tem mais de uma intenção. Esse conjunto de intenções representa os seus diferentes interesses. No entanto, em um ciclo, apenas uma intenção pode ser executada e para solucionar esse problema existe a função de "Seleção de Intenções". Essa função também pode ser implementada novamente. No seu padrão é implementado um escalonamento do tipo "round-robin", ou seja, a primeira intenção da lista é escolhida, e depois de executada vai para o final da lista e assim por diante com todas as intenções. Dessa maneira, o agente equilibra a atenção oferecida a cada uma das intenções.

\section{Passo 10 - Executando um Passo de uma Intenção}

No último passo, o agente executa o plano relacionado à intenção selecionada. Além de realizar ações no ambiente onde está inserido e enviar mensagens para outros agentes, o agente ainda pode realizar operações internas tais como atualização de intenções, geração de eventos internos e inserção ou exclusão de crenças da base de conhecimento.

\section{$3.2 \quad$ A Arquitetura}

A construção de um personagem com personalidade e emoção teve como base a arquitetura do Jason que, conforme apresentada na sessão anterior, é composta por módulos distintos que se relacionam entre si. No entanto, a arquitetura do Jason, para esse estudo, foi customizada e estendida. Customizada, pois filtros de percepção, memória e planos foram implementados para que o estado afetivo seja considerado nas atividades cognitivas e estendida, pois um módulo foi acrescentado: o Módulo Afetivo. Dessa maneira, o Módulo Afetivo influencia os filtros que por sua vez influenciam os processos de percepção, memória e tomada de decisão do agente. A figura 3.2 apresenta um diagrama simplificado do funcionamento da arquitetura onde os retângulos representam os módulos, as linhas contínuas o fluxo dos dados e as linhas tracejadas as consultas.

A seguir são descritos os módulos Percepção, Eventos, Base de Conhecimento, Plano, Biblioteca de Planos, Interação, Ação e Afetivo (com os submódulos Personalidade, Humor e Emoção) e filtros de Percepção, de Memória e de Planos da arquitetura.

\section{Percepção}

O módulo "Percepção" é responsável por receber informações do ambiente por meio de algum sensor. 


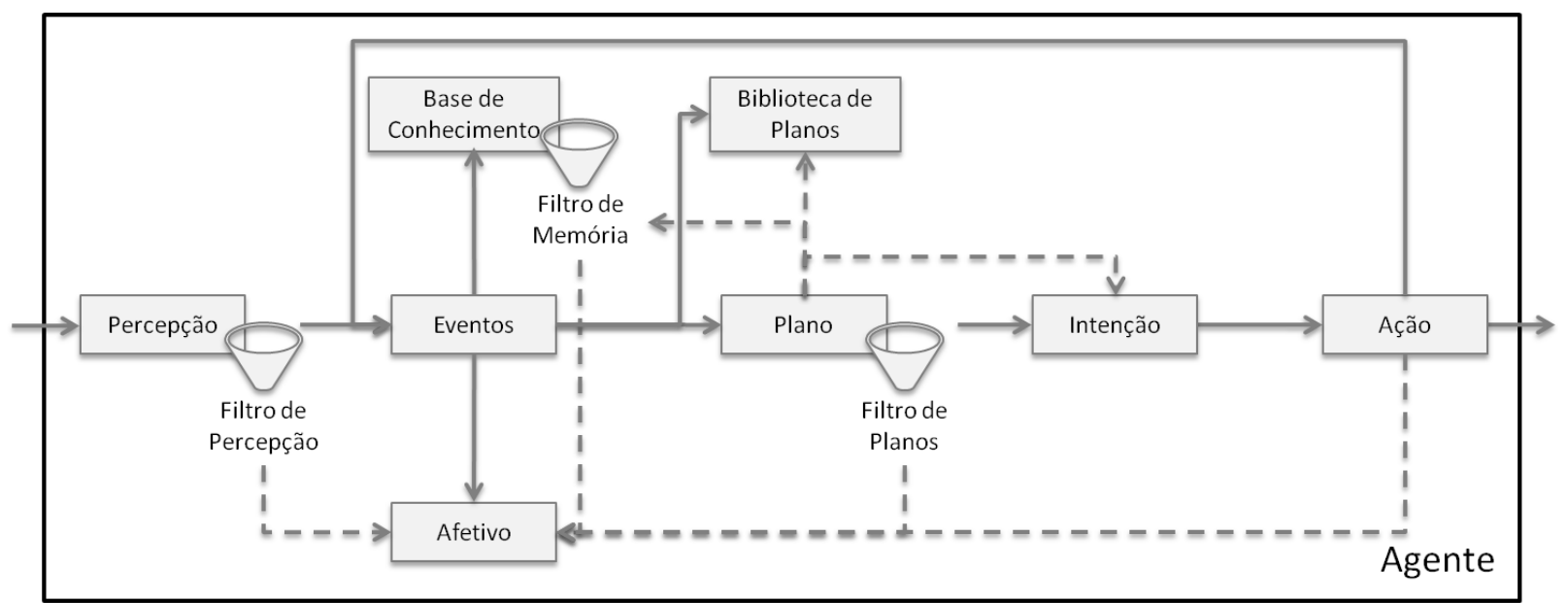

Figura 3.2: Diagrama de funcionamento da arquitetura proposta.

\section{Eventos}

Um evento descreve uma ocorrência significativa que o agente deve responder de alguma maneira. Os eventos são normalmente classificados em dois tipos: externos e internos. Os eventos externos são extraídos da percepção e eventos internos são gerados pelo próprio agente quando, por exemplo, um estado interno atinge um determinado valor, ou após um determinado tempo. Um evento pode provocar uma ação imediata do agente, ou ainda gerar uma mudança na base de conhecimento. As ações geradas diretamente pelos eventos são conhecidas como ações reflexivas e são executadas sem nenhum tipo de deliberação. Essas ações são importantes para a execução da parte reativa do agente, que tem a função de identificar mudanças importantes no ambiente.

\section{Base de Conhecimento}

É no módulo "Base de Conhecimento" que estão armazenadas as crenças sobre o ambiente, o próprio agente e os outros agentes.

\section{Plano}

Como os agentes estão inseridos em um ambiente dinâmico, eles precisam, a todo o momento, adaptar suas tarefas em função dos seus objetivos e do estado atual do ambiente. Portanto, esse módulo é responsável por determinar as ações mais adequadas a serem escolhidas para atingir uma determinada meta.

\section{Biblioteca de Planos}

Esse módulo armazena uma coleção de planos, definida pelo desenvolvedor, que o agente pode utilizar para atingir seus objetivos. 


\section{Intenção}

O módulo de "Intenção" é responsável por motivar e orientar o agente a realizar suas ações, o que lhe permite apresentar um grau de autonomia e automotivação. Esse módulo contém informações sobre os objetivos (estados do ambiente) que o agente quer alcançar, bem como as prioridades e custos associados.

\section{Ação}

Ação é a habilidade que o agente tem de intervir instantaneamente no ambiente.

\section{Afetivo}

O módulo "Afetivo" tem destaque neste estudo pela influência que exerce sobre os demais módulos e filtros diversificando o comportamento do agente. Internamente, o módulo estabelece uma intensa relação entre três tipos de afetos: personalidade, humor e emoção. Segundo Vinayagamoorthy et al. [2006] esses tipos de afeto podem ser categorizados em função da influência que têm no comportamento do agente e das características temporais.

A estrutura interna do módulo afetivo é similar ao apresentado em ALMA [Gebhard, 2005], Arquitetura de Interação [Kasap et al., 2009] e BASIC [Romano et al., 2005] no sentido de utilizar o modelo de Mehrabian [1995] que expressa o relacionamento dos submódulos Personalidade, Humor e Emoção utilizando os parâmetros do modelo dos Cinco Grandes Fatores de Personalidade [McCrae e John, 1992], do modelo de Humor PAD [Mehrabian, 1995] e do Modelo de Emoção OCC [Ortony et al., 1988]. Ele foi escolhido, pois define parâmetros concretos para o fluxo de informação e por ser utilizado com sucesso nos três trabalhos referenciados. Entretanto, a arquitetura desenvolvida se diferencia das demais, pois, mostra a influência da personalidade, humor e emoção, nas atividades cognitivas e não nas fisiológicas.

O diagrama do módulo afetivo e o relacionamento entre os submódulos Personalidade, Humor e Emoção é apresentado na figura 3.3. No diagrama os retângulos representam os submódulos, as linhas contínuas o fluxo dos dados e as linhas tracejadas as consultas. Inicialmente o submódulo personalidade estabelece parâmetros que determinam o estado de humor inicial. Com a execução do agente, as informações chegam ao módulo por meio da emoção. Ao receber essas informações, os submódulos emoção e humor são atualizados, disponibilizando assim o novo estado afetivo do agente para a arquitetura. A seguir, são apresentados cada um dos três afetos, bem como os modelos que foram utilizados na arquitetura e a relação que existe entre eles.

\section{Personalidade}

O estudo utilizou o modelo dos Cinco Grandes Fatores de Personalidade [McCrae e John, 1992] por ser intuitivo, ter o foco na descrição e por ser amplamente utilizado na simulação de agentes com personalidade. 


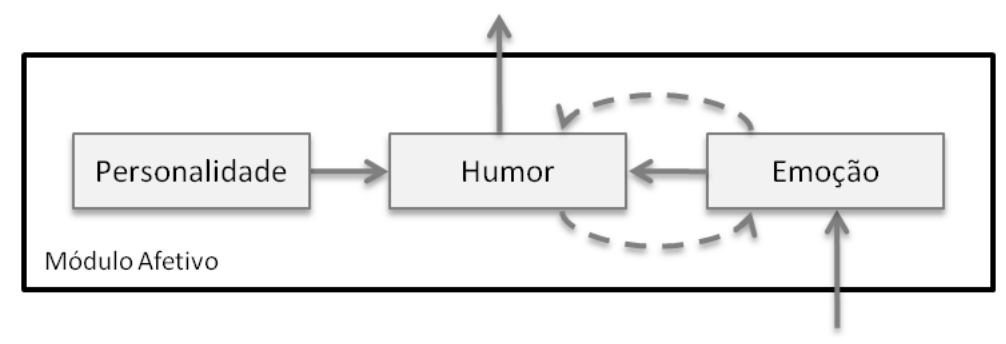

Figura 3.3: Diagrama de funcionamento do Módulo Afetivo.

Embora alguns pesquisadores acreditem que os valores de personalidade podem sofrer alterações ao longo da vida de uma pessoa, a personalidade é considerada, nesse trabalho, um estado afetivo de longo prazo. Neste sentido, a construção de personagens sintéticos como simulações de personagens reais, foi baseada em fatores de personalidade fixos, ou seja, imutáveis ao longo do tempo.

No módulo Afetivo, a personalidade é representada por um vetor de cinco posições que variam de $-1,0$ até $+1,0$ e os valores iniciais (Abertura à Experiência [A], Responsabilidade [R], Extroversão [E], Cordialidade [C] e Neuroticismo [N]) são definidos pelo usuário.

$$
P=[A, R, E, C, N] \text { onde } A, R, E, C, N \in[-1,1]
$$

\section{Humor}

O humor é um estado afetivo de médio prazo resultado do efeito acumulativo das emoções e que exerce forte influência nas funções cognitivas humanas [Davidson, 1994]. Para esse trabalho foi utilizado o modelo PAD definido por Mehrabian [1995] que divide o humor em três dimensões (prazer, excitação e dominância). Um ponto nesse espaço tridimensional representa o estado de humor de uma pessoa. Em termos numéricos, o intervalo de cada posição varia de $-1,0$ até $+1,0$, definindo assim os oito estados de humor apresentados na tabela 2.4 .

O estado de humor é representado como um vetor no módulo Afetivo:

$$
M=\left[m_{1}, m_{2}, m_{3}\right], \text { onde } m_{i} \in[-1,1]
$$

O estado de humor inicial (ou estado de humor base) do agente é dado pelo relacionamento entre o modelo dos Cinco Grandes Fatores de Personalidade e o modelo de humor PAD também definido por Mehrabian [1995], onde o vetor de personalidade é transformado em um ponto no espaço tridimensional de humor. 


$$
\begin{gathered}
M_{\text {base }}=\left[m_{1}, m_{2}, m_{3}\right], \text { onde } m_{i} \in[-1,1] \\
m_{1}=0,21 * P[E]+0,59 * P[C]+0,19 * P[N] \\
m_{2}=0,15 * P[A]+0,30 * P[C]-0,57 * P[N] \\
m_{3}=0,25 * P[A]+0,17 * P[R]+0,60 * P[E]-0,32 * P[C]
\end{gathered}
$$

\section{Emoção}

As emoções refletem um afeto de curto prazo, que após ser ativado por um evento, ação ou objeto específico, volta ao estado inicial em um curto espaço de tempo. Nos seres humanos, as emoções normalmente influenciam atividades fisiológicas como expressões faciais, gestos, movimentos e entonação de voz. O modelo utilizado para a construção do agente inteligente foi o OCC [Ortony et al., 1988], pois apresenta regras que podem ser implementadas em linguagem de programação. Por ter um padrão bem descrito e detalhado para sintetizar emoções em máquinas é amplamente utilizado para a simulação de emoções em agentes [Kasap e Magnenat-Thalmann, 2007]. A tabela 3.2 apresenta as 22 emoções descritas pelo modelo OCC (classificadas de forma positivas e negativas) e as ações que devem ocorrer para que elas sejam ativadas.

$\mathrm{Na}$ arquitetura desenvolvida, o módulo Emoção é composto de 22 emoções assim descritas: Admiração, Alegria, Alívio, Angústia, Censura, Desapontamento, Desgosto, Esperança, Feliz por, Gosto, Gratidão, Gratificação, Medo, Medo Confirmado, Orgulho, Pena, Raiva, Remorso, Ressentimento, Satisfação, Satisfação Maldosa, Vergonha. Tal módulo é representado por um vetor de 22 posições capazes de registrar a intensidade de cada umas das emoções acima citadas. Em termos numéricos de 0,0 até $+1,0$ onde 0,0 é a ausência daquela emoção e $+1,0$ a intensidade máxima.

$$
E=\left[e_{1}, e_{2}, \ldots, e_{22}\right], \text { onde } e_{n} \in[0,1]
$$

\section{Filtro de Percepção}

Conforme visto anteriormente, o estado afetivo facilita a percepção dependendo do tipo e intensidade da emoção percebida. Para conseguir esse efeito, algumas modificações foram realizadas. Primeiramente a informação procedente do módulo "Percepção" recebe dois novos atributos: um vetor que indica quais emoções estão associadas a essa percepção e com qual intensidade cada emoção está associada.

Além da modificação nas informações procedentes do módulo "Percepção", um "Filtro de Percepção" (figura 3.4) foi desenvolvido com o objetivo de selecionar previamente as percepções seguindo dois critérios: 


\begin{tabular}{|c|c|c|}
\hline Classificação & Emoção & Eventos de Ativação \\
\hline+ & Admiração & $\begin{array}{l}\text { Sobre um ato louvável iniciado por outro indi- } \\
\text { víduo }\end{array}$ \\
\hline+ & Alegria & Porque algo de bom aconteceu \\
\hline+ & Alívio & $\begin{array}{l}\text { A não confirmação da perspectiva do aconteci- } \\
\text { mento de um evento não desejado }\end{array}$ \\
\hline - & Angústia & Porque algo ruim aconteceu \\
\hline- & Censura & $\begin{array}{l}\text { Sobre um ato censurável iniciado por outro in- } \\
\text { divíduo }\end{array}$ \\
\hline- & Desapontamento & $\begin{array}{l}\text { A não confirmação da perspectiva do aconteci- } \\
\text { mento de um evento desejado }\end{array}$ \\
\hline- & Desgosto & $\begin{array}{l}\text { Porque encontra um indivíduo ou um objeto de- } \\
\text { sagradável }\end{array}$ \\
\hline+ & Esperança & $\begin{array}{l}\text { A perspectiva do acontecimento de um evento } \\
\text { desejado }\end{array}$ \\
\hline+ & Feliz por & $\begin{array}{l}\text { Porque algo bom aconteceu com uma pessoa } \\
\text { querida }\end{array}$ \\
\hline+ & Gosto & $\begin{array}{l}\text { Porque encontra um indivíduo ou um objeto } \\
\text { agradável }\end{array}$ \\
\hline+ & Gratidão & $\begin{array}{l}\text { Sobre um ato louvável iniciado por outro indi- } \\
\text { víduo em um evento desejado }\end{array}$ \\
\hline+ & Gratificação & $\begin{array}{l}\text { Sobre um ato louvável iniciado pelo próprio in- } \\
\text { divíduo em um evento desejado }\end{array}$ \\
\hline- & Medo & $\begin{array}{l}\text { A perspectiva do acontecimento de um evento } \\
\text { não desejado }\end{array}$ \\
\hline- & Medo Confirmado & $\begin{array}{l}\text { A confirmação da perspectiva do acontecimento } \\
\text { de um evento não desejado }\end{array}$ \\
\hline+ & Orgulho & $\begin{array}{l}\text { Sobre um ato louvável iniciado pelo próprio in- } \\
\text { divíduo }\end{array}$ \\
\hline- & Pena & $\begin{array}{l}\text { Porque algo de ruim aconteceu com uma pessoa } \\
\text { querida }\end{array}$ \\
\hline- & Raiva & $\begin{array}{l}\text { Sobre um ato censurável iniciado por outro in- } \\
\text { divíduo em um evento desejado }\end{array}$ \\
\hline- & Remorso & $\begin{array}{l}\text { Sobre um ato censurável iniciado pelo próprio } \\
\text { indivíduo em um evento desejado }\end{array}$ \\
\hline- & Ressentimento & $\begin{array}{l}\text { Porque algo bom aconteceu com uma pessoa não } \\
\text { querida }\end{array}$ \\
\hline+ & Satisfação & $\begin{array}{l}\text { A confirmação da perspectiva do acontecimento } \\
\text { de um evento desejado }\end{array}$ \\
\hline+ & Satisfação Maldosa & $\begin{array}{l}\text { Porque algo de ruim aconteceu com uma pessoa } \\
\text { não querida }\end{array}$ \\
\hline- & Vergonha & $\begin{array}{l}\text { Sobre um ato censurável iniciado pelo próprio } \\
\text { indivíduo }\end{array}$ \\
\hline
\end{tabular}

Tabela 3.2: As 22 emoções do modelo OCC [Ortony et al., 1988]. 
- a percepção está associada a uma emoção de grande intensidade;

- o resultado das emoções percebidas (se as emoções são predominantemente positivas ou negativas) seja congruente com o estado atual do agente.

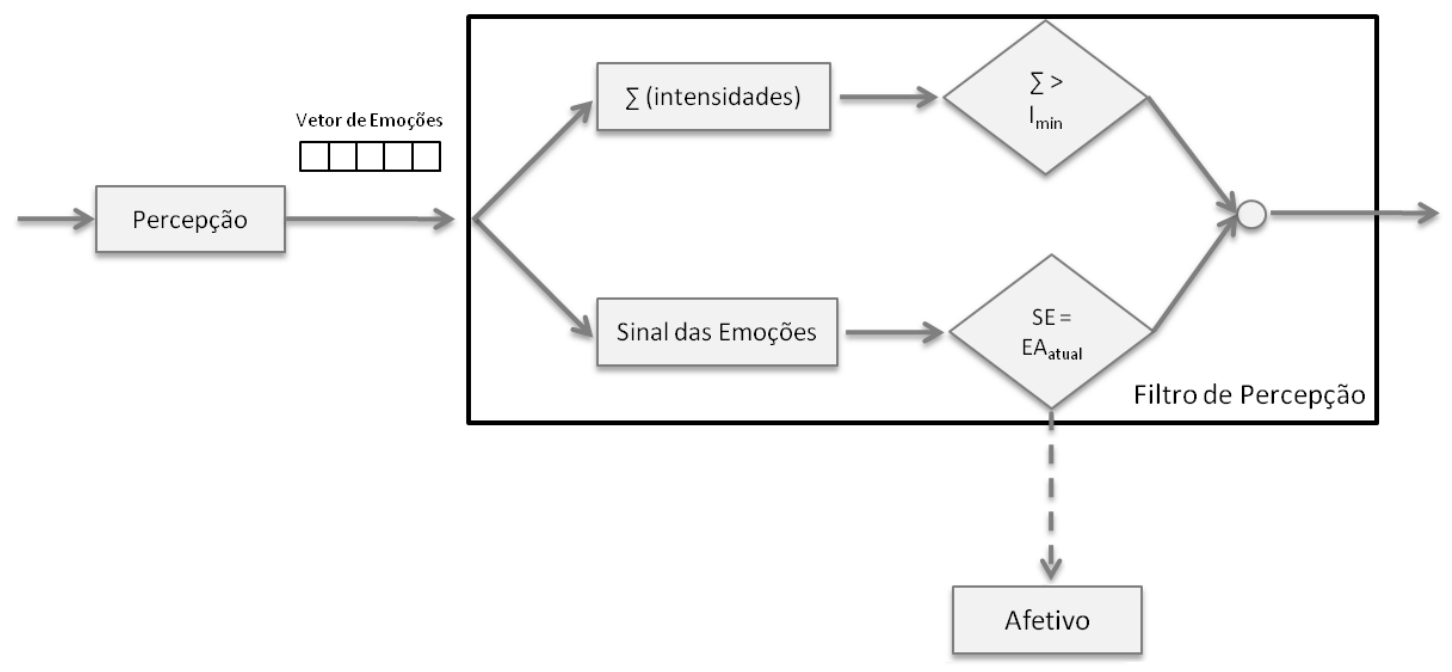

Figura 3.4: Diagrama de funcionamento do Filtro de Percepção.

No primeiro critério é feito um somatório das intensidades das emoções percebidas e se esse valor for maior que o valor da intensidade mínima $\left(I_{\min }\right)$ definido pelo usuário a percepção é selecionada senão é descartada. No segundo uma avaliação é feita sobre o número de emoções positivas e negativas provocadas pela percepção. O tipo (positivo ou negativo) de emoção predominante é comparado com o estado afetivo atual do agente (tanto para o filtro de percepção quanto para os demais, o estado afetivo atual do agente é representado pelo sinal do valor da dimensão P do humor). Se os valores forem congruentes a percepção é selecionada senão é descartada. Dessa maneira, o módulo afetivo influencia, potencializa e seleciona a percepção do agente. Uma combinação dos dois critérios do filtro são determinados pelo usuário no momento da criação do agente.

\section{Filtro de Memória}

A base de conhecimento funciona como a memória do agente. Segundo Bower [1981] os estados afetivos e suas intensidades podem propiciar um contexto que afeta a recuperação posterior da informação. Para tanto, um filtro de memória foi construído com o objetivo de selecionar da base de conhecimento somente informações relacionadas ao estado afetivo atual do agente. Desse modo, são armazenadas, na memória, além da informação, as emoções associadas a ela, bem como suas intensidades e o estado afetivo atual do agente. Assim, as informações da base de conhecimento podem ser recuperadas no futuro por meio do "Filtro de Memória" (figura 3.5) seguindo os seguintes critérios:

- a intensidade da emoção associada a informação é superior ao valor da intensidade mínima definida pelo usuário $\left(I_{\min }\right)$; 
- o tipo (positivo ou negativo) de emoção predominante associada à informação armazenada é congruente ao estado afetivo atual;

- o estado afetivo no momento do armazenamento da memória é congruente ao estado afetivo atual.

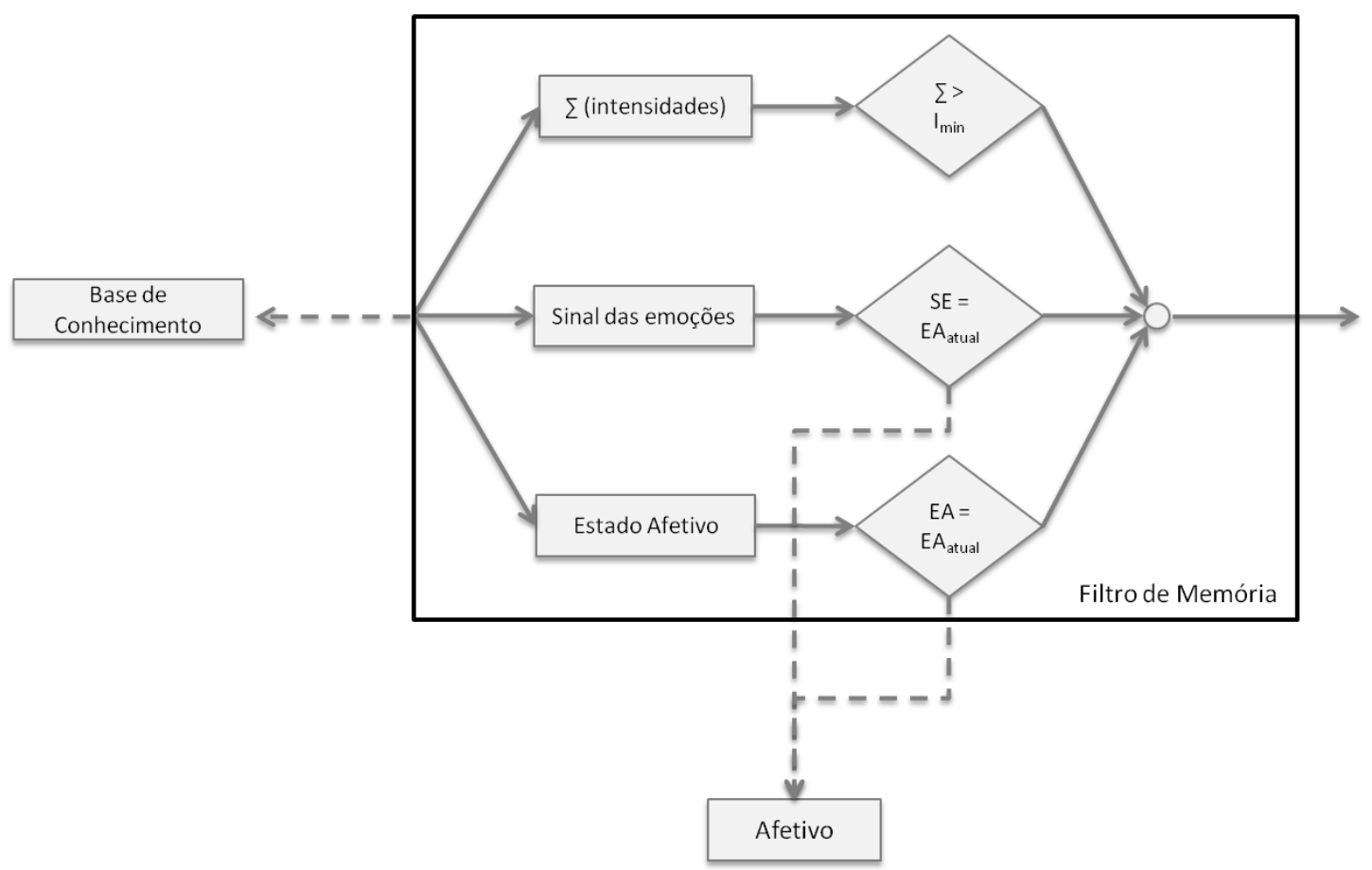

Figura 3.5: Diagrama de funcionamento do Filtro de Memória.

Esses critérios não são excludentes, o que possibilita o estabelecimento de uma combinação dos critérios. Os parâmetros do filtro de memória devem ser definidos no código fonte do agente. Com a inserção desse filtro na arquitetura, o módulo afetivo exerce influência na memória do agente.

\section{Filtro de Planos}

Para influenciar a tomada de decisão, foi utilizada a hipótese dos Marcadores Somáticos de Damásio [Damásio, 1996]. Essa hipótese indica que antes de uma pessoa tomar uma decisão, fundamentada em um pensamento racional, o cérebro reduz significativamente o número de opções de escolha baseada em aspectos somáticos de experiências anteriores. Segundo Damásio [1996], para cada plano é associada uma marca positiva ou negativa dependendo da avaliação corporal realizada no momento da ação. Nesse sentido, uma variável "marca" é associada a cada plano. Um "Filtro de Planos" (figura 3.6) foi desenvolvido para reduzir o número de planos a serem selecionados. Desta forma, esse filtro utiliza os marcadores somáticos para fazer uma pré-seleção dos planos de ação possíveis rejeitando imediatamente aqueles que possuem uma marca negativa (ou aqueles com marcas mais negativas) potencializando o processo de tomada de decisão. 


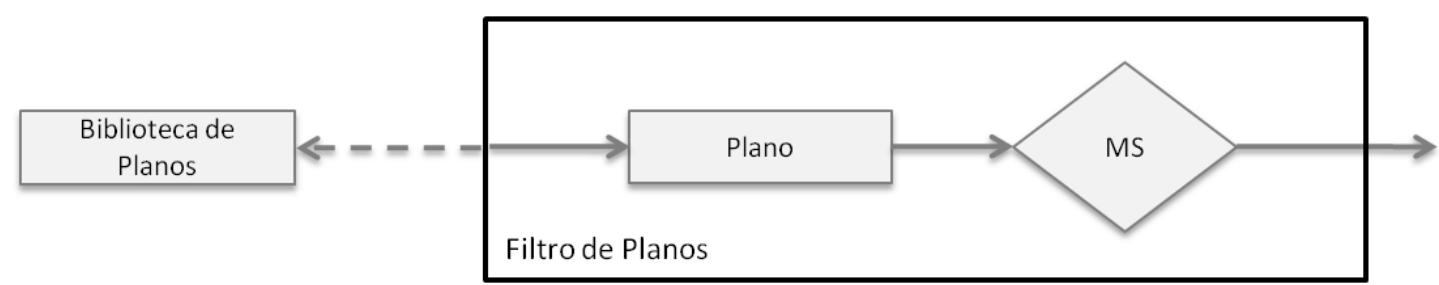

Figura 3.6: Diagrama de funcionamento do Filtro de Planos.

Assim como no desenvolvimento de um agente utilizando Jason, para construir um agente com a nova arquitetura é necessário especificar um conjunto inicial de crenças, objetivos e planos. Porém, na nova arquitetura é necessário especificar também um vetor de personalidade do personagem que conforme descrito anteriormente é representado por um vetor de cinco posições onde na primeira posição é atribuído o valor de abertura à experiência, responsabilidade, extroversão, cordialidade, neuroticismo. Além do vetor de personalidade, são definidos todos os parâmetros para os filtros de percepção, memória e planos.

Depois de especificar os conjuntos iniciais, o vetor de personalidade e os parâmetros dos filtros, o ciclo de iteração é iniciado. Como no ciclo apresentado por Bordini et al. [2007] sobre o Jason, o ciclo da nova arquitetura (figura 3.2) foi dividido em passos. A seguir, é realizada uma breve descrição de cada um dos passos, enfatizando as tarefas que foram adicionadas em relação aos passos descritos anteriormente sobre o Jason.

\section{Passo Inicial - Criação do Agente com Estado Afetivo:}

Antes do início do ciclo de iteração da arquitetura, o agente é criado com todos os conjuntos iniciais definidos em seu código fonte. Também são realizados os cálculos apresentados anteriormente para a determinação do estado de humor base do agente. Dessa maneira, com a definição do estado de humor, o estado afetivo já está pronto para influenciar as atividades cognitivas do agente.

\section{Passo 1 - Percepção do Ambiente:}

As informações são capturadas do ambiente externo pelo módulo "Percepção". A cada nova informação, duas outras características são atribuídas: que emoções elas provocam e com qual intensidade. Para estabelecer quais emoções foram provocadas, são verificados os eventos de ativação associados a cada uma das emoções (conforme descrito na tabela 3.2). Os eventos de ativação são especificados pelo desenvolvedor em função do contexto da aplicação. Por exemplo, em um ambiente virtual de ensino a emoção "alegria", que tem como evento de ativação "Porque algo de bom aconteceu", pode ser ativada quando um agente percebe que acertou uma questão. As intensidades das emoções provocadas também são estabelecidas pelo desenvolver que constrói uma tabela indicando com qual intensidade um agente que está em um determinado estado de humor percebe uma determinada emoção. 


\section{Passo 2 - Filtro das Percepções:}

As informações sobre o meio externo passam pelo "Filtro de Percepções" onde são selecionadas dependendo dos parâmetros de emoção e intensidade escolhidos pelo usuário.

\section{Passo 3 - Geração de Eventos:}

As informações procedentes do módulo "Percepção" geram novos eventos externos. Cada um desses eventos provoca a atualização da "Base de Conhecimento" e do módulo "Afetivo" do agente. As informações procedentes da "Ação" geram novos eventos internos que, assim como no caso dos eventos externos, podem provocar a atualização da "Base de Conhecimento" e do módulo "Afetivo" do agente, além de atualizar o marcador somático do plano executado na "Biblioteca de Planos".

\section{Passo 4 - Atualização da Base de Conhecimento:}

Depois de capturar e filtrar as informações do módulo "Percepção", a "Base de Conhecimento" é atualizada. A cada nova informação inserida ou atualizada na memória, a elas são atribuídas três novas informações: emoção provocada por aquela informação e sua intensidade (que são estabelecidas no módulo "Percepção") e estado afetivo atual do agente.

\section{Passo 5 - Atualização do Estado Afetivo:}

Quando novas informações chegam até o agente, elas devem impactar o módulo "Afetivo" dependendo de sua intensidade. Para tanto, é necessário recalcular os valores de emoção e de humor do agente (conforme explicado anteriormente, o valor da personalidade se mantém estável ao longo do tempo). Essa atualização é realizada utilizando-se duas funções descritas por Kasap et al. [2009]:

Atualização da emoção:

$$
E_{S}=E_{S}+\operatorname{filter}\left(E_{a}, M_{\text {cur }}\right)
$$

onde,

$$
\operatorname{filter}\left(E_{a}, M_{\text {cur }}\right)=E_{a}+\frac{\sum_{i=1}^{22} \sum_{j=1}^{3} \alpha_{i j} * m_{i j}}{\sum_{i=1}^{22} \sum_{j=1}^{3} \alpha_{i j}}
$$

Atualização do humor:

$$
M_{\text {cur }}=M_{\text {cur }}+\operatorname{UpdateMood}\left(E_{s}\right)
$$

onde,

$$
\operatorname{Update} \operatorname{Mood}\left(E_{s}\right)=\sum_{i=1}^{22} \sum_{j=1}^{3} e_{i} * \alpha_{i j}
$$

Na atualização da emoção, o estado emocional $\left(E_{s}\right)$ é calculado como a soma do seu valor anterior com o valor da função chamada "filter" que recebe como parâmetro o estado emocional avaliado no módulo "Percepção" $\left(E_{a}\right)$ e o estado de humor atual $\left(M_{\text {cur }}\right)$. O objetivo da função "filter" 
é calcular a influência que o estado de humor atual causa sobre o estado emocional avaliado e para tanto utiliza um valor que relaciona todas as 22 emoções com as três dimensões do humor. Esse mapeamento foi originalmente desenvolvido por Mehrabian [1995] somente para algumas emoções e estendido posteriormente por Gebhard [2005] para as 22. A tabela 3.3 apresenta o mapeamento realizado por Gebhard [2005] e utilizado na nova arquitetura.

Depois da atualização da emoção, é executada a tarefa de atualização do humor. A função responsável por essa tarefa determina que o estado de humor atual $\left(M_{\text {cur }}\right)$ é a soma entre seu valor anterior e uma função "UpdateMood" que recebe como parâmetro o estado emocional $\left(E_{s}\right)$. A função "UpdateMood" também usa a tabela 3.3 para calcular a influência do novo estado emocional no estado de humor atual.

Além das funções de atualização, é executada uma função de declínio. Essa função é igualmente importante, pois se o agente não receber mais nenhuma informação procedente do módulo "Percepção", o seu estado afetivo deve voltar ao estado inicial. Conforme sugere Kasap et al. [2009] o declínio do estado afetivo é baseado em uma curva exponencial e possui duas características: a intensidade de declínio da emoção é mais rápido do que do humor e a velocidade de queda da emoção e do humor é influenciado pelo neuroticismo (um dos cinco fatores de personalidade). Isso pode ser justificado pois, para pessoas com alto escore de neuroticismo, as emoções positivas devem desaparecer mais rapidamente do que as emoções negativas e deve acontecer o contrário para pessoas com baixo escore nesse fator.

\section{Passo 6 - Recuperação de todos os Planos Relevantes:}

Depois de todas as atualizações, o evento é enviado para o módulo "Plano" responsável por selecionar o plano a ser executado. Nesse módulo primeiramente os planos relacionados ao evento recebido são recuperados da "Biblioteca de Planos". O contexto dos planos recuperados é verificado com as informações armazenadas na "Base de Conhecimento" do agente. As informações recuperadas dessa base passam pelo "Filtro da Memória" que, dependendo dos parâmetros estabelecidos pelo usuário, filtra as informações em função de emoções específicas relacionadas, estado de humor atual ou intensidade da emoção.

\section{Passo 7 - Seleção de um Plano:}

Esse passo é responsável por selecionar qual plano deve ser executado. Para isso, os planos selecionados anteriormente passam pelo "Filtro de Planos" que elimina todos os planos que possuem um marcador somático mais negativo associado. Depois de aplicado o filtro, uma consulta ao conjunto de objetivos do agente é realizada para determinar qual dos planos deve ser escolhido.

\section{Passo 8 - Seleção de uma Intenção para Futura Execução:}

O plano selecionado no passo anterior é inserido no módulo de intenções. Esse plano é mais uma das intenções que o agente possui. Nesse passo o agente escolhe qual das intenções deve ser executada. 


\begin{tabular}{|l|c|c|c|}
\hline Emoção & $\mathrm{P}$ & $\mathrm{A}$ & $\mathrm{D}$ \\
\hline \hline Admiração & 0,5 & 0,3 & $-0,2$ \\
Alegria & 0,4 & 0,2 & 0,1 \\
Alívio & 0,2 & $-0,3$ & 0,4 \\
Angústia & $-0,4$ & $-0,2$ & $-0,5$ \\
Censura & $-0,3$ & $-0,1$ & 0,4 \\
Desapontamento & $-0,3$ & 0,1 & $-0,4$ \\
Desgosto & $-0,6$ & 0,6 & 0,3 \\
Esperança & 0,2 & 0,2 & $-0,1$ \\
Feliz por & 0,4 & 0,2 & 0,2 \\
Gosto & 0,3 & 0,1 & 0,2 \\
Gratidão & 0,4 & 0,2 & $-0,3$ \\
Gratificação & 0,6 & 0,5 & 0,4 \\
Medo & $-0,64$ & 0,6 & $-0,43$ \\
Medo Confirmado & $-0,5$ & $-0,3$ & $-0,7$ \\
Orgulho & 0,4 & 0,3 & 0,3 \\
Pena & $-0,4$ & $-0,2$ & $-0,5$ \\
Raiva & $-0,51$ & 0,59 & 0,25 \\
Remorso & $-0,3$ & 0,1 & $-0,6$ \\
Ressentimento & $-0,2$ & $-0,3$ & $-0,2$ \\
Satisfação & 0,3 & $-0,2$ & 0,4 \\
Satisfação Maldosa & 0,3 & $-0,3$ & $-0,1$ \\
Vergonha & $-0,3$ & 0,1 & $-0,6$ \\
\hline
\end{tabular}

Tabela 3.3: Mapeamento entre as emoções do modelo OCC e as dimensões de humor do modelo PAD [Gebhard, 2005].

\section{Passo 9 - Execução de uma Intenção:}

No último passo, o agente executa o plano "Ação" relacionado à intenção selecionada. Essa ação pode provocar uma alteração no ambiente onde o agente está inserido ou gerar eventos internos que atualizem a "Base de Conhecimento", o estado afetivo e o marcador somático do plano executado.

Neste capítulo apresentou-se a arquitetura desenvolvida para esse trabalho. Inicialmente realizou-se uma revisão do conceito de agentes e suas principais arquiteturas. Das arquiteturas descritas, a BDI foi escolhida como modelo base, pois fornece uma estrutura capaz de produzir comportamentos adaptativos, oferece um conjunto de regras que delimitam a compreensão do raciocínio e já foi utilizada com sucesso em outros projetos. Depois foi apresentado e analisado um estudo comparativo de seis frameworks que implementam o modelo BDI. O resultado desse estudo indicou que o Jason foi o mais apropriado, pois permite a customização de parte do seu código e possui uma classe que facilita a comunicação do agente com o ambiente. Em seguida delineou-se um modelo conceitual da arquitetura e os detalhes de implementação dos módulos e filtros, assim como os passos do seu ciclo de iteração. 


\section{Capítulo 4}

\section{Provas de Conceito}

O capítulo anterior apresentou a arquitetura para o desenvolvimento de agentes com personalidade e emoção desenvolvida para este trabalho. Esse capítulo descreve e analisa dois experimentos utilizados como prova de conceito para avaliar o comportamento produzido pelos agentes construídos com a arquitetura proposta. Inicialmente, discute-se os critérios e hipóteses usados na avaliação. Depois são descritos em detalhes a metodologia empregada no desenvolvimento das duas provas de conceito. A primeira é a simulação do problema do "Dilema do Prisioneiro Iterado". Nesse experimento o problema é tratado como um jogo de computador onde dois agentes criados com a nova arquitetura interagem durante sucessivas rodadas. O segundo experimento é uma versão computadorizada do "Jogo da Memória" no qual o usuário enfrenta diferentes tipos de agentes. Por fim, os resultados dos experimentos são analisados, considerando os critérios definidos inicialmente.

\subsection{Critérios de Avaliação}

A maior parte dos experimentos na área de simulação de emoção em agentes inteligentes utiliza como método avaliativo a aplicação de questionários e/ou entrevistas com os usuários. Esse tipo de avaliação tem por objetivo medir qual o impacto que o agente causa na percepção do usuário. No entanto, o objetivo do trabalho não é avaliar esse impacto, mas sim se os agentes desenvolvidos com a nova arquitetura são capazes de produzir um comportamento coerente. Nesse sentido, cinco hipóteses foram formuladas para auxiliar no delineamento dos experimentos e na análise empírica dos resultados.

Hipótese 1 A utilização do Módulo Afetivo na arquitetura provoca uma alteração coerente no comportamento do agente.

Hipótese 2 A influência do Módulo Afetivo nas atividades cognitivas de percepção, memória e tomada de decisão faz com que os agentes apresentem uma maior variedade de comportamentos e uma maior mudança de estado afetivo.

Hipótese 3 A influência do Módulo Afetivo nas atividades cognitivas de percepção, memória e tomada de decisão provoca um comportamento mais adaptativo.

Hipótese 4 A influência do Módulo Afetivo nas atividades cognitivas de percepção, memória e tomada de decisão produz um comportamento mais cooperativo. 
Hipótese 5 A construção de agentes utilizando a arquitetura desenvolvida produz um comportamento mais próximo de um usuário do que de um comportamento ótimo ou aleatório.

Nas seções a seguir são descritos os dois experimentos construídos para validar as hipóteses. O experimento 1 é prova de conceito para as Hipóteses de 1 a 4 e o experimento 2 para a Hipótese 5. Por fim, na seção 4.4 são apresentadas as observações esperadas, os resultados observados e as conclusões de cada uma das cinco hipóteses.

\subsection{Experimento 1: O Dilema do Prisioneiro Iterado}

O Dilema do Prisioneiro é um problema clássico de teoria dos jogos que propõe a um indivíduo um conflito de tomar uma decisão racional considerando a si mesmo ou o grupo.

Elaborado inicialmente pelos matemáticos norte americanos Merrill Flood e Melvin Dresher em 1950 e formalizado, contextualizado e nomeado pelo matemático canadense Albert W. Tucker o problema é objeto de estudo de áreas como Ciências Sociais, Economia, Ciência Política, Etologia e Biologia Evolutiva [Russell e Norvig, 2003] e foi escolhido como primeiro experimento do trabalho pois permite avaliar empiricamente a influência do módulo afetivo (personalidade, humor e emoção) no desempenho e comportamento dos personagens sintéticos.

O problema apresenta o seguinte enunciado:

Dois suspeitos de roubo, P1 e P2, são presos em flagrante pela polícia próximo a cena do crime. A polícia não tem provas suficientes para condená-los, mas, oferece separadamente a cada um deles o mesmo acordo: se um dos prisioneiros, testemunhar contra o seu parceiro e o outro permanecer em silêncio, o que testemunhou ficará livre enquanto que o outro cumprirá uma sentença de 5 anos de prisão. Se ambos testemunharem, cada um cumprirá uma sentença de 3 anos de prisão e se ambos não testemunharem a pena é de 1 ano para cada um.

O objetivo de cada um dos suspeitos é de minimizar a sua pena. Sendo assim, qual decisão cada um dos suspeitos deve tomar? Para facilitar a visualização das possibilidades de escolha e suas penas, a tabela 4.1 apresenta uma matriz de recompensa que fornece a pena associada a cada par de ações realizadas pelos jogadores.

\begin{tabular}{|c|c|c|}
\hline & P2: Testemunhar & P2: Não Testemunhar \\
\hline P1: Testemunhar & P1: 3 anos, P2: 3 anos & P1: livre, P2: 5 anos \\
P1: Não Testemunhar & P1: 5 anos, P2: livre & P1: 1 ano, P2: 1 ano \\
\hline
\end{tabular}

Tabela 4.1: Matriz de recompensa do Dilema do Prisioneiro.

Então, pode-se descrever quatro situações: 
Situação 1: se P1 testemunhar e P2 também testemunhar, ambos deverão cumprir 3 anos de prisão.

Situação 2: se P1 testemunhar e P2 não testemunhar, o prisioneiro P1 não irá para a prisão e o prisioneiro P2 deverá cumprir 5 anos de prisão.

Situação 3: se P1 não testemunhar e P2 testemunhar, o prisioneiro P1 deverá cumprir 5 anos de prisão e o prisioneiro P2 não irá para a prisão.

Situação 4: se P1 não testemunhar e P2 também não testemunhar, ambos deverão cumprir 1 ano de prisão.

Analisando a matriz de recompensa e as quatro situações existentes nota-se que independentemente da resposta do outro prisioneiro a melhor escolha é sempre acusar. Por exemplo, sob o ponto de vista do prisioneiro P1, se P2 acusá-lo ele pode pegar 3 anos de prisão (caso também acuse) ou 5 anos (caso não acuse) e se P2 não acusá-lo ele pode ficar livre da prisão (caso acuse) ou 1 ano (caso também não acuse). Logo, a estratégia acusar é a estratégia dominante. Uma estratégia é dominante quando seu resultado correspondente é melhor para um jogador do que qualquer outra considerando todas as estratégias disponíveis [Russell e Norvig, 2003].

Em 1984 em seu livro intitulado "A evolução da cooperação: o dilema do prisioneiro e a teoria de jogos" o cientista político e professor norte-americano Robert Axelrod propôs uma versão estendida do Dilema do Prisioneiro: o Dilema do Prisioneiro Iterado. Nessa nova versão, os prisioneiros interagem um número finito de vezes armazenando na memória as decisões e castigos das rodadas anteriores o que tornou possível o desenvolvimento de estratégias de cooperação. Então, Axelrod convidou pesquisadores do mundo todo para uma competição de estratégias automatizadas (algoritmos) para o problema do Dilema do Prisioneiro Iterado.

Diversas estratégias foram enviadas para a competição, uma vez que nessa nova versão não havia uma estratégia dominante. As estratégias variavam basicamente na escolha da ação inicial e na capacidade de cooperação. Segue abaixo uma lista disponível no site "Iterated Prisoner's Dilemma Online Game and Simulation" [Davis, 2007] com diversas estratégias possíveis para o Dilema do Prisioneiro Iterado.

1. Olho por olho - Repetir a última escolha do adversário.

2. Olho por olho e Aleatório - Repetir a última escolha do adversário, mas por vezes distorcida com escolhas aleatórias.

3. Olho por Olho Duas Vezes - Como olho por olho, exceto que o adversário deve fazer a mesma escolha duas vezes para ser repetido.

4. Olho por Olho Duas Vezes e Aleatório - Como olho por olho, exceto que o adversário deve fazer a mesma escolha duas vezes seguida antes de ser retribuído. A escolha é influenciada por escolhas aleatórias. 
5. Olho por Olho e Acusação Aleatória - Repetir a última escolha do adversário, mas escolher a opção "testemunhar" aleatoriamente.

6. Olho por Olho e Não Acusação Aleatória - Repetir a última escolha do adversário, mas escolher a opção "não testemunhar" aleatoriamente.

7. Olho por Olho Suspeito - Igual ao Olho por Olho, mas inicia o jogo com a opção "testemunhar".

8. Aleatória - Escolher aleatoriamente entre "testemunhar" e "não testemunhar".

9. Testemunhar sempre - Sempre escolher a opção "testemunhar".

10. Nunca testemunhar - Sempre escolher a opção "não testemunhar".

11. Cooperar somente uma vez - Inicialmente sempre escolher "não testemunhar". Se o oponente escolher "testemunhar", passa a "testemunhar" sempre.

12. Cooperação mas com Represália - Inicialmente sempre escolher "não testemunhar". Se o oponente escolher "testemunhar", seleciona a opção "testemunhar" por quatro rodadas seguidas, depois volta a "não testemunhar".

13. Pavlov - Se a pena atribuída na última rodada for 0 ou 1 ano, repetir a última escolha, senão, trocar escolha.

14. Pavlov e Aleatória - Se a pena atribuída na última rodada for 0 ou 1 ano, repetir a última escolha, senão, trocar escolha, mas por vezes distorcida por escolhas aleatórias.

Ao final da competição, a estratégia campeã foi a Tit-for-Tat (Olho por olho) desenvolvida pelo matemático russo Anatol Rapoport. Essa estratégia simplesmente repete a escolha feita pelo oponente na última rodada (e na primeira rodada sempre escolhe a opção "não-testemunhar"). Segundo Rapoport a estratégia "Tit-for-Tat" obteve o melhor desempenho, pois nunca acusa o oponente na primeira rodada, ou seja, nunca inicia um ciclo de acusações e tem a capacidade de se vingar e perdoar o adversário rapidamente. Para Robert Axelrod as estratégias cooperativas obtinham melhores resultados a longo prazo, enquanto que, as estratégias mais individualistas, obtinham resultados piores.

\section{Experimento}

A implementação do jogo que simula o problema do Dilema do Prisioneiro Iterado é dividida em interações onde os jogadores devem escolher entre as opções "Testemunhar" e "Não Testemunhar". Depois eles enviam suas decisões para o controlador do jogo que retorna o valor da pena aplicada a cada um deles. Com essa nova informação, os agentes devem escolher novamente uma das opções, iniciando então uma nova interação. 
Para a avaliação da influência do estado afetivo do agente, dividiu-se a execução do experimento em dois: Experimento 1.A e Experimento 1.B. No experimento 1.A os agentes foram construídos com a arquitetura apresentada no capítulo anterior, porém o estado afetivo (apesar de atualizado a cada rodada) não influencia nas atividades de percepção, memória e tomada de decisão. No experimento 1.B os agente envolvidos também utilizaram a arquitetura proposta nesse trabalho e o estado afetivo influencia nas atividades cognitivas. A seguir são descritas as duas partes do experimento.

\section{Experimento 1.A}

Nessa primeira parte do Experimento 1 realizou-se 36 testes $^{1}$. Esses testes consistem na disputa entre oito agentes que selecionados dois a dois, disputam o jogo do Dilema do Prisioneiro Iterado por 100 rodadas, onde cada um dos agentes representa um estado de humor inicial (Exuberante, Dependente, Relaxado, Dócil, Entediado, Arrogante, Ansioso e Hostil). Como descrito no capítulo 2, o estado de humor é responsável pela influência nas atividades cognitivas e por esse motivo ele é o ponto chave nesse trabalho influenciando a percepção, a memória e a tomada de decisão dos agentes. Portanto, em ambas as partes desse experimento, o estado afetivo do agente é representado pelo seu estado de humor atual. A tabela 4.2 a seguir apresenta os oito estados de humor definidos pelo modelo PAD [Mehrabian, 1995] que, apesar de já descrito anteriormente na tabela 2.4, são reapresentados, devido a sua importância e utilização, enfatizando as propriedades: Estado Emocional, Nível de Atividade Física e Sensação de Controle.

\begin{tabular}{|c|c|c|c|c|}
\hline ID & Estado de Humor & Estado Emocional & Nível de Atividade Física & Sensação de Controle \\
\hline \hline 1 & Exuberante & + & + & + \\
2 & Dependente & + & + & - \\
3 & Relaxado & + & - & + \\
4 & Dócil & + & - & - \\
5 & Entediado & - & - & + \\
6 & Arrogante & - & - & - \\
7 & Ansioso & - & + & + \\
8 & Hostil & - & + & + \\
\hline
\end{tabular}

Tabela 4.2: Os oito estados de humor do modelo PAD [Mehrabian, 1995].

No experimento 1.A, a estratégia de ação do agente é definida em função do seu estado afetivo atual. Nesse sentido, a cada um dos oito estados de humor foi atribuída uma estratégia (tabela 4.3).

Durante a execução dos testes, um arquivo de $\log$ armazenou o estado afetivo atual e o tempo de prisão de cada um dos agentes por rodada. Assim, ao final dos testes

\footnotetext{
${ }^{1} \mathrm{O}$ número total de testes envolvendo oito agentes seria 64 (incluindo os jogos entre agentes de mesmo estado afetivo). No entanto, foram excluídos 28 testes que envolviam uma permutação dos envolvidos, pois apresentavam o mesmo resultado.
} 


\begin{tabular}{|c|c|}
\hline Humor & Estratégia \\
\hline \hline Exuberante & Tit for Tat \\
Dependente & Tit for Tat \\
Relaxado & Não acusa \\
Dócil & Não acusa \\
Entediado & Randômico \\
Arrogante & Acusa \\
Ansioso & Pavlov \\
Hostil & Acusa \\
\hline
\end{tabular}

Tabela 4.3: Estratégias para tomada de decisão.

foi possível desenhar gráficos que mostraram a evolução do estado afetivo dos agentes ao longo das iterações. Os gráficos de todos os testes (figuras de A.1 a A.5) e uma tabela (A.1) com o número total de anos de prisão que cada um dos agentes recebeu são apresentados no anexo A.

\section{Experimento 1.B}

A segunda parte do Experimento 1 repete os mesmos 36 testes descritos anteriormente envolvendo os oito agentes nas mesmas condições. A arquitetura, nessa segunda parte do experimento, possui o mesmo ciclo de iteração descrito no capítulo anterior, pois o estado afetivo influencia nas atividades cognitivas.

Inicialmente, os conjuntos iniciais de crenças, objetivos e planos, bem como o vetor de personalidade e os parâmetros dos filtros foram especificados no código fonte de cada um dos agentes. Estabelecidos os parâmetros iniciais, os valores de personalidade são transformados em um ponto no estado de humor e o agente deve escolher a ação "Testemunhar" ou "Não Testemunhar" com a qual ele iniciará o jogo. Essa primeira tomada de decisão é conhecida como o problema da "Partida a Frio", ou seja, o agente deve tomar uma decisão antes mesmo de ter alguma informação sobre o seu adversário. Para solucionar esse problema estabeleceu-se que os agentes que apresentam um estado de humor com a propriedade Estado Emocional positiva (Exuberante, Dependente, Relaxado e Dócil) decidem "Não Testemunhar", enquanto que os agentes com estado de humor com a propriedade Estado Emocional negativa (Entediado, Arrogante, Ansioso e Hostil) decidem "Testemunhar".

Solucionado o problema da "Partida a Frio", calcula-se as penas para cada um dos jogadores. Esse cálculo é baseado na matriz de recompensa (tabela 4.1). Em seguida, a informação com o tempo de prisão a ser cumprido é enviada para cada um dos jogadores. O Módulo "Percepção" recebe a informação e como o jogador conhece qual foi sua decisão na última rodada, descobre qual foi a decisão do seu oponente e o tempo de prisão que o outro deverá cumprir. 
Conforme discutido anteriormente, quando uma nova informação chega ao Módulo "Percepção", calcula-se quais as emoções provocadas como resposta a esse novo estímulo e qual a intensidade. Das vinte e duas emoções descritas no modelo OCC [Ortony et al., 1988], somente dezesseis são aplicadas no contexto desse jogo. As emoções envolvidas no jogo e seus eventos de ativação são apresentados na tabela 4.4.

\begin{tabular}{|c|l|l|}
\hline ID & Emoção & Evento de Ativação \\
\hline \hline 1 & Alegria & Porque algo de bom aconteceu \\
2 & Angústia & Porque algo ruim aconteceu \\
3 & Feliz por & Porque algo bom aconteceu com uma pessoa querida \\
4 & Ressentimento & Porque algo bom aconteceu com uma pessoa não querida \\
5 & Satisfação Maldosa & Porque algo de ruim aconteceu com uma pessoa não querida \\
6 & Pena & Porque algo de ruim aconteceu com uma pessoa querida \\
13 & Orgulho & Sobre um ato louvável iniciado pelo próprio indivíduo \\
14 & Vergonha & Sobre um ato censurável iniciado pelo próprio indivíduo \\
15 & Admiração & Sobre um ato louvável iniciado por outro indivíduo \\
16 & Censura & Sobre um ato censurável iniciado por outro indivíduo \\
17 & Gratidão & Sobre um ato louvável iniciado por outro indivíduo em um evento desejado \\
18 & Raiva & Sobre um ato censurável iniciado por outro indivíduo em um evento desejado \\
19 & Satisfação & Sobre um ato louvável iniciado pelo próprio indivíduo em um evento desejado \\
20 & Remorso & Sobre um ato censurável iniciado pelo próprio indivíduo em um evento desejado \\
21 & Gosto & Porque encontra um indivíduo ou um objeto agradável \\
22 & Desgosto & Porque encontra um indivíduo ou um objeto desagradável \\
\hline
\end{tabular}

Tabela 4.4: As dezesseis emoções utilizadas nesse experimento, baseadas no modelo OCC [Ortony et al., 1988].

O algoritmo responsável pelo cálculo da ativação e intensidade das emoções é indicado abaixo. Esse algoritmo faz referência à matriz "intensidade" que indica com qual intensidade cada uma das emoções será percebida em função do estado de humor do jogador. Os valores desse mapeamento, apresentados na tabela 4.5, foram estabelecidos para diferenciar a intensidade das emoções percebidas pelos agentes em diferentes estados afetivos.

$m \leftarrow$ humor Atual ()

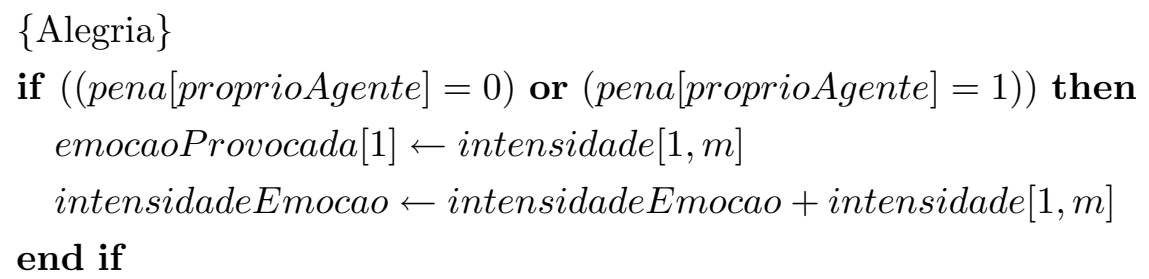




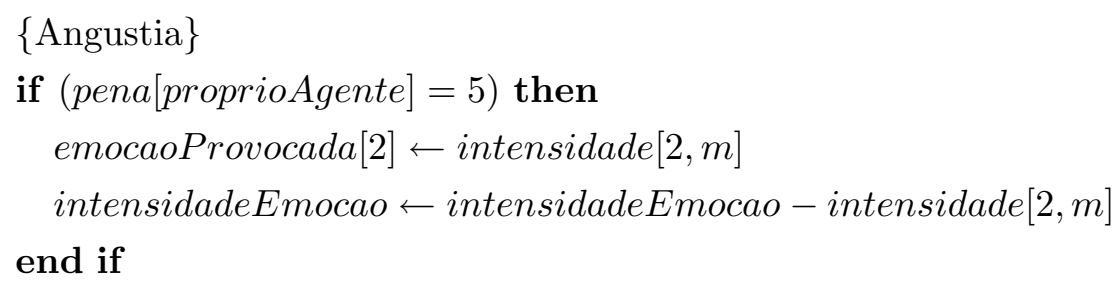

$\{$ Feliz por $\}$

if $(($ emocao $[20] \geq$ emocao[21]) and $($ pena[outroAgente $]=0))$ then emocaoProvocada $[3] \leftarrow$ intensidade $[3, m]$ intensidadeEmocao $\leftarrow$ intensidadeEmocao + intensidade $[3, m]$ end if

$\{$ Ressentimento

if $(($ emocao $[20] \leq$ emocao $[21])$ and $($ pena $[$ outroAgente $]=0))$ then emocaoProvocada $[4] \leftarrow$ intensidade $[4, m]$ intensidadeEmocao $\leftarrow$ intensidadeEmocao - intensidade $[4, m]$ end if

\{Satisfacao\}

if $(($ emocao $[20] \geq$ emocao $[21])$ and $($ pena $[$ outroAgente $]=5))$ then emocaoProvocada $[5] \leftarrow$ intensidade $[5, m]$ intensidadeEmocao $\leftarrow$ intensidadeEmocao + intensidade $[5, m]$ end if

$\{$ Pena $\}$

if $(($ emocao $[20] \leq$ emocao $[21])$ and $($ pena $[$ outroAgente $]=5))$ then emocaoProvocada $[6] \leftarrow$ intensidade $[6, m]$ intensidadeEmocao $\leftarrow$ intensidadeEmocao - intensidade $[6, m]$ end if

\{Orgulho\}

if (pena[outroAgente $]=0)$ then emocaoProvocada $[13] \leftarrow$ intensidade $[13, m]$ intensidadeEmocao $\leftarrow$ intensidadeEmocao + intensidade $[13, m]$ end if 

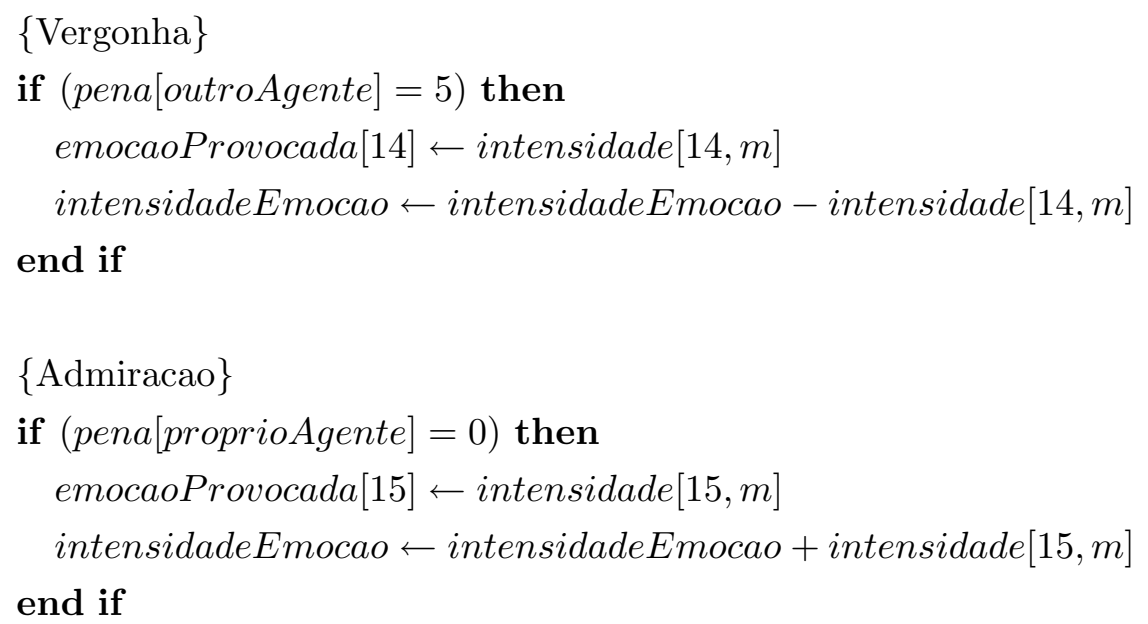

\{Censura\}

if $($ pena $[$ proprioAgente $]=5)$ then emocaoProvocada $[16] \leftarrow$ intensidade $[16, m]$ intensidadeEmocao $\leftarrow$ intensidadeEmocao - intensidade [16, $m]$ end if
\{Gratidao\}
if (outroAgenteAnswer $=0$ ) then emocaoProvocada $[17] \leftarrow$ intensidade $[17, m]$ intensidadeEmocao $\leftarrow$ intensidadeEmocao + intensidade $[17, m]$ end if
\{Raiva\}
if (outroAgenteAnswer $=1$ ) then emocaoProvocada $[18] \leftarrow$ intensidade $[18, m]$ intensidadeEmocao $\leftarrow$ intensidadeEmocao - intensidade $[18, m]$ end if
$\{$ Satisfacao $\}$
if (proprioAgenteAnswer $=0$ ) then emocaoProvocada $[19] \leftarrow$ intensidade $[19, m]$ intensidadeEmocao $\leftarrow$ intensidadeEmocao + intensidade $[19, m]$ end if




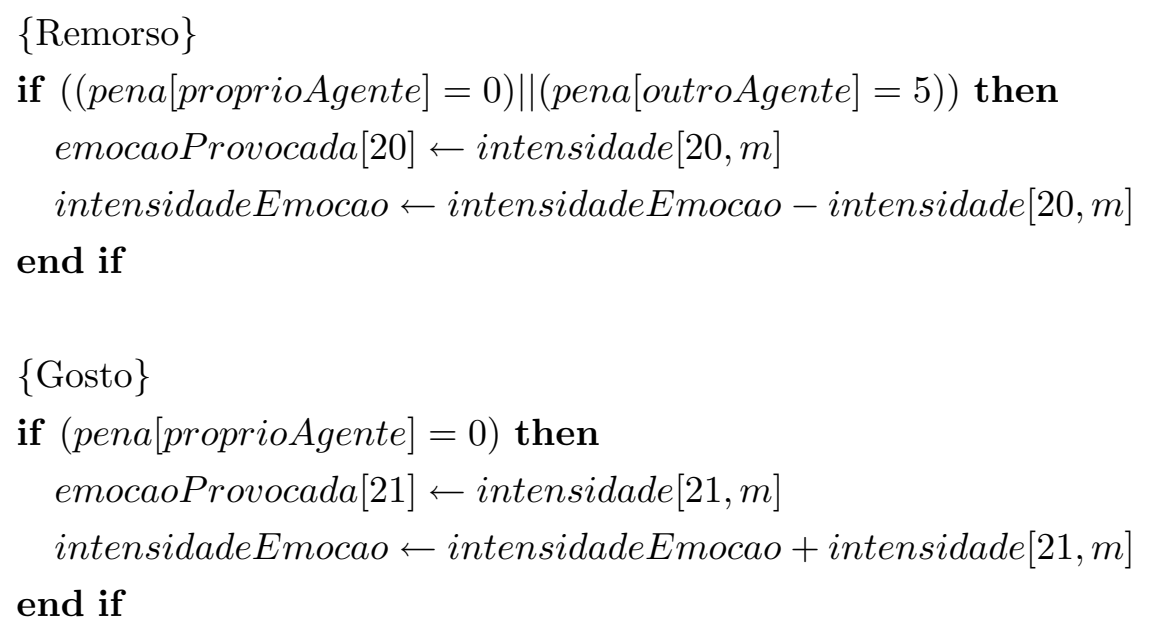

$\{$ Desgosto $\}$

if (pena[proprioAgente $]=5)$ then

emocaoProvocada $[22] \leftarrow$ intensidade $[22, m]$

intensidadeEmocao $\leftarrow$ intensidadeEmocao - intensidade $[22, m]$

end if

\begin{tabular}{|c|c|c|c|c|c|c|c|c|c|}
\hline & \multicolumn{8}{|c|}{ Estados de Humor } \\
\hline & & 1 & 2 & 3 & 4 & 5 & 6 & 7 & 8 \\
\hline \multirow{16}{*}{ 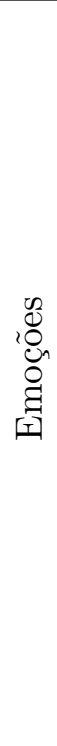 } & 1 & 1 & 2 & 1 & 2 & 1 & 1 & 2 & 1 \\
\hline & 2 & 1 & 2 & 1 & 2 & 1 & 1 & 2 & 1 \\
\hline & 3 & 2 & 2 & 1 & 2 & 1 & 0,5 & 1 & 0 \\
\hline & 4 & 0,5 & 1 & 1 & 1 & 1 & 0,5 & 1 & 0 \\
\hline & 5 & 1 & 1 & 1 & 1 & 1 & 2 & 1 & 2 \\
\hline & 6 & 1 & 2 & 1 & 2 & 1 & 1 & 2 & 1 \\
\hline & 13 & 2 & 1 & 1 & 2 & 1 & 2 & 2 & 2 \\
\hline & 14 & 0,5 & 2 & 1 & 2 & 1 & 0,5 & 2 & 0,5 \\
\hline & 15 & 2 & 1 & 1 & 1 & 1 & 2 & 1 & 2 \\
\hline & 16 & 1 & 1 & 1 & 0,5 & 1 & 2 & 1 & 2 \\
\hline & 17 & 1 & 2 & 1 & 2 & 1 & 1 & 2 & 1 \\
\hline & 18 & 1 & 1 & 1 & 0,5 & 2 & 2 & 2 & 2 \\
\hline & 19 & 2 & 1 & 1 & 1 & 1 & 2 & 1 & 2 \\
\hline & 20 & 1 & 2 & 1 & 2 & 1 & 1 & 2 & 1 \\
\hline & 21 & 1 & 2 & 1 & 2 & 1 & 1 & 2 & 1 \\
\hline & 22 & 1 & 2 & 1 & 1 & 1 & 2 & 2 & 2 \\
\hline
\end{tabular}

Tabela 4.5: Mapeamento que relaciona a intensidade das emoções percebidas com os estados de humor.

Para o experimento 1.B utilizou-se o filtro de percepção com o seguinte parâmetro: somente as percepções associadas a grandes intensidades emocionais (positivas ou negativas) seriam consideradas pelo agente. Seguindo o ciclo de iteração, as informações que passaram pelo filtro e suas respectivas emoções e intensidades são transformadas 
em um evento que atualiza a Base de Conhecimento e o Módulo Afetivo.

O próximo passo é a seleção do plano que será executado. Assim como no Experimento 1.A, no Experimento 1.B só existem dois planos armazenados na Biblioteca de Planos: "Testemunhar" e "Não Testemunhar". A seleção do plano depende de uma estratégia definida para o agente que varia dependendo do seu estado afetivo atual. Nesse sentido, a cada um dos oito estados de humor foi atribuída uma estratégia (tabela 4.3). Essas estratégias formam a base do processo de tomada de decisão dos agentes, pois para a decisão final, eles ainda consultam a memória e os marcadores somáticos. Os algoritmos de tomada de decisão são descritos abaixo.

$m \leftarrow$ humor Atual ()

$m s \_n t \leftarrow$ marcadoSomaticoNT $(m)$ \{Retorna o número de marcas positivas associadas ao plano "Nao_Testemunhar" no estado afetivo $m\}$

$m s \_t \leftarrow$ marcadoSomatico $T(m)$ \{Retorna o número de marcas positivas associadas ao plano "Testemunhar" no estado afetivo $m\}$

pena[proprioAgente] \{Número de anos que o agente deve ficar preso devido a última rodada\}

pena[outroAgente] \{Número de anos que o adversário deve ficar preso devido a última rodada\}

resposta[proprioAgente] \{Resposta do agente na última rodada\}

resposta[outroAgente] \{Resposta do adversário na última rodada\}

\{Funçao que retorna a açao do agente\}

function Decidir(ms_nt, ms_t)

if $\left(m s \_n t>m s \_t\right)$ then

return ("Nao_Testemunhar")

else

return ("Testemunhar")

end if

$\{$ Exuberante $(1)\}$

if $(m=1)$ then

if $($ resposta[outroAgente $]=$ "Nao_Testemunhar" $)$ then

$m s \_n t \leftarrow m s \_n t * 3$

$m s \_t \leftarrow m s \_t * 1$

end if

if $($ resposta[outroAgente $]=$ "Testemunhar" $)$ then

$m s \_n t \leftarrow m s \_n t * 1$

$m s \_t \leftarrow m s \_t * 3$

end if 


\section{$\operatorname{Decidir}\left(m s \_n t, m s \_t\right)$}

\section{end if}

$\{$ Dependente $(2)\}$

if $(m=2)$ then

if $($ resposta[outroAgente $]=$ "Nao_Testemunhar") then

$m s \_n t \leftarrow m s \_n t * 5$

$m s \_t \leftarrow m s \_t * 1$

end if

if $($ resposta[outroAgente $]=$ "Testemunhar" $)$ then

$m s \_n t \leftarrow m s \_n t * 1$

$m s \_t \leftarrow m s \_t * 5$

end if

$\operatorname{Decidir}\left(m s \_n t, m s \_t\right)$

end if

$\{$ Relaxado (3) $\}$

if $(m=3)$ then

$m s \_n t \leftarrow m s \_n t * 3$

$m s \_t \leftarrow m s \_t * 1$

Decidir $\left(m s \_n t, m s \_t\right)$

end if

\{Dócil (4)\}

if $(m=4)$ then

$m s \_n t \leftarrow m s \_n t * 5$

$m s \_t \leftarrow m s \_t * 1$

Decidir (ms_nt, ms_t $)$

end if

\{Entediado (5) $\}$

if $(m=5)$ then

$m s \_n t \leftarrow m s \_n t * 1$

$m s \_t \leftarrow m s \_t * 1$

$\operatorname{Decidir}\left(m s \_n t, m s \_t\right)$

end if 


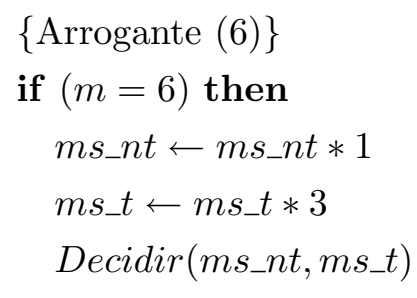

end if

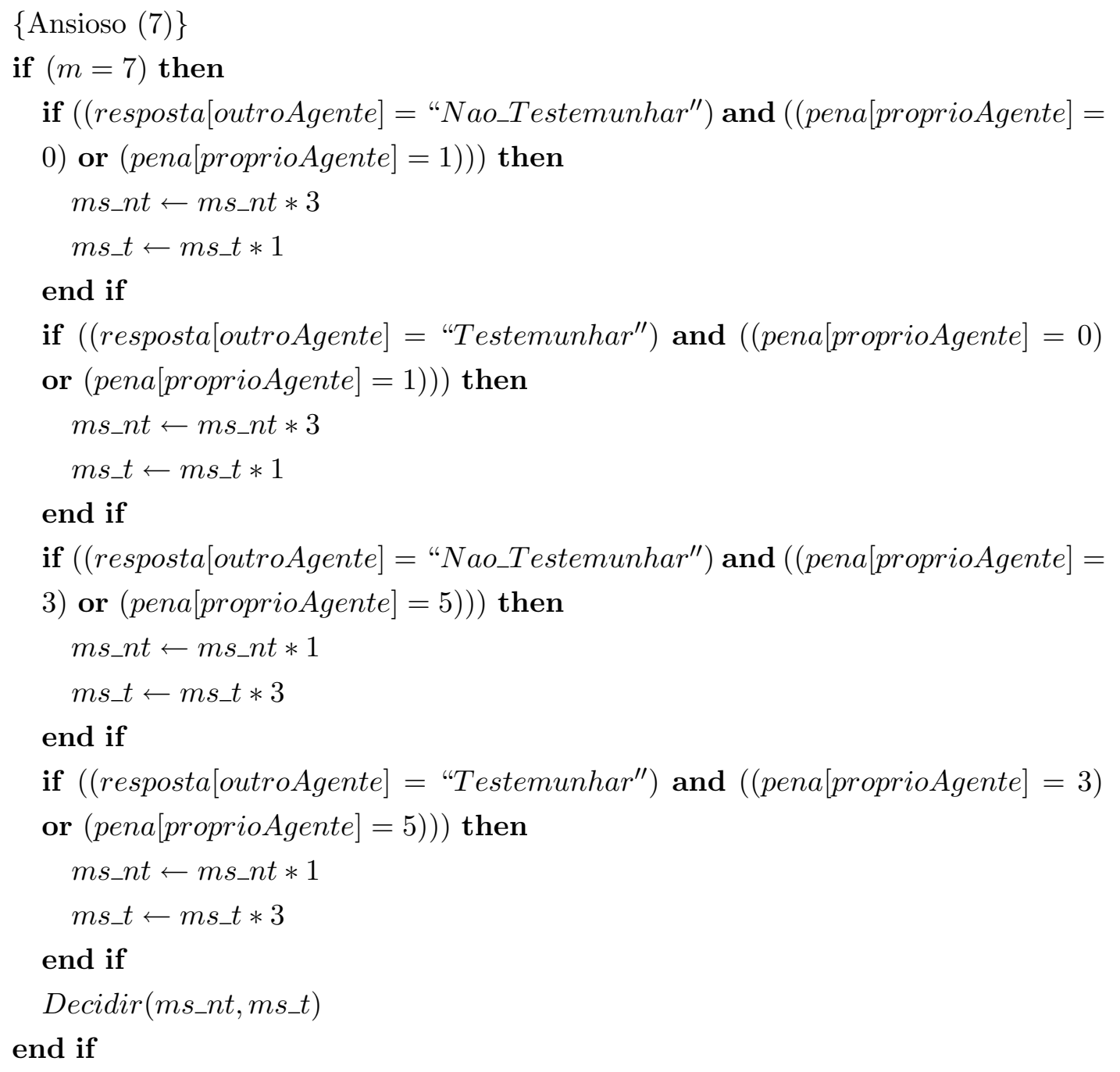

$\{$ Hostil (8)\}

if $(m=8)$ then

$m s \_n t \leftarrow m s \_n t * 1$

$m s \_t \leftarrow m s \_t * 5$

$\operatorname{Decidir}\left(m s \_n t, m s \_t\right)$

end if 
Depois da aplicar o algoritmo da estratégia correspondente, um plano é selecionado e executado. Essa execução gera um evento interno que atualiza o marcador somático atrelado ao plano executado, fechando o ciclo de iteração do agente.

Assim como no experimento 1.A, esse experimento obteve como resultado um conjunto de gráficos que mostraram a evolução do estado afetivo dos agente em cada teste ao longo das iterações e uma tabela com o número total de anos de prisão que cada agente recebeu nos testes. Os gráficos (figuras de B.1 a B.5) e a tabela (B.1) são apresentados no anexo B.

\subsection{Experimento 2: O Jogo da Memória}

O Jogo da Memória é um clássico jogo infantil que exige concentração e memória dos participantes. As cartas utilizadas são originalmente as do baralho, no entanto, novas versões foram desenvolvidas com foco em diferentes públicos, variando os temas. Atualmente, na área de Educação ele é utilizado como material didático/pedagógico de apoio ao ensino para diferentes faixas etárias.

O jogo tem a seguinte dinâmica:

O jogo da memória consiste de um conjunto de cartas com figuras que se repete em duas cartas diferentes. Inicialmente, as cartas são colocadas com as figuras viradas para baixo, embaralhadas e dispostas em linhas e colunas. O primeiro jogador vira duas cartas de maneira que todos possam ver. Se as figuras forem iguais, ele retira as duas cartas da mesa, guarda esse par e joga uma nova rodada. Se as figuras forem diferentes, ele volta às cartas viradas para a posição original com as figuras para baixo e passa a vez para o próximo jogador. Depois que todos os pares foram retirados da mesa, ganha o jogador que tiver o maior número de cartas.

A simulação computacional desse jogo é particularmente interessante, porque, desafiar o computador em um jogo onde ele é capaz de memorizar todas as cartas que foram abertas é muito desigual e por isso as implementações normalmente oferecem somente um ambiente para a disputa entre dois usuários. Nesse sentido, esse jogo foi escolhido como segunda prova de conceito, pois permite a comparação de desempenho (pontuação) dos jogadores e do computador ao longo das rodadas possibilitando o monitoramento da nova arquitetura no que tange a criação de agentes com comportamento mais próximo de um usuário do que de um comportamento ótimo ou aleatório.

\section{Implementação}

As figuras 4.1 e 4.2 apresentam as duas interfaces desenvolvidas para o jogo. Na primeira, o usuário escolhe contra qual dos quatro tipos de adversário quer jogar. A segunda interface que apresenta as 32 cartas do jogo bem como um placar que indica a pontuação de cada participante. 


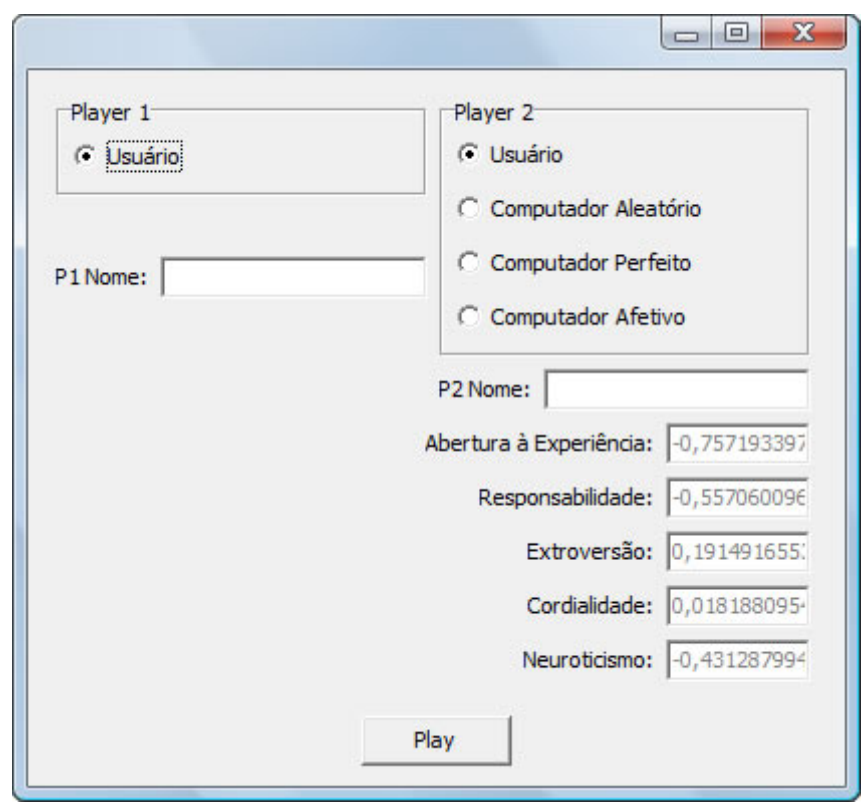

Figura 4.1: Primeira interface do Jogo da Memória.

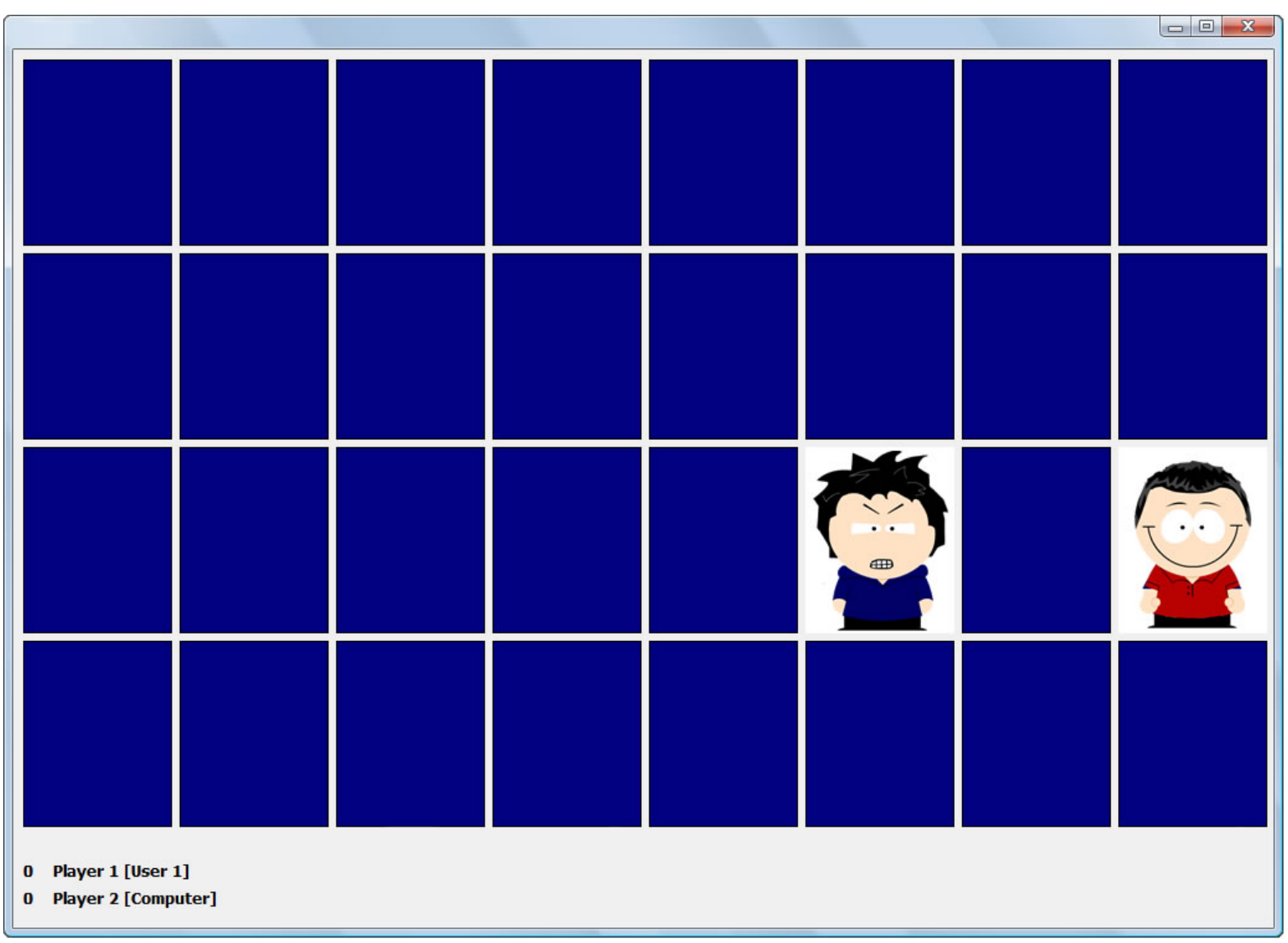

Figura 4.2: Segunda interface do Jogo da Memória. 
Para fazer o tema das cartas do jogo utilizou-se uma ferramenta de desenhos de bonecos disponível no site "SP Studio"2. Todos os 16 bonecos (figura 4.3) expressam algum tipo emoção (positiva ou negativa) em diferentes intensidades.

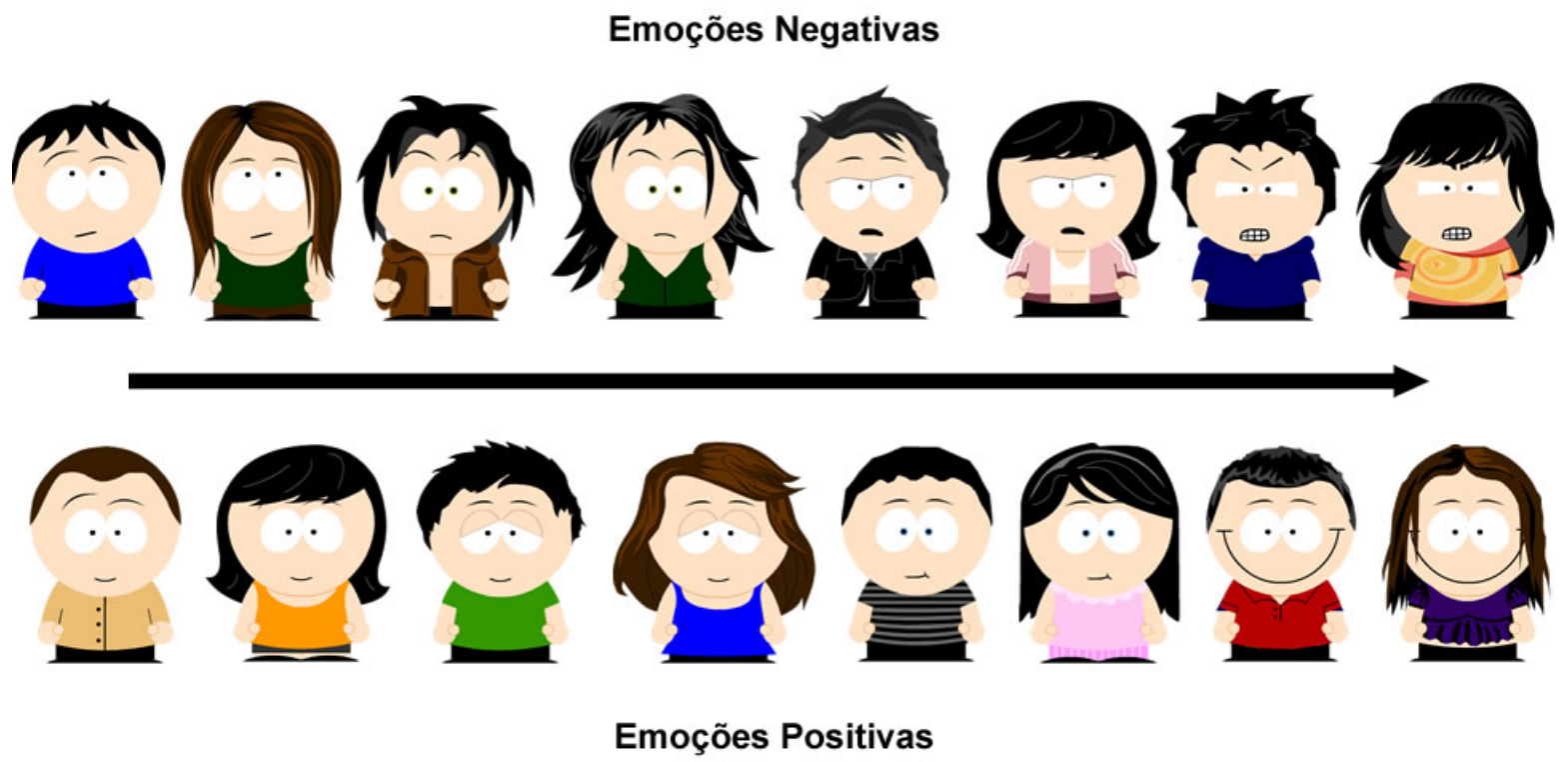

Figura 4.3: Os 16 bonecos utilizados no Jogo da Memória separados pelo tipo de emoção e ordenados por intensidade.

Se o usuário decidir jogar contra outro usuário, o jogo funciona apenas como ambiente de interação e controle das regras. Caso escolha alguma das outras estratégias, o sistema funciona também como adversário controlando um agente. A estratégia desse agente varia conforme a escolha e são descritas abaixo:

Computador Randômico: as cartas são escolhidas aleatoriamente sem considerar as jogadas anteriores.

Computador Perfeito: as cartas aberta são armazenadas na memória do computador, permitindo a realização de um jogo "perfeito".

Computador Afetivo: essa estratégia utiliza um agente desenvolvido com a arquitetura apresentada no capítulo anterior.

Os agentes da opção "Computador Afetivo" seguem o mesmo ciclo de iteração descrito para o experimento do Dilema do Prisioneiro Iterado, no entanto difere-se em seis características: atribuição dos valores de personalidade, emoções e intensidades percebidas pela percepção, parâmetros do

\footnotetext{
${ }^{2}$ SP Studio: http://www.sp-studio.de
} 
filtro de percepção, parâmetros do filtro de memória, estratégias associadas aos estados de humor, parâmetros do filtro de planos.

- Atribuição dos valores de Personalidade: Os valores de personalidade são estabelecidos aleatoriamente.

- Emoções e intensidades percebidas pela percepção: As dez emoções provocadas como resposta a um estímulo são descritas na tabela 4.6 e o algoritmo responsável pelo cálculo da ativação e intensidade é apresentado abaixo. Como no experimento anterior, o algoritmo faz referência à matriz "intensidade" (tabela 4.7) que é um mapeamento que indica com qual intensidade cada uma das emoções será percebida em função do estado de humor do jogador.

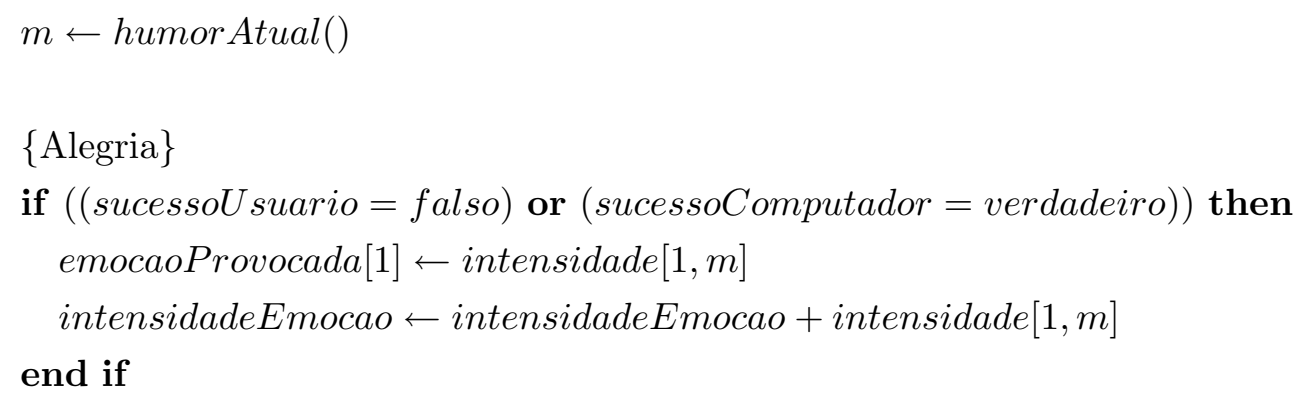




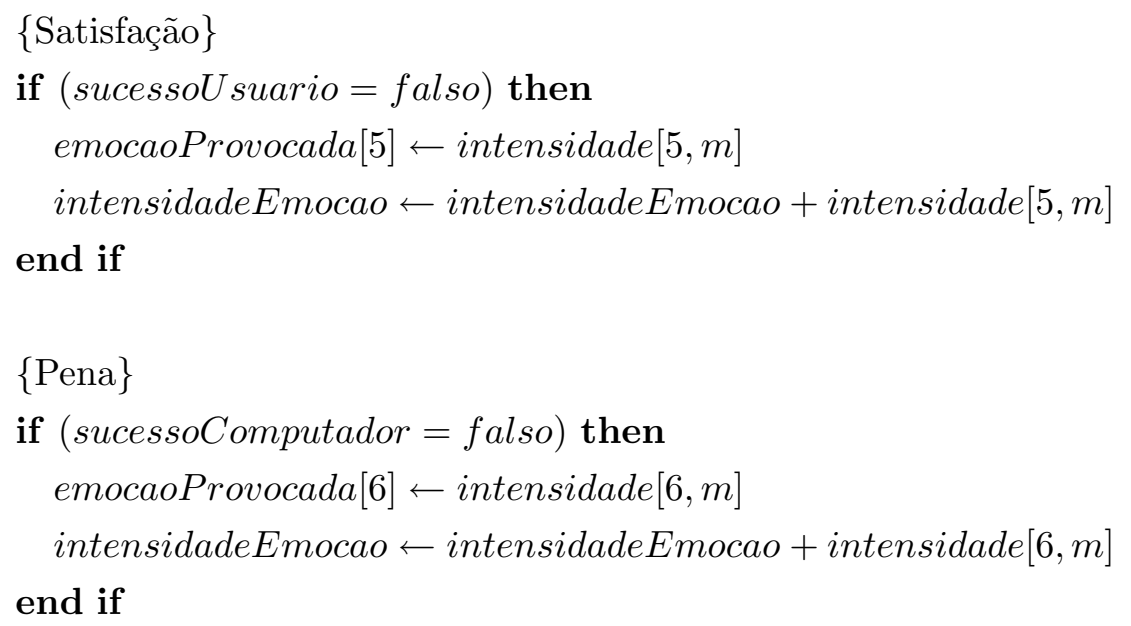

\{Esperança\}

if $(($ sucessoU suario $=$ falso $)$ or $($ sucessoComputador $=$ verdadeiro $))$ then emocaoProvocada $[7] \leftarrow$ intensidade $[7, m]$ intensidadeEmocao $\leftarrow$ intensidadeEmocao + intensidade $[7, m]$

end if

$\{$ Medo $\}$

if $(($ sucessoUsuario $=$ verdadeiro $)$ or $($ sucessoComputador $=$ falso $))$ then emocaoProvocada $[8] \leftarrow$ intensidade $[8, m]$ intensidadeEmocao $\leftarrow$ intensidadeEmocao + intensidade $[8, m]$ end if

\{Orgulho\}

if (sucessoComputador $=$ verdadeiro) then

emocaoProvocada $[13] \leftarrow$ intensidade $[13, m]$

intensidadeEmocao $\leftarrow$ intensidadeEmocao + intensidade $[13, m]$

end if

\{Vergonha\}

if (sucessoComputador $=$ falso) then

emocaoProvocada $[14] \leftarrow$ inten sidade $[14, m]$

intensidadeEmocao $\leftarrow$ intensidadeEmocao + intensidade $[14, m]$

end if 


\begin{tabular}{|c|l|l|}
\hline ID & Emoção & Evento de Ativação \\
\hline \hline 1 & Alegria & Porque algo de bom aconteceu \\
2 & Angústia & Porque algo ruim aconteceu \\
3 & Feliz por & Porque algo bom aconteceu com uma pessoa querida \\
4 & Ressentimento & Porque algo bom aconteceu com uma pessoa não querida \\
5 & Satisfação Maldosa & Porque algo de ruim aconteceu com uma pessoa não querida \\
6 & Pena & Porque algo de ruim aconteceu com uma pessoa querida \\
7 & Esperança & Sobre a possibilidade de alguma coisa boa acontecer \\
8 & Medo & Sobre a possibilidade de alguma coisa boa ruim \\
13 & Orgulho & Sobre um ato louvável iniciado pelo próprio indivíduo \\
14 & Vergonha & Sobre um ato censurável iniciado pelo próprio indivíduo \\
\hline
\end{tabular}

Tabela 4.6: As dez emoções utilizadas nesse experimento, baseadas no modelo OCC [Ortony et al., 1988].

\begin{tabular}{|c|c|c|c|c|c|c|c|c|c|}
\hline & \multicolumn{8}{|c|}{ Estados de Humor } \\
\hline & & 1 & 2 & 3 & 4 & 5 & 6 & 7 & 8 \\
\hline \multirow{10}{*}{ 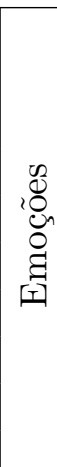 } & 1 & 1 & 2 & 1 & 2 & 1 & 1 & 2 & 1 \\
\hline & 2 & 1 & 2 & 1 & 2 & 1 & 1 & 2 & 1 \\
\hline & 3 & 2 & 2 & 1 & 2 & 1 & 0,5 & 1 & 0 \\
\hline & 4 & 0,5 & 1 & 1 & 1 & 1 & 0.5 & 1 & 0 \\
\hline & 5 & 1 & 1 & 1 & 1 & 1 & 2 & 1 & 2 \\
\hline & 6 & 1 & 2 & 1 & 2 & 1 & 1 & 2 & 1 \\
\hline & 7 & 2 & 1 & 1 & 2 & 1 & 2 & 2 & 2 \\
\hline & 8 & 2 & 1 & 1 & 2 & 1 & 2 & 2 & 2 \\
\hline & 13 & 1 & 1 & 1 & 0,5 & 2 & 2 & 2 & 2 \\
\hline & 14 & 2 & 1 & 1 & 1 & 1 & 2 & 1 & 2 \\
\hline
\end{tabular}

Tabela 4.7: Mapeamento que relaciona a intensidade das emoções percebidas com os estados de humor.

- Parâmetros do filtro de percepção: Quando o agente estiver em um estado afetivo de "Sensação de Controle" positiva, somente as cartas que apresentam os bonecos com as 5 faces positivas mais intensas e as 2 faces negativas mais intensas serão observadas e se o agente estiver em um estado afetivo de "Sensação de Controle" negativa, somente as cartas que apresentam os bonecos com as 2 faces positivas mais intensas e as 5 faces negativas mais intensas. Em ambos os casos, são consideradas somente as intensidades das cartas que ainda estão em jogo.

- Parâmetros do filtro de memória: Quando o agente estiver em um estado afetivo de "Sensação de Controle" positiva, o filtro da memória retornará a posição das cartas armazenadas que apresentam os bonecos com as 5 faces positivas mais intensas e as 2 faces negativas mais intensas e se o agente estiver em um estado afetivo de "Sensação de Controle" negativa, o filtro retornará a posição das cartas que apresentam os bonecos com as 2 faces positivas mais intensas e as 5 faces negativas mais intensas. No caso de um usuário acertar um par de cartas, a posição dessas cartas é retirada da memória do agente. 
- Estratégias associadas aos estados de humor: A seleção do plano que será executado pelo agente depende de uma estratégia definida em função do seu estado afetivo atual. Na tabela 4.8 são apresentados todos os oito estados afetivos e as estratégias associadas a escolha da primeira e segunda carta. A seguir são descritas as estratégias.

\begin{tabular}{|c|c|}
\hline Humor & Estratégia \\
\hline \hline Exuberante & Memória + Memória \\
Dependente & Aleatória + Memória \\
Relaxado & Memória + Memória \\
Dócil & Aleatória + Memória \\
Entediado & Aleatória + Aleatória \\
Arrogante & Memória + Memória \\
Ansioso & Aleatória + Memória \\
Hostil & Memória + Memória \\
\hline
\end{tabular}

Tabela 4.8: Estratégias para tomada de decisão.

- Aleatória (para a primeira ou segunda carta): o agente seleciona uma carta aleatoriamente.

- Memória (para a primeira carta): o agente procura na base de conhecimento se conhece a posição de duas cartas que formam um par. Se conhecer escolhe uma delas, senão seleciona aleatoriamente uma carta que ainda não conhece.

- Memória (para a segunda carta): o agente pesquisa na base de conhecimento se conhece a posição da carta que forma um par com a carta aberta anteriormente. Se souber, abre a carta, senão, seleciona aleatoriamente uma carta que ainda não conhece.

- Parâmetros do filtro de planos: Os marcadores somáticos não são aplicados nesse experimento.

\section{Experimento}

Para avaliar o desempenho dos agentes construídos com a nova arquitetura, foi solicitado a 8 usuários (U1, U2, U3, U4, U5, U6, U7 e U8), sendo 3 homens e 5 mulheres na faixa de 20 à 30 anos de idade, que utilizassem o Jogo da Memória. Os usuários enfrentaram 3 vezes cada uma das estratégias implementadas (Computador Randômico, Computador Perfeito e Computador Afetivo) além de alguns jogos competitivos entre os oito usuários. O resultado final dos teste realizados é apresentado na tabela 4.9 .

Em cada um dos jogos, avaliou-se o desempenho da pontuação ao longo das jogadas. Dessa maneira foi possível desenhar um gráfico mostrando a evolução do placar (por exemplo, a figura 4.4 apresenta o gráfico do jogo entre o usuário U1 e a estratégia "Computador Afetivo"). Com os dados dessa evolução é possível utilizar estatística descritiva para identificar qual das estratégias computacionais utilizadas mais se aproxima do desempenho de um usuário. Assim, calculou-se o desvio padrão das diferenças de pontuação em cada rodada e o resultado é apresentado na coluna "Des. Pad. Diferenças" da tabela 4.9. 


\begin{tabular}{|c|c|c|c|c|c|}
\hline Jogador 1 & Pontuação & Jogador 2 & Pontuação & Diferença & Des. Pad. Diferenças \\
\hline $\mathrm{U} 1$ & 8 & Computador Afetivo & 8 & 0 & 0,56 \\
\hline U1 & 9 & Computador Afetivo & 7 & 2 & 1,22 \\
\hline U1 & 10 & Computador Afetivo & 6 & 4 & 0,97 \\
\hline U1 & 0 & Computador Perfeito & 16 & 16 & 4,87 \\
\hline $\mathrm{U} 1$ & 2 & Computador Perfeito & 14 & 12 & 4,25 \\
\hline U1 & 1 & Computador Perfeito & 15 & 14 & 4,69 \\
\hline U1 & 15 & Computador Randômico & 1 & 14 & 4,07 \\
\hline U1 & 15 & Computador Randômico & 1 & 14 & 4,27 \\
\hline U1 & 14 & Computador Randômico & 2 & 12 & 4,18 \\
\hline U1 & 8 & $\mathrm{U} 6$ & 8 & 0 & 1,2 \\
\hline U1 & 7 & U6 & 9 & 2 & 1,14 \\
\hline $\mathrm{U} 2$ & 6 & Computador Afetivo & 10 & 4 & 1,11 \\
\hline $\mathrm{U} 2$ & 6 & Computador Afetivo & 10 & 4 & 1,54 \\
\hline $\mathrm{U} 2$ & 7 & Computador Afetivo & 9 & 2 & 0,98 \\
\hline $\mathrm{U} 2$ & 1 & Computador Perfeito & 15 & 14 & 4,15 \\
\hline $\mathrm{U} 2$ & 1 & Computador Perfeito & 15 & 14 & 4,46 \\
\hline $\mathrm{U} 2$ & 1 & Computador Perfeito & 15 & 14 & 4,2 \\
\hline $\mathrm{U} 2$ & 14 & Computador Randômico & 2 & 12 & 4,06 \\
\hline $\mathrm{U} 2$ & 15 & Computador Randômico & 1 & 14 & 3,73 \\
\hline $\mathrm{U} 2$ & 16 & Computador Randômico & 0 & 16 & 4,38 \\
\hline U3 & 10 & Computador Afetivo & 6 & 4 & 1,86 \\
\hline $\mathrm{U} 3$ & 6 & Computador Afetivo & 10 & 4 & 1,64 \\
\hline U3 & 7 & Computador Afetivo & 9 & 2 & 1,56 \\
\hline U3 & 1 & Computador Perfeito & 15 & 14 & 4,67 \\
\hline U3 & 2 & Computador Perfeito & 14 & 12 & 3,91 \\
\hline U3 & 2 & Computador Perfeito & 14 & 12 & 3,69 \\
\hline U3 & 12 & Computador Randômico & 4 & 8 & 2,89 \\
\hline $\mathrm{U} 3$ & 15 & Computador Randômico & 1 & 14 & 3,25 \\
\hline U3 & 13 & Computador Randômico & 3 & 10 & 3,16 \\
\hline U3 & 5 & U6 & 11 & 6 & 1,29 \\
\hline $\mathrm{U} 3$ & 8 & U6 & 8 & 0 & 1,05 \\
\hline $\mathrm{U} 4$ & 11 & Computador Afetivo & 5 & 6 & 1,49 \\
\hline $\mathrm{U} 4$ & 6 & Computador Afetivo & 10 & 4 & 1,79 \\
\hline $\mathrm{U} 4$ & 11 & Computador Afetivo & 5 & 6 & 1,32 \\
\hline $\mathrm{U} 4$ & 1 & Computador Perfeito & 15 & 14 & 4,59 \\
\hline $\mathrm{U} 4$ & 1 & Computador Perfeito & 15 & 14 & 4,64 \\
\hline $\mathrm{U} 4$ & 2 & Computador Perfeito & 14 & 12 & 4,26 \\
\hline
\end{tabular}

Tabela 4.9: Resultados dos testes realizados no Experimento 2. (continua na próxima página) 


\begin{tabular}{|c|c|c|c|c|c|}
\hline Jogador 1 & Pontuação & Jogador 2 & Pontuação & Diferença & Des. Pad. Diferenças \\
\hline $\mathrm{U} 4$ & 14 & Computador Randômico & 2 & 12 & 3,28 \\
\hline $\mathrm{U} 4$ & 13 & Computador Randômico & 3 & 10 & 2,28 \\
\hline $\mathrm{U} 4$ & 14 & Computador Randômico & 2 & 12 & 3,92 \\
\hline U5 & 8 & Computador Afetivo & 8 & 0 & 1,21 \\
\hline U5 & 8 & Computador Afetivo & 8 & 0 & 1,81 \\
\hline U5 & 8 & Computador Afetivo & 8 & 0 & 0,55 \\
\hline U5 & 2 & Computador Perfeito & 14 & 12 & 3,9 \\
\hline U5 & 2 & Computador Perfeito & 14 & 12 & 3,72 \\
\hline U5 & 1 & Computador Perfeito & 15 & 14 & 4,71 \\
\hline U5 & 14 & Computador Randômico & 2 & 12 & 3,48 \\
\hline U5 & 16 & Computador Randômico & 0 & 16 & 4,56 \\
\hline U5 & 15 & Computador Randômico & 1 & 14 & 4,13 \\
\hline U6 & 7 & Computador Afetivo & 9 & 2 & 1,09 \\
\hline $\mathrm{U} 6$ & 9 & Computador Afetivo & 7 & 2 & 0,87 \\
\hline U6 & 8 & Computador Afetivo & 8 & 0 & 0,75 \\
\hline U6 & 1 & Computador Perfeito & 15 & 14 & 4,89 \\
\hline U6 & 1 & Computador Perfeito & 15 & 14 & 5,21 \\
\hline U6 & 2 & Computador Perfeito & 14 & 12 & 3,53 \\
\hline U6 & 15 & Computador Randômico & 1 & 14 & 2,83 \\
\hline U6 & 16 & Computador Randômico & 0 & 16 & 4,16 \\
\hline U6 & 14 & Computador Randômico & 2 & 12 & 3,13 \\
\hline U6 & 11 & U3 & 5 & 6 & 1,8 \\
\hline U6 & 6 & U3 & 10 & 4 & 2,23 \\
\hline U6 & 8 & U3 & 8 & 0 & 1,18 \\
\hline $\mathrm{U} 7$ & 9 & Computador Afetivo & 7 & 2 & 0,98 \\
\hline $\mathrm{U} 7$ & 9 & Computador Afetivo & 7 & 2 & 1,47 \\
\hline U7 & 8 & Computador Afetivo & 8 & 0 & 1,4 \\
\hline U7 & 2 & Computador Perfeito & 14 & 12 & 3,64 \\
\hline U7 & 1 & Computador Perfeito & 15 & 14 & 5,12 \\
\hline $\mathrm{U} 7$ & 2 & Computador Perfeito & 14 & 12 & 3,57 \\
\hline U7 & 13 & Computador Randômico & 3 & 10 & 2,84 \\
\hline U7 & 16 & Computador Randômico & 0 & 16 & 3,97 \\
\hline U7 & 13 & Computador Randômico & 3 & 10 & 2,5 \\
\hline U7 & 9 & U6 & 7 & 2 & 0,87 \\
\hline $\mathrm{U} 7$ & 7 & U6 & 9 & 2 & 1,37 \\
\hline U7 & 8 & U6 & 8 & 0 & 1,17 \\
\hline U8 & 7 & Computador Afetivo & 9 & 2 & 2,19 \\
\hline
\end{tabular}

Tabela 4.9: Resultados dos testes realizados no Experimento 2. (continua na próxima página) 


\begin{tabular}{|c|c|c|c|c|c|}
\hline Jogador 1 & Pontuação & Jogador 2 & Pontuação & Diferença & Des. Pad. Diferenças \\
\hline U8 & 4 & Computador Afetivo & 12 & 8 & 2,15 \\
U8 & 5 & Computador Afetivo & 11 & 6 & 1,53 \\
\hline U8 & 3 & Computador Perfeito & 13 & 10 & 4,5 \\
U8 & 1 & Computador Perfeito & 15 & 14 & 4,63 \\
U8 & 0 & Computador Perfeito & 16 & 16 & 5,43 \\
\hline U8 & 13 & Computador Randômico & 3 & 10 & 3,04 \\
U8 & 15 & Computador Randômico & 1 & 14 & 3,57 \\
U8 & 16 & Computador Randômico & 0 & 16 & 4,12 \\
\hline U8 & 5 & U3 & 11 & 6 & 1,42 \\
U8 & 7 & U6 & 9 & 2 & 0,88 \\
U8 & 6 & U6 & 10 & 4 & 1,21 \\
\hline
\end{tabular}

Tabela 4.9: Resultados dos testes realizados no Experimento 2.

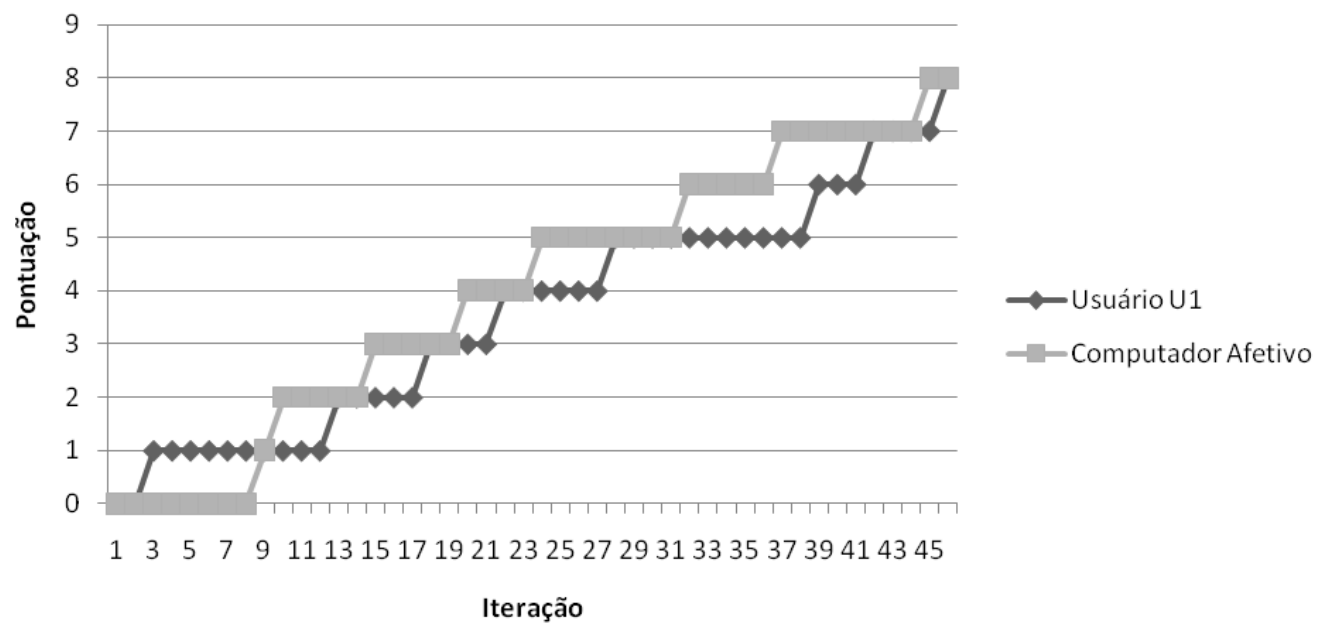

Figura 4.4: Resultado do jogo Usuário U1 x Computador Afetivo.

\subsection{Discussão dos Resultados}

Depois de executar os experimentos, analisou-se os resultados para confirmar ou reprovar as hipóteses formuladas anteriormente. Nessa seção, cada uma das hipóteses é analisada e discutida separadamente.

Hipótese 1 A utilização do Módulo Afetivo na arquitetura provoca uma alteração coerente no comportamento do agente. 
Observação Esperada: Na primeira hipótese espera-se que a cada nova interação, o agente altere seu estado afetivo e consequentemente o seu comportamento de maneira coerente em função da pena que recebe na interação anterior. Então, quando dois agentes de quaisquer estado afetivo inicial se enfrentarem, devem terminar o jogo com estados afetivos de mesmo sinal (positivo ou negativo). Esse resultado é esperado, pois após um grande número de interações devem convergir para um mesmo comportamento ("testemunhar" ou "não testemunhar").

Resultados Observados: As duas tabelas abaixo (4.10 e 4.11) apresentam respectivamente o estado afetivo final de todos os testes dos experimentos 1.A e 1.B. Nas duas tabelas, a coluna "Estado Final" indica o estado afetivo final dos dois agentes (por exemplo "1-3" significa que o primeiro agente terminou o teste no estado exuberante e o segundo agente no estado relaxado), e a coluna "Testes" os 36 testes realizados (por exemplo " $4-8$ " indica o teste entre os agentes com estados iniciais dócil e hostil)

Conclusão: A hipótese 1 foi comprovada pois, pois dos 36 testes realizados no experimento 1.A, somente em dois (3x6 e 4x6) os agentes não terminam a partida com estados afetivos de mesmo sinal. Isso significa que o estado afetivo é alterado de maneira coerente ao longo do tempo. Essas exceções aconteceram, pois um dos agentes ficou muito tempo no estado afetivo Entediado (5) e o outro no estado Ansioso (7) e então havia a interação entre uma estratégia aleatória contra uma "Pavlov". Depois de algum tempo, a estratégia aleatória repetiu muitas vezes a opção "não testemunhar" o que fez com que o outro repetisse a opção. Assim, no final o agente passou de entediado para dócil e o que estava ansioso continuou ansioso e repetindo as escolhas do outro agente. No experimento 1.B, essa hipótese também pode ser verificada em todos os testes, exceto $(2 \times 5,2 \times 6,4 \times 5)$. Nessas exceções, os agentes em algum momento apresentam o estado afetivo Entendiado (5) utilizando a estratégia aleatória, o que dificulta a identificação de um padrão no comportamento.

\begin{tabular}{|c|c|}
\hline Estado Final & Testes (Prisioneiro $1 \times$ Prisioneiro 2) \\
\hline \hline $1-1$ & $1 \times 1,1 \times 2$ \\
$1-3$ & $1 \times 3,1 \times 4,2 \times 3,2 \times 4$ \\
$3-3$ & $3 \times 3,3 \times 4,4 \times 4$ \\
$4-7$ & $3 \times 6,4 \times 6$ \\
$5-5$ & $5 \times 5$ \\
$5-7$ & $4 \times 5,5 \times 6,5 \times 7,6 \times 6,6 \times 7,6 \times 8$ \\
$7-7$ & $1 \times 5,1 \times 6,1 \times 7,1 \times 8,2 \times 2,2 \times 5,2 \times 6,2 \times 7,2 \times 8,3 \times 5,3 \times 7,3 \times 8,4 \times 7,4 \times 8,5 \times 8,7 \times 7,7 \times 8,8 \times 8$ \\
\hline
\end{tabular}

Tabela 4.10: Estado de humor dos agentes ao final de cada um dos teste do Experimento 1.A.

Hipótese 2 A influência do Módulo Afetivo nas atividades cognitivas de percepção, memória e tomada de decisão faz com que os agentes apresentem uma maior variedade de comportamentos e uma maior mudança de estado afetivo.

Observação Esperada: A utilização do módulo afetivo na arquitetura e a sua influência nas atividades cognitivas, permite ao agente manipular um número maior de informações sobre o jogo 


\begin{tabular}{|c|c|}
\hline Estado Final & Testes (Prisioneiro $1 \times$ Prisioneiro 2) \\
\hline \hline $1-1$ & $1 \times 7,8 \times 8$ \\
$1-3$ & $3 \times 8$ \\
$2-5$ & $2 \times 5,2 \times 6,4 \times 5$ \\
$3-3$ & $1 \times 1,1 \times 2,1 \times 3,1 \times 4,2 \times 2,2 \times 3,2 \times 4,3 \times 3,3 \times 4,3 \times 7,4 \times 4,4 \times 7,7 \times 7$ \\
$5-5$ & $5 \times 5$ \\
$5-7$ & $1 \times 5,1 \times 6,3 \times 5,3 \times 6,4 \times 6,5 \times 6,5 \times 7,5 \times 8,6 \times 6,6 \times 7,6 \times 8$ \\
$7-7$ & $1 \times 8,2 \times 7,2 \times 8,4 \times 8,7 \times 8$ \\
\hline
\end{tabular}

Tabela 4.11: Estado de humor dos agentes ao final de cada um dos teste do Experimento 1.B.

e o adversário. Dessa maneira, espera-se nessa segunda hipótese que o estado afetivo do agente seja alterado com maior frequência provocando consequentemente uma maior variedade de comportamentos.

Resultados Observados: As duas tabelas abaixo (4.12 e 4.13) apresentam o número de agentes que terminaram o jogo em cada um dos estados afetivos nos experimentos 1.A e 1.B respectivamente.

Conclusão: As duas tabelas apresentadas indicam que o número de estados finais deixou de ser concentrado no estado de humor Ansioso (7) a passou a ser melhor distribuída e três agentes terminaram com o estado Dependente (2) o que não havia acontecido anteriormente. Nesse sentido, a hipótese 2 pode ser comprovada.

\begin{tabular}{|c|c|c|}
\hline Estado de Humor & Número de agentes & Porcentagem de agentes \\
\hline \hline [1] Exuberante & 8 & $11,1 \%$ \\
[2] Dependente & 0 & $0,0 \%$ \\
[3] Relaxado & 10 & $13,9 \%$ \\
[4] Dócil & 2 & $2,8 \%$ \\
[5] Entediado & 8 & $11,1 \%$ \\
[6] Arrogante & 0 & $0,0 \%$ \\
[7] Ansioso & 44 & $61,1 \%$ \\
[8] Hostil & 0 & $0,0 \%$ \\
Total & 72 & $100,0 \%$ \\
\hline
\end{tabular}

Tabela 4.12: Estado de humor do agente no final dos testes do Experimento 1.A. 


\begin{tabular}{|c|c|c|}
\hline Estado de Humor & Número de agentes & Porcentagem de agentes \\
\hline \hline [1] Exuberante & 5 & $6,9 \%$ \\
[2] Dependente & 3 & $4,2 \%$ \\
[3] Relaxado & 27 & $37,5 \%$ \\
[4] Dócil & 0 & $0,0 \%$ \\
[5] Entediado & 16 & $22,2 \%$ \\
[6] Arrogante & 0 & $0,0 \%$ \\
[7] Ansioso & 21 & $29,2 \%$ \\
[8] Hostil & 0 & $0,0 \%$ \\
Total & 72 & $100,0 \%$ \\
\hline
\end{tabular}

Tabela 4.13: Estado de humor do agente no final dos testes do Experimento 1.B.

Hipótese 3 A influência do Módulo Afetivo nas atividades cognitivas de percepção, memória e tomada de decisão provoca um comportamento mais adaptativo.

Observação Esperada: A influência do módulo afetivo como um fator que potencializa principalmente a percepção e a memória deve provocar um comportamento mais adaptativo nos agentes, ou seja, a análise do histórico de jogadas deve fazer com que ele seja capaz de responder mais rapidamente ao adversário.

Resultados Observados: Uma análise comparativa entre os gráficos produzidos nos experimentos 1.A e 1.B revelam que a interação entre os agentes $1 \times 8,2 \times 7,2 \times 8$ e $4 \times 8$ apresentam comportamentos semelhantes, mas que, no entanto, a troca de estado afetivo acontece em diferentes iterações.

Conclusão: No gráfico do jogo entre os agentes 1x8 (experimento 1.A), tem-se inicialmente o agente Exuberante (1) "não testemunhar" e o agente Hostil (8) "testemunhar". A mudança do estado afetivo Exuberante (1) para o Dependente (2) acontece na interação número 18 e a troca do estado Dependente (2) para o estado Ansioso (7) na interação 35. Já no gráfico do experimento 1.B, o prisioneiro 1 permanece no estado Exuberante (1) por 16 interações, na interação 17 ele torna-se Dependente (2) até finalmente na interação 18 tornar-se Ansioso (7) respondendo as sucessivas acusações do prisioneiro 2. Uma observação análoga pode ser feita aos outros gráficos. Nesse sentido, o agente apresenta um comportamento mais adaptativo comprovando a hipótese 3 .

Hipótese 4 A influência do Módulo Afetivo nas atividades cognitivas de percepção, memória e tomada de decisão produz um comportamento mais cooperativo.

Observação Esperada: A influência do módulo afetivo principalmente na tomada de decisão por meio da utilização dos marcadores somáticos deve provocar um comportamento mais cooperativo nos agentes, ou seja, como seu objetivo é sempre minimizar sua pena, ele deve produzir um comportamento mais cooperativo.

Resultados Observados: A interação entre os agentes com estados afetivos opostos (1x7, 1x8, $3 \times 7,3 \times 8$ e $4 \times 7)$ e agentes com estados afetivo iguais $(7 \times 7$ e $8 \times 8)$ que no experimento 1.A convergiam para um comportamentos onde os dois "testemunhavam", no experimento 1.B passaram a convergir 
para um comportamento cooperativo onde ambos "não testemunhavam". A tabela 4.14 a seguir mostra a quantidade de anos que cada agente recebeu como pena em cada um dos testes e a diferença da pena do mesmo agente nos dois experimentos.

Conclusão: Uma análise sobre os gráficos dos testes $(1 \times 7,1 \times 8,3 \times 7,3 \times 8,4 \times 7,7 \times 7$ e 8x8) e na tabela 4.14 indicam que a influência do estado afetivo e principalmente dos marcadores somáticos tornaram o comportamento do agente mais cooperativo validando a hipótese 4. Outro fator que valida essa hipótese é que o total da soma das penas dos agentes no experimento 1.A é maior do que o total no experimento 1.B.

Hipótese 5 A construção de agentes utilizando a arquitetura desenvolvida produz um comportamento mais próximo de um usuário do que de um comportamento ótimo ou aleatório.

Observação Esperada: A utilização da memória do agente no jogo deve melhorar sua performance em relação a estratégia Computador Randômico, e a limitação da memória produzirá um resultado abaixo do Computador Perfeito. Logo, a performance do Computador Afetivo deve ser mais próxima do desempenho do usuário (em relação as outras duas estratégias), mas não tão próxima quanto a de um usuário com outro.

Resultados Observados: O desvio padrão da diferença entre os resultados dos jogadores foram colocados em uma escala para que possam ser comparados. A figura 4.5 apresenta esse resultado. Uma análise dessa figura indica que o computador afetivo teve um comportamento mais próximo ao de um usuário do que o Computador Randômico e o Computador Perfeito.

Conclusão: A utilização da arquitetura e do filtro da memória como um limitante congruente com o estado afetivo produziu um resultado bem próximo ao de um usuário.
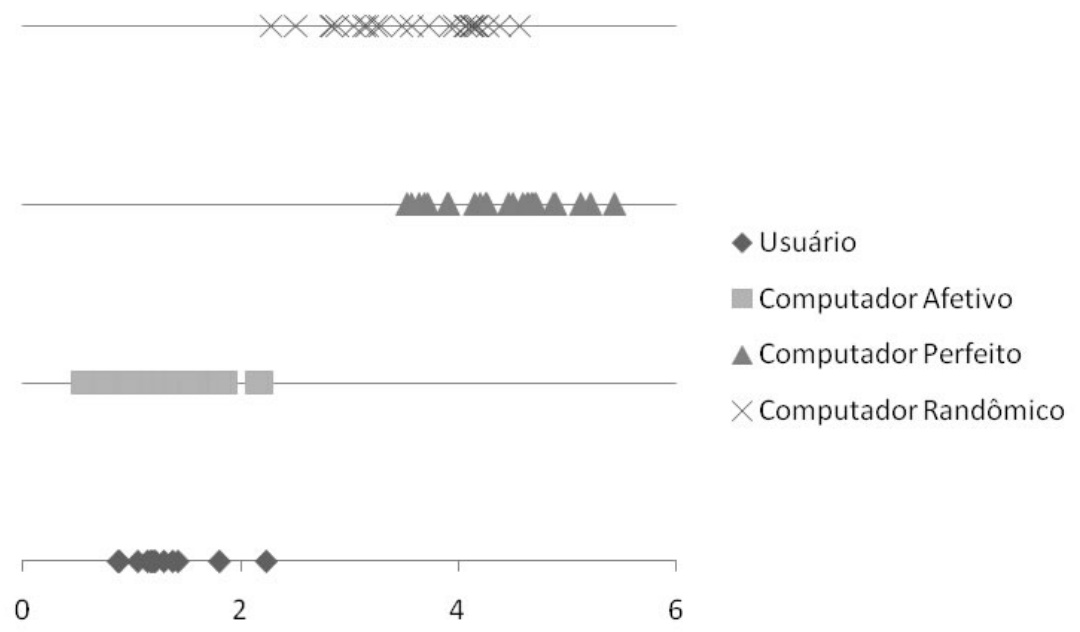

Figura 4.5: Resultado do Desvio Padrão das Diferenças apresentado na tabela 4.9. 


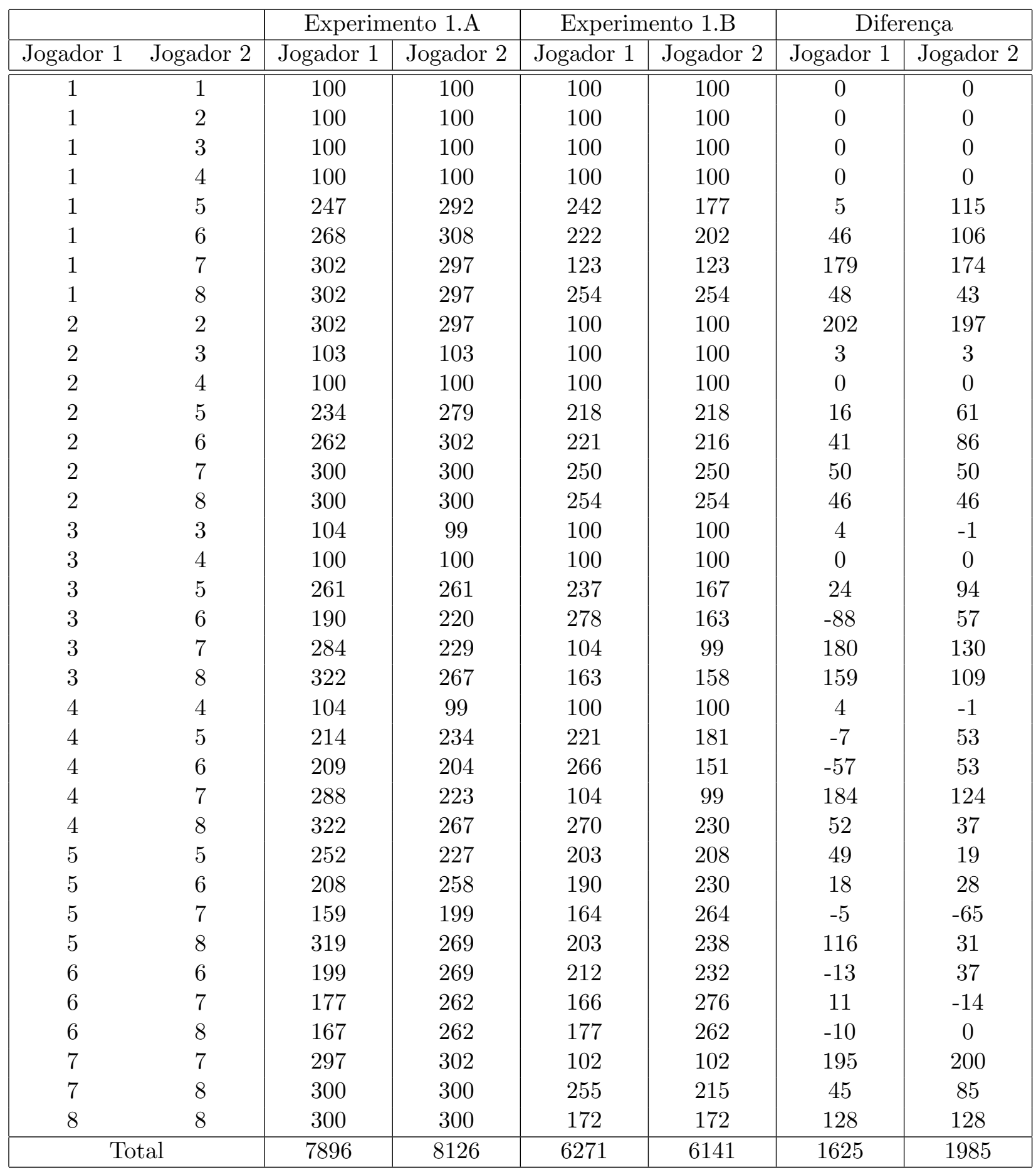

Tabela 4.14: Somatório do número de anos de prisão dos agentes ao final de cada um dos teste do Experimento 1. 
Esse capítulo inicialmente estabeleceu cinco hipóteses que além de definir os critérios de avaliação, direcionaram o desenvolvimento das provas de conceito. Depois os dois experimentos desenvolvidos (Simulação do Dilema do Prisioneiro Iterado e o Jogo da Memória) como prova de conceito foram descritos, bem como a metodologia utilizada e os resultados. A construção desses experimentos permitiu avaliar empiricamente a influência da personalidade, humor e emoção nas atividades cognitivas dos agentes e consequentemente no seu comportamento. Ao final, as cinco hipóteses são retomadas e cada uma delas é dividida em observação esperada, resultados observados e uma conclusão que indica se a hipótese foi comprovada ou rejeitada. 


\section{Capítulo 5}

\section{Considerações Finais}

Com o avanço da tecnologia e os progressos nas áreas de Computação Gráfica e Computação Musical, os usuários de sistemas de Entretenimento Digital são convidados a acreditar que estão vendo um cenário fidedigno ao mundo real. Neste contexto, umas das principais motivações da Inteligência Artificial é criar personagens mais adaptáveis à novas situações, menos previsíveis, com aprendizado rápido, memória de situações passadas e uma grande diversidade de comportamentos consistente e convincente ao longo do tempo. Para alcançar esse efeito, a Inteligência Artificial recorre a outras áreas (como por exemplo, Psicologia, Neurociência e Computação Afetiva) no sentido de incorporar novos elementos a teoria dos agentes inteligentes objetivando a construção de Agente com Comportamento Convincente (Believable Agent).

Para o aperfeiçoamento desse agente, estudos recentes têm procurado explorar conhecimentos sobre os usuários, principalmente, no que tange a aspectos da Psicologia que possam ajudar a descrever a natureza e a compreender a intensidade dos afetos humanos. Tal exploração, com objetivo de transferência aos personagens sintéticos, amplia a capacidade de expressão de comportamento convincente, gerando aos usuários de sistemas de Entretenimento Digital uma interação mais natural e de maior qualidade o que possibilita a construção de uma maior diversidade de aplicações que justificam a necessidade de continuidade e aperfeiçoamento de pesquisas nessa área.

Nesta perspectiva, tornou-se relevante, para a construção de Agentes com Comportamento Convincente, a investigação dos fenômenos afetivos como respostas reativas do corpo, e como elementos que influenciam diretamente os processos cognitivos. No entanto, nos últimos anos, a exploração desses fenômenos como respostas reativas, por meio de expressões faciais, gestos e entonação de voz prevaleceu na maioria das pesquisas.

Assim, a influência dos estados afetivos nos processos cognitivos de percepção, memória e tomada de decisão é o problema central abordado nessa dissertação.

Inicialmente, foi proposto um estudo multidisciplinar integrando conhecimentos das áreas de Inteligência Artificial, Agentes Inteligentes, Computação Afetiva, Psicologia, Neurociência e Ciência Cognitiva. Tal estudo foi realizado com três objetivos, que apesar de distintos, se integravam: (1) identificar os modelos de personalidade, humor e emoção existentes nas áreas de Psicologia e Neurociência e (2) selecionar aqueles mais adequados ao desenvolvimento de personagens sintéticos capazes de expressar um comportamento convincente e 3) explorar modelos que associam os estados 
afetivos aos processos cognitivos.

Com essa investigação inicial foi possível delinear e implementar uma arquitetura de agente inteligente. Para o desenvolvimento de tal arquitetura utilizou-se o modelo BDI (Beliefs, Desires e Intentions) como base e aos módulos existentes foi incluído um Módulo Afetivo. Esse módulo afetivo é constituído de três submódulos (Personalidade, Humor e Emoção) e influencia nas atividades cognitivas de percepção, memória e tomada de decisão do agente.

Para avaliar a viabilidade da arquitetura proposta, duas provas de conceito foram construídas baseadas em cinco hipóteses. Essas provas de conceito permitiram avaliar empiricamente o impacto dos estados afetivos nas atividades cognitivas dos agentes e consequentemente, no seu comportamento.

Como resultado da validação das hipóteses pode-se concluir que quando comparada a uma arquitetura que implementa um Módulo Afetivo, mas as atividades cognitivas não consideram o estado afetivo, a arquitetura proposta provoca:

- uma alteração coerente no comportamento do agente;

- uma maior variedade de comportamentos e uma maior mudança de estado afetivo;

- um comportamento mais adaptativo;

- um comportamento mais cooperativo;

- um comportamento mais próximo de um usuário do que de um comportamento ótimo ou aleatório.

Essas evidências geradas pelas provas de conceito indicam que os agentes construídos com a arquitetura proposta avançaram em direção ao desenvolvimento dos Agentes com Comportamento Convincente.

\subsection{Trabalhos Futuros}

Apesar do foco da dissertação ser o impacto do módulo afetivo nas atividades cognitivas, pequenas alterações ampliariam suas possibilidades de aplicação. Por exemplo, a inclusão de uma função que convertesse as 22 emoções do modelo OCC para as 6 emoções básicas de Ekman, tornaria possível a expressão facial de emoções. Assim, o Módulo Afetivo poderia potencializar atividades fisiológicas como gestos, movimentos e entonação de voz.

Quanto às provas de conceito, algumas modificações teriam, como hipótese, outros resultados. No experimento do Dilema do Prisioneiro Iterado, uma possível alteração seria considerar o conhecimento prévio que um indivíduo tem a respeito do outro, ou ainda, que uma parede de vidro separa os dois suspeitos e que ambos podem perceber em que estado afetivo o outro está. Qual seria o efeito dessas informações sobre o resultado da tomada de decisão? Já no experimento do Jogo da Memória, uma interação entre o agente e o usuário, como manifestação de reações depois de cada rodada, poderia distrair ou influenciar a concentração dos participantes. 
A arquitetura foi desenvolvida de maneira conceitual, sem o direcionamento para uma aplicação específica. Dessa maneira, algumas configurações e adaptações permitiriam a construção de outras aplicações e experimentos, como por exemplo:

Reconhecimento de Gestos: Um trabalho também desenvolvido no LIDET (Laboratory of Interactivity and Digital Entertainment Technology) do IME-USP propõe o reconhecimento de gestos por meio de sensores. Uma possível aplicação seria desenvolver agentes com diferentes personalidades e fazer com que esses agentes interpretassem, de maneira diferente, cada gesto do usuário;

Dilema do Prisioneiro com faces (agentes que provocam emoção): Com o objetivo de estudar como os sistemas de Entretenimento Digital podem produzir uma atitude de relação com o usuário, o referido experimento poderia ser modificado para que um usuário jogasse contra um agente. Essa modificação também permitiria a expressão da emoção do agente por meio da uma face. O experimento investigaria qual o impacto que a expressão facial do agente tem sobre a decisão do usuário;

Processamento de linguagem natural: Com os avanços nas pesquisas na área de Linguística Computacional, os sistemas que empregam técnicas de processamento de linguagem natural são cada vez mais utilizados. A arquitetura proposta possibilitaria, ao agente sintético, a capacidade de expressar e reconhecer o estado afetivo, por meio da entonação de voz e seleção de frases e palavras;

Sistemas de Recomendação: Um sistema de recomendação tem por objetivo sugerir produtos e serviços de qualquer natureza para usuários dependendo de suas avaliações anteriores e de outros usuários. Se durante a avaliação de produtos ou serviços o sistema armazenasse o estado afetivo, seria possível recomendar itens, levando-se em consideração o estado afetivo atual do usuário;

Tutores inteligentes: São agentes utilizados em sistemas educativos que visam apoiar a relação ensino/aprendizagem potencializando o uso do computador como ferramenta educativa. A arquitetura proposta seria utilizada para a construção de personagens - com expressão facial, gestos e entonação de voz - capazes de auxiliar alunos na exploração de conteúdos escolares. 


\section{Apêndice A}

\section{Anexo A}

Durante a execução dos testes do Experimento 1.A, um arquivo de log armazenou o estado afetivo atual e o tempo de prisão de cada um dos agentes por rodada. Assim, ao final dos testes foi possível construir uma tabela (A.1) com o número total de anos de prisão que cada um dos agentes recebeu, e gráficos que mostraram a evolução do estado afetivo dos agentes ao longo das interações (figuras de A.1 a A.5). Por exemplo, o último gráfico apresentado na figura A.1 descreve a evolução do estado afetivo de dois agentes que participaram de um teste. O primeiro agente, que inicialmente apresenta estado afetivo Exuberante (1), após 18 rodadas seu estado afetivo torna-se Dependente (2) mudando posteriormente para Ansioso (7) na interação 35. Já o segundo agente inicia no estado Hostil (8) e permanece nesse estado por 16 interações. Na interação 17 ele torna-se Ansioso(7) permanecendo assim até o final do teste. 


\begin{tabular}{|c|c|c|c|}
\hline Jogador 1 & Jogador 2 & Punição do Jogador 1 & Punição do Jogador 2 \\
\hline 1 & 1 & 100 & 100 \\
\hline 1 & 2 & 100 & 100 \\
\hline 1 & 3 & 100 & 100 \\
\hline 1 & 4 & 100 & 100 \\
\hline 1 & 5 & 247 & 292 \\
\hline 1 & 6 & 268 & 308 \\
\hline 1 & 7 & 302 & 297 \\
\hline 1 & 8 & 302 & 297 \\
\hline 2 & 2 & 302 & 297 \\
\hline 2 & 3 & 103 & 103 \\
\hline 2 & 4 & 100 & 100 \\
\hline 2 & 5 & 234 & 279 \\
\hline 2 & 6 & 262 & 302 \\
\hline 2 & 7 & 300 & 300 \\
\hline 2 & 8 & 300 & 300 \\
\hline 3 & 3 & 104 & 99 \\
\hline 3 & 4 & 100 & 100 \\
\hline 3 & 5 & 261 & 261 \\
\hline 3 & 6 & 190 & 220 \\
\hline 3 & 7 & 284 & 229 \\
\hline 3 & 8 & 322 & 267 \\
\hline 4 & 4 & 104 & 99 \\
\hline 4 & 5 & 214 & 234 \\
\hline 4 & 6 & 209 & 204 \\
\hline 4 & 7 & 288 & 223 \\
\hline 4 & 8 & 322 & 267 \\
\hline 5 & 5 & 252 & 227 \\
\hline 5 & 6 & 208 & 258 \\
\hline 5 & 7 & 159 & 199 \\
\hline 5 & 8 & 319 & 269 \\
\hline 6 & 6 & 199 & 269 \\
\hline 6 & 7 & 177 & 262 \\
\hline 6 & 8 & 167 & 262 \\
\hline 7 & 7 & 297 & 302 \\
\hline 7 & 8 & 300 & 300 \\
\hline 8 & 8 & 300 & 300 \\
\hline
\end{tabular}

Tabela A.1: Número de anos de prisão que os agentes receberam em cada um dos testes do Experimento 1.A. 
(1) Exuberante x (1) Exuberante

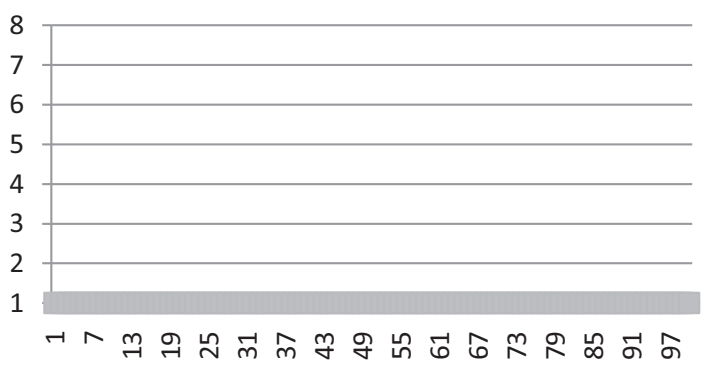

(1) Exuberante x (3) Relaxado

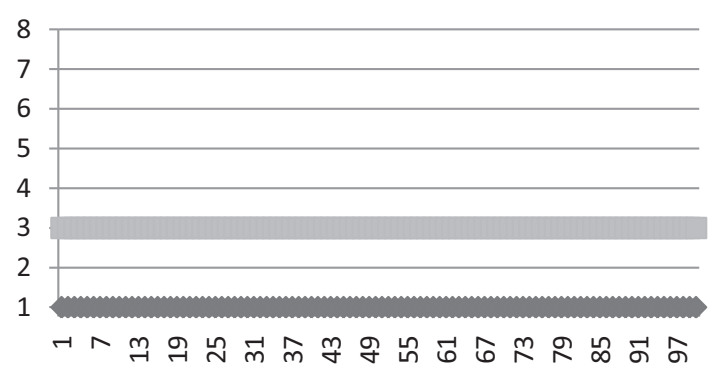

(1) Exuberante x (5) Entediado

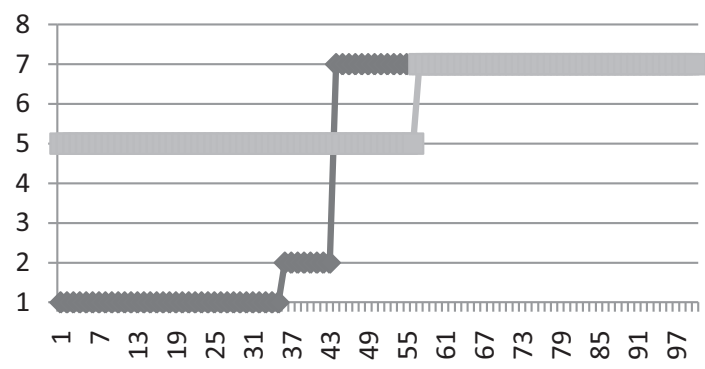

(1) Exuberante x (7) Arrogante
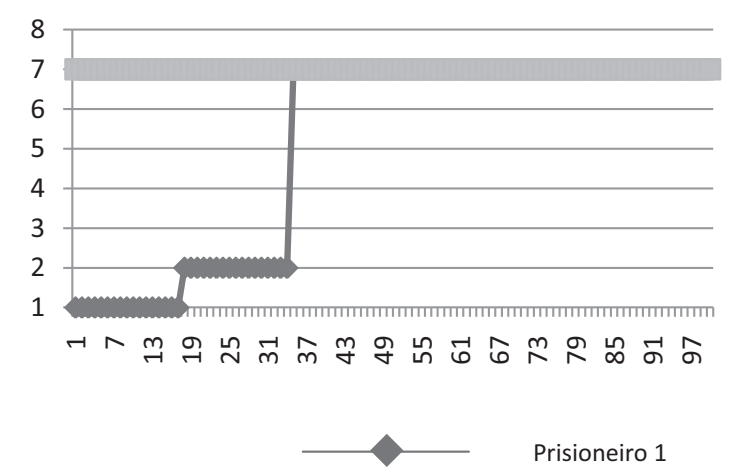

\section{(1) Exuberante x (2) Dependente}

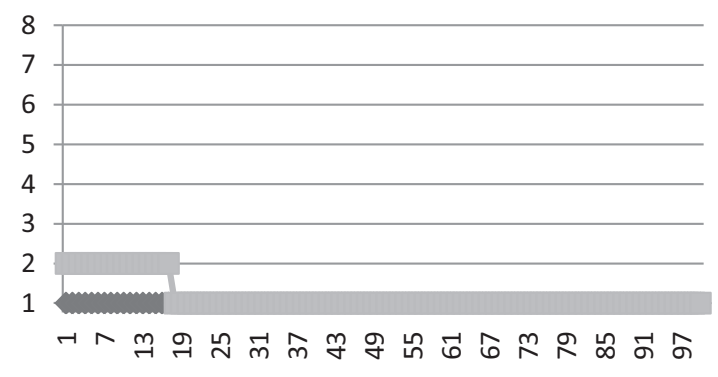

(1) Exuberante x (4) Dócil

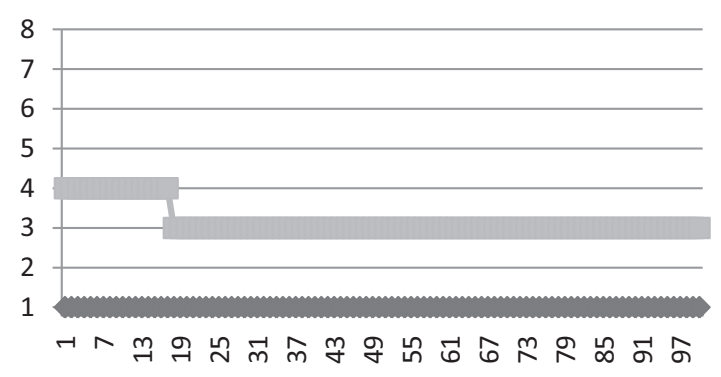

(1) Exuberante x (6) Arrogante

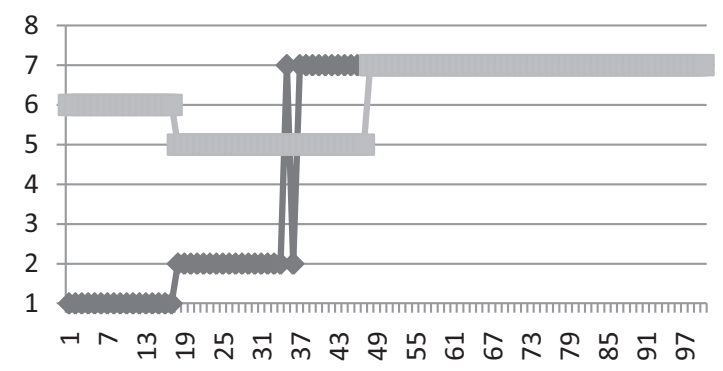

(1) Exuberante x (8) Hostil

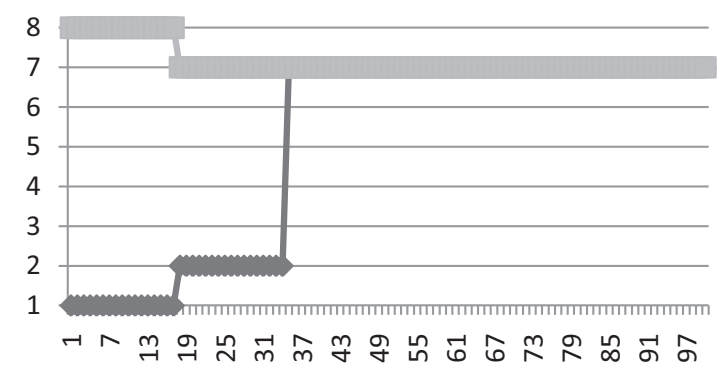

Prisioneiro 2

Figura A.1: Gráficos que apresentam a evolução do estado afetivo ao longo das iterações. 
(2) Dependente x (2) Dependente

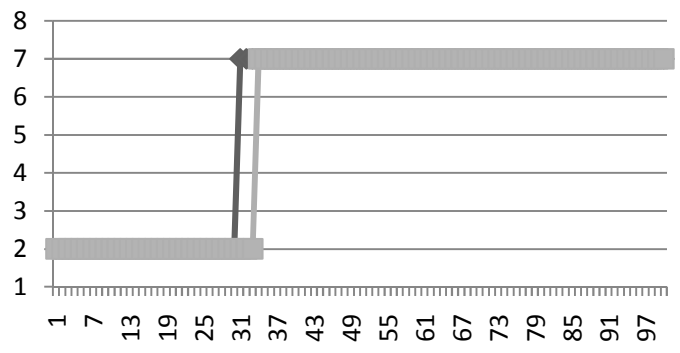

(2) Dependente x (4) Dócil

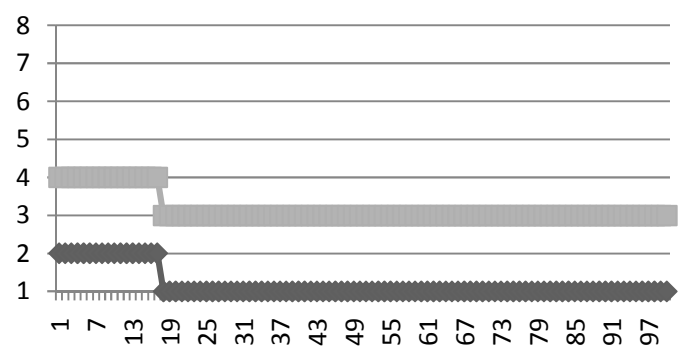

(2) Dependente x (6) Arrogante

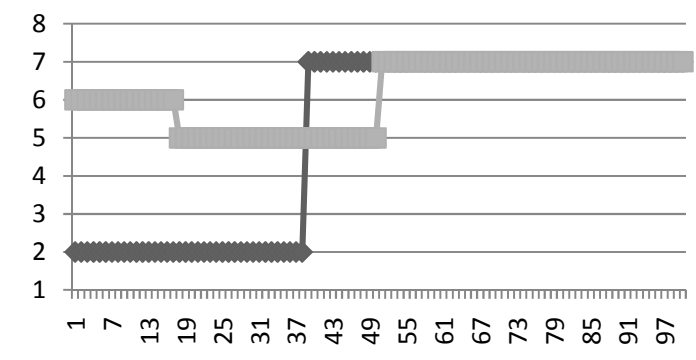

(2) Dependente x (8) Hostil

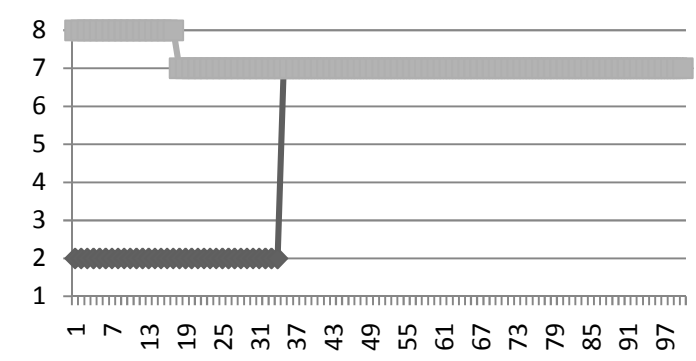

(2) Dependente x (3) Relaxado

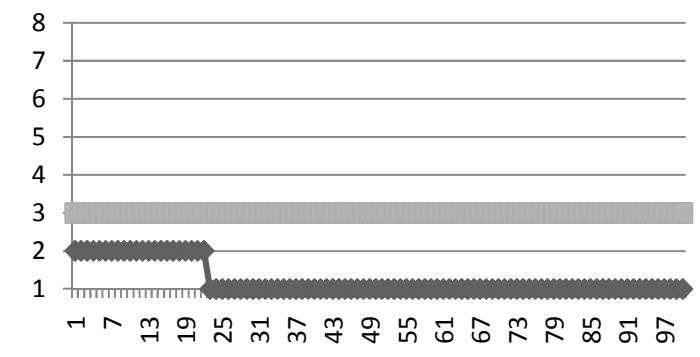

(2) Dependente x (5) Entediado

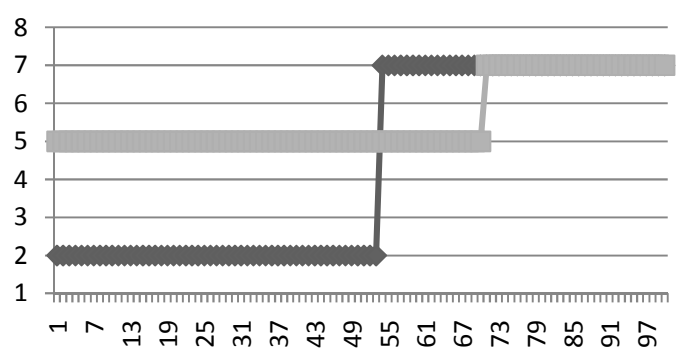

(2) Dependente x (7) Arrogante

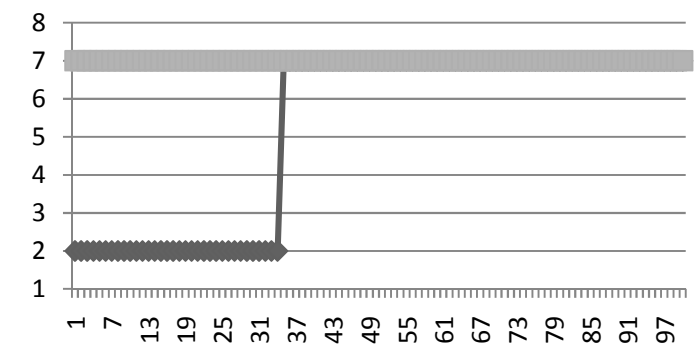

(3) Relaxado x (3) Relaxado

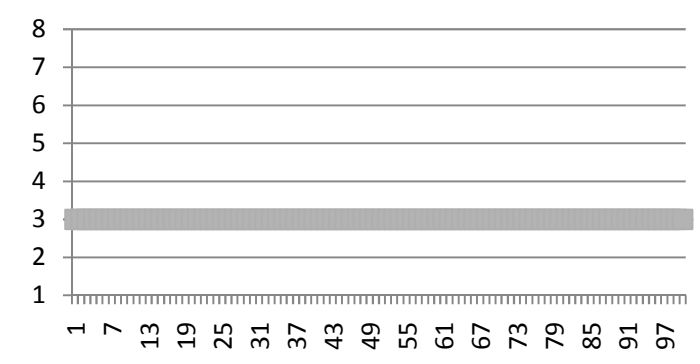

Prisioneiro 2

Figura A.2: Gráficos que apresentam a evolução do estado afetivo ao longo das iterações. 
(3) Relaxado x (4) Dócil

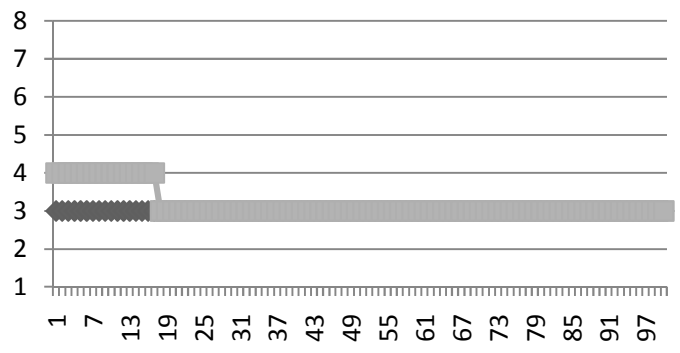

(3) Relaxado x (6) Arrogante

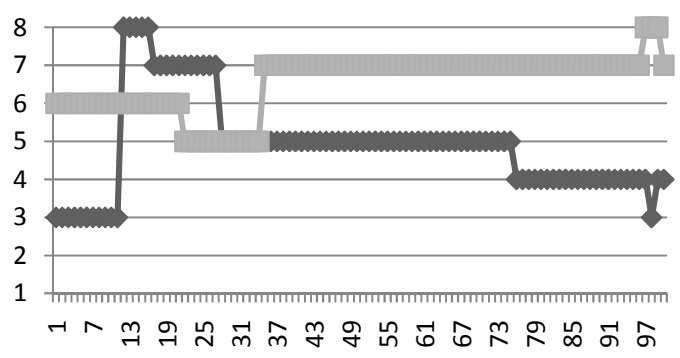

(3) Relaxado x (8) Hostil

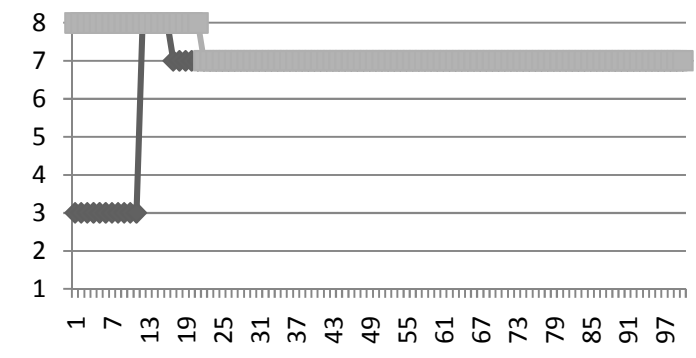

(4) Dócil x (5) Entediado

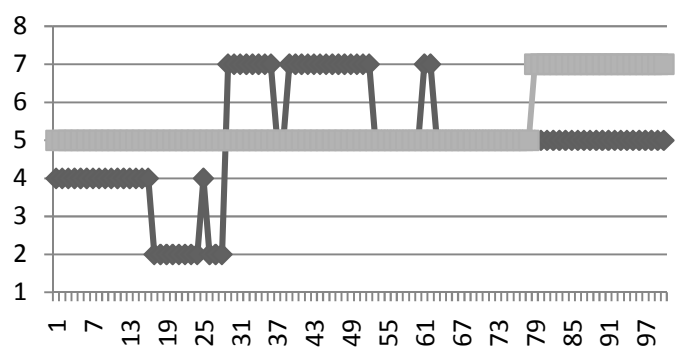

(3) Relaxado x (5) Entediado

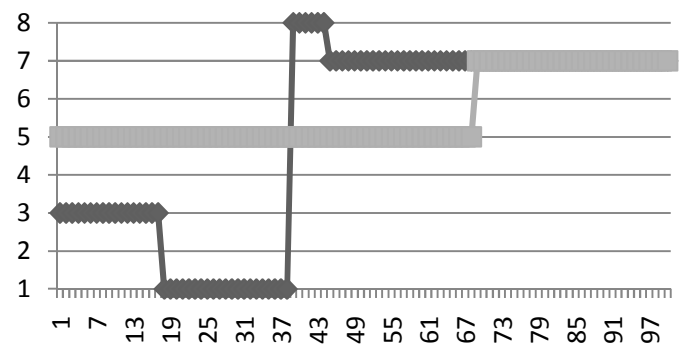

(3) Relaxado x (7) Arrogante

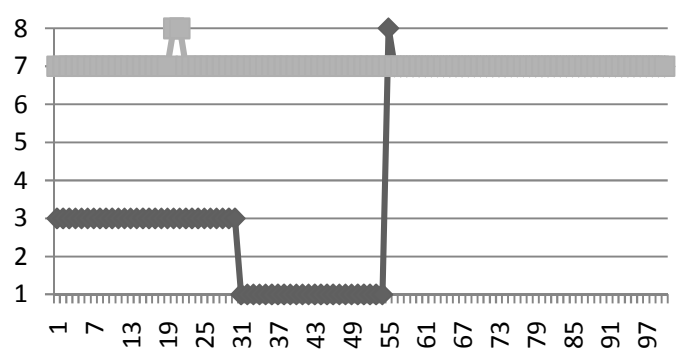

(4) Dócil x (4) Dócil

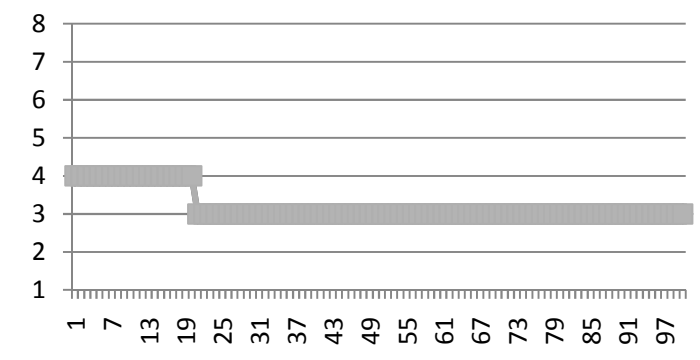

(4) Dócil x (6) Arrogante

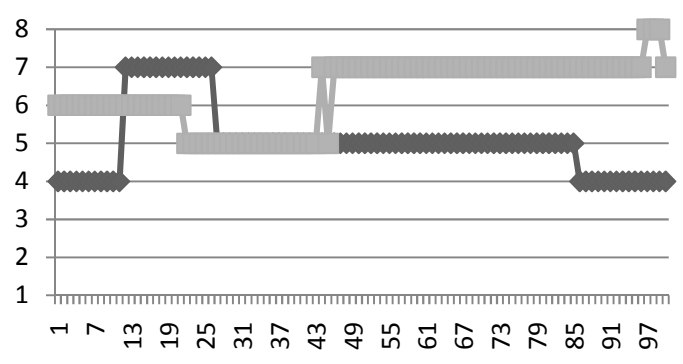

Prisioneiro 2

Figura A.3: Gráficos que apresentam a evolução do estado afetivo ao longo das iterações. 
(4) Dócil x (7) Arrogante

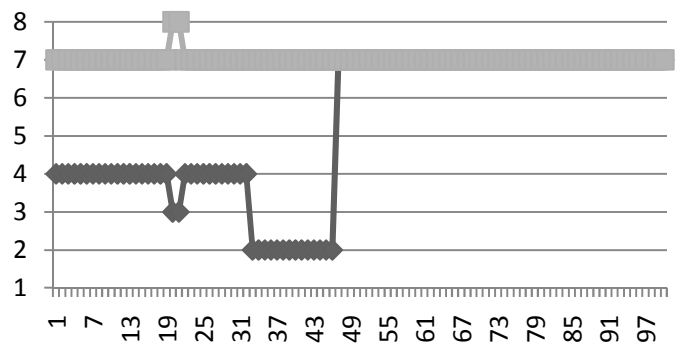

(5) Entediado x (5) Entediado

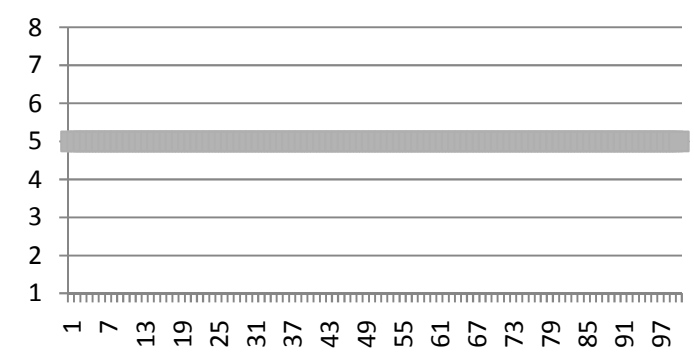

(5) Entediado x (7) Arrogante

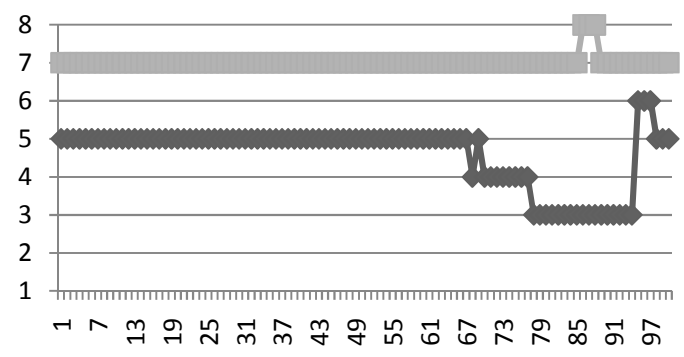

(6) Arrogante x (6) Arrogante

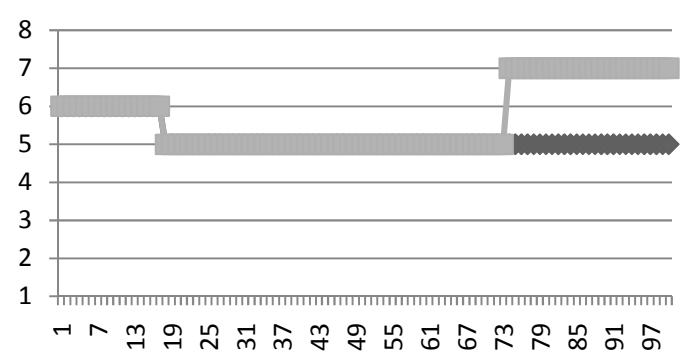

(4) Dócil x (8) Hostil

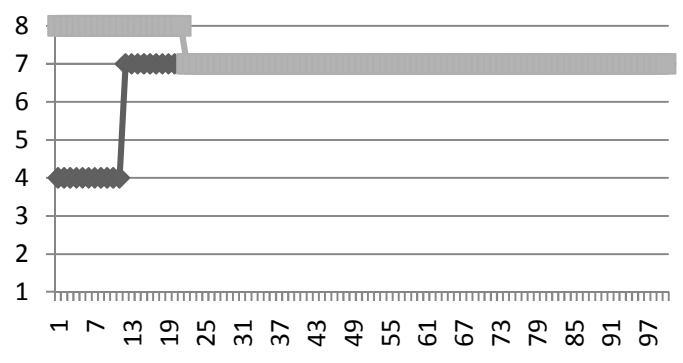

(5) Entediado x (6) Arrogante

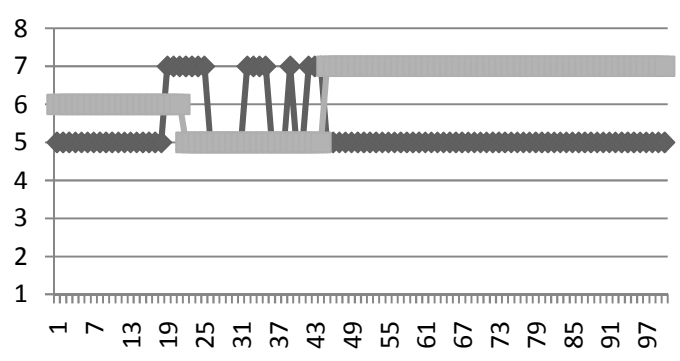

(5) Entediado x (8) Hostil

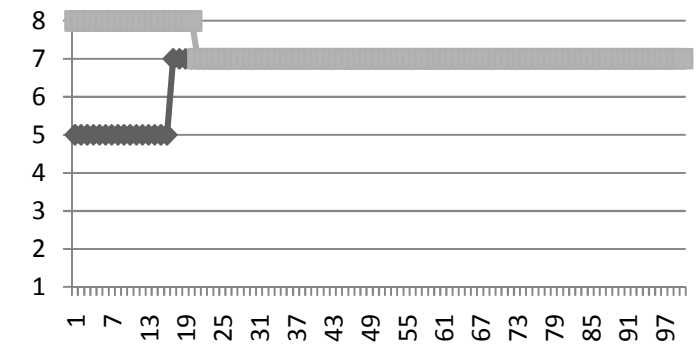

(6) Arrogante x (7) Arrogante

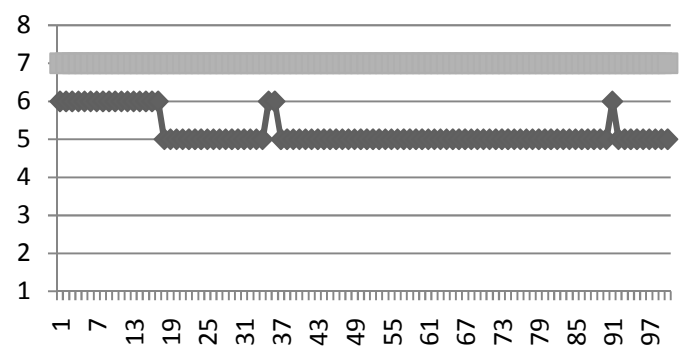

Prisioneiro 2

Figura A.4: Gráficos que apresentam a evolução do estado afetivo ao longo das iterações. 
(6) Arrogante x (8) Hostil

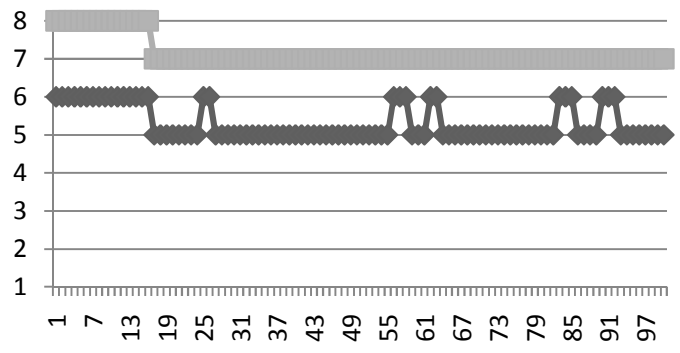

(7) Arrogante x (8) Hostil

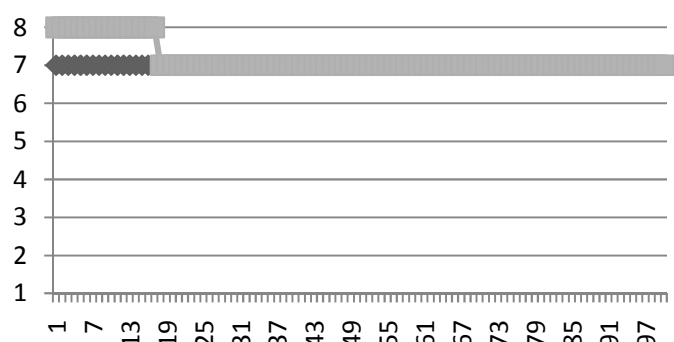

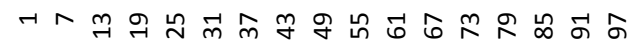

(7) Arrogante x (7) Arrogante

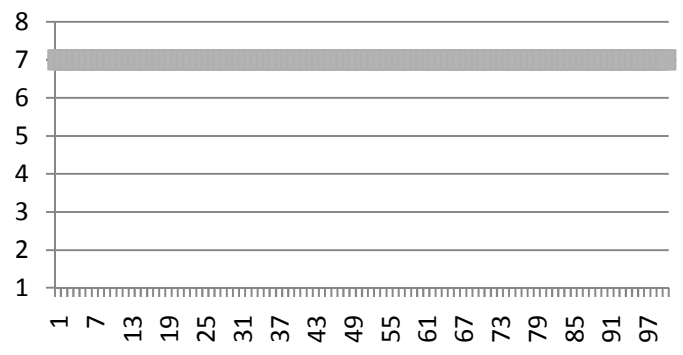

(8) Hostil x (8) Hostil

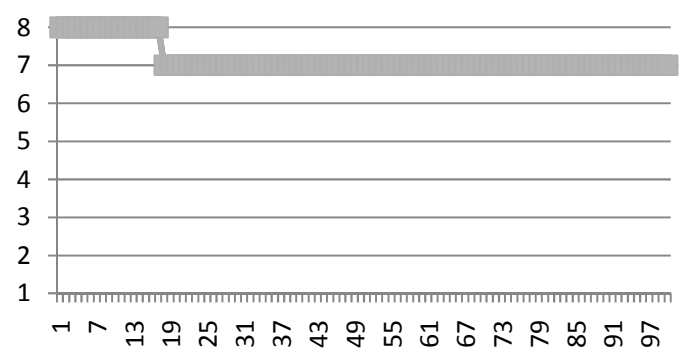

Prisioneiro 2

Figura A.5: Gráficos que apresentam a evolução do estado afetivo ao longo das iterações. 


\section{Apêndice B}

\section{Anexo B}

Durante a execução dos testes do Experimento 1.B, um arquivo de $\log$ armazenou o estado afetivo atual e o tempo de prisão de cada um dos agentes por rodada. Assim, ao final dos testes foi possível construir uma tabela (B.1) com o número total de anos de prisão que cada um dos agentes recebeu, e gráficos que mostraram a evolução do estado afetivo dos agentes ao longo das interações (figuras de B.1 a B.5). Por exemplo, o último gráfico apresentado na figura B.1 descreve a evolução do estado afetivo de dois agentes que participaram de um teste. O primeiro agente apresenta estado Exuberante (1) nas primeiras 16 interações. Na interação 17 ele torna-se Dependente (2) até finalmente na interação 18 tornar-se Ansioso (7). Já o segundo agente inicia no estado Hostil (8) e permanece nesse estado por 7 interações. Na interação 8 ele torna-se Ansioso(7) permanecendo assim até o final do teste. 


\begin{tabular}{|c|c|c|c|}
\hline Jogador 1 & Jogador 2 & Punição do Jogador 1 & Punição do Jogador 2 \\
\hline 1 & 1 & 100 & 100 \\
\hline 1 & 2 & 100 & 100 \\
\hline 1 & 3 & 100 & 100 \\
\hline 1 & 4 & 100 & 100 \\
\hline 1 & 5 & 242 & 177 \\
\hline 1 & 6 & 222 & 202 \\
\hline 1 & 7 & 123 & 123 \\
\hline 1 & 8 & 254 & 254 \\
\hline 2 & 2 & 100 & 100 \\
\hline 2 & 3 & 100 & 100 \\
\hline 2 & 4 & 100 & 100 \\
\hline 2 & 5 & 218 & 218 \\
\hline 2 & 6 & 221 & 216 \\
\hline 2 & 7 & 250 & 250 \\
\hline 2 & 8 & 254 & 254 \\
\hline 3 & 3 & 100 & 100 \\
\hline 3 & 4 & 100 & 100 \\
\hline 3 & 5 & 237 & 167 \\
\hline 3 & 6 & 278 & 163 \\
\hline 3 & 7 & 104 & 99 \\
\hline 3 & 8 & 163 & 158 \\
\hline 4 & 4 & 100 & 100 \\
\hline 4 & 5 & 221 & 181 \\
\hline 4 & 6 & 266 & 151 \\
\hline 4 & 7 & 104 & 99 \\
\hline 4 & 8 & 270 & 230 \\
\hline 5 & 5 & 203 & 208 \\
\hline 5 & 6 & 190 & 230 \\
\hline 5 & 7 & 164 & 264 \\
\hline 5 & 8 & 203 & 238 \\
\hline 6 & 6 & 212 & 232 \\
\hline 6 & 7 & 166 & 276 \\
\hline 6 & 8 & 177 & 262 \\
\hline 7 & 7 & 102 & 102 \\
\hline 7 & 8 & 255 & 215 \\
\hline 8 & 8 & 172 & 172 \\
\hline
\end{tabular}

Tabela B.1: Número de anos de prisão que os agentes receberam em cada um dos testes do Experimento 1.B. 
(1) Exuberante x (1) Exuberante

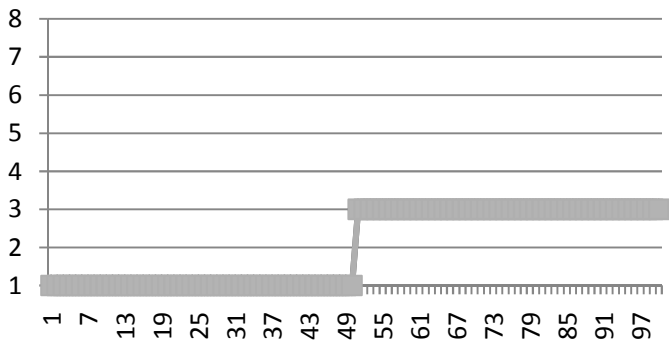

(1) Exuberante x (3) Relaxado

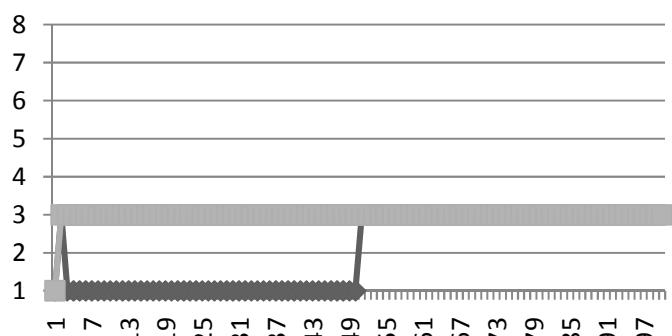

(1) Exuberante x (5) Entediado

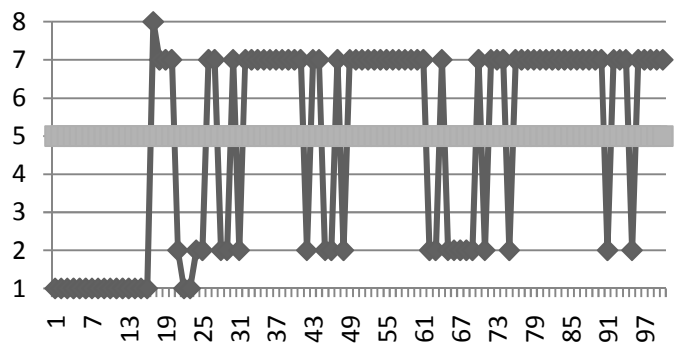

(1) Exuberante x (7) Arrogante
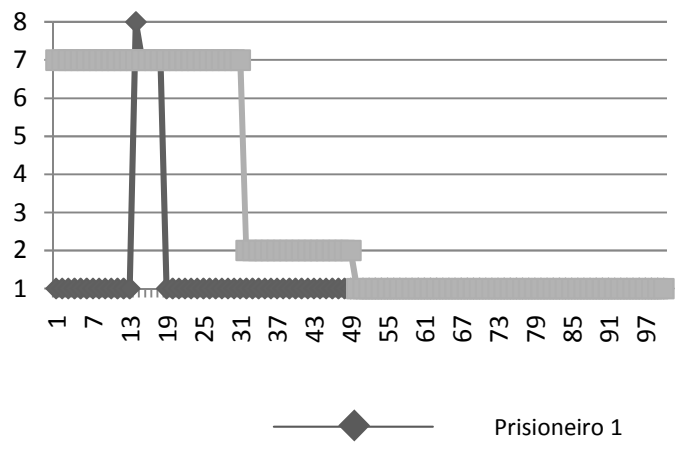

(1) Exuberante x (2) Dependente

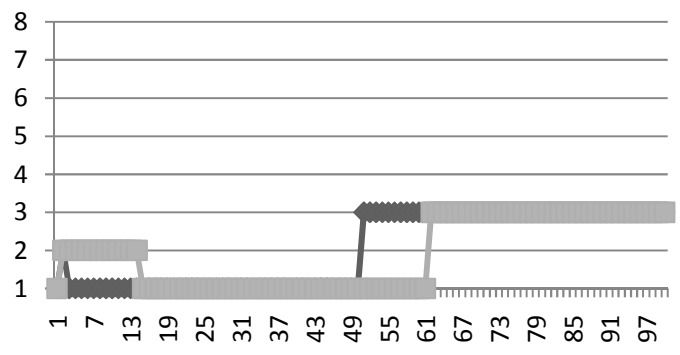

(1) Exuberante x (4) Dócil

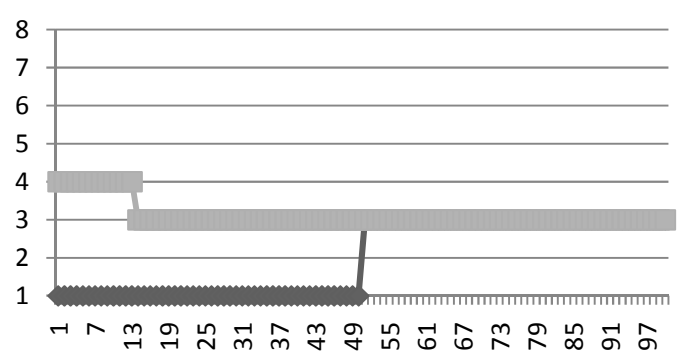

(1) Exuberante x (6) Arrogante

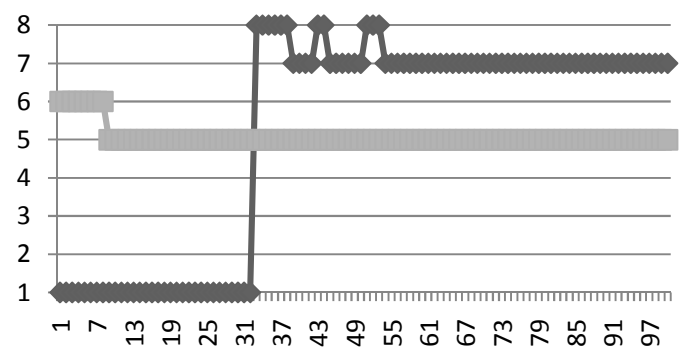

(1) Exuberante x (8) Hostil

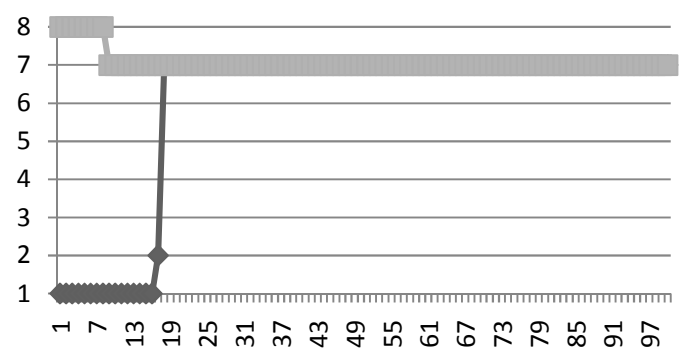

Prisioneiro 2

Figura B.1: Gráficos que apresentam a evolução do estado afetivo ao longo das iterações. 
(2) Dependente x (2) Dependente

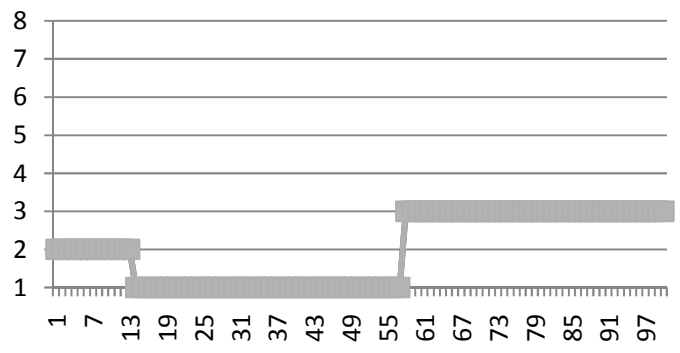

(2) Dependente x (4) Dócil

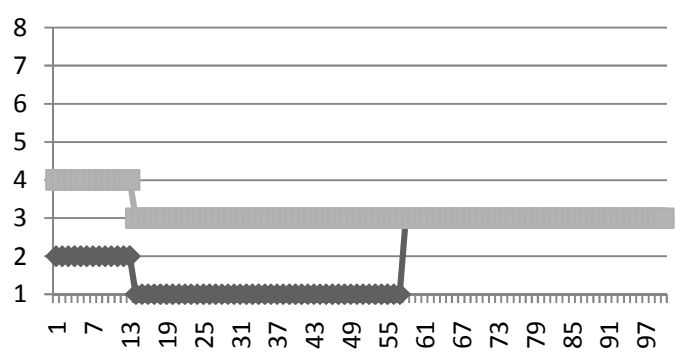

(2) Dependente x (6) Arrogante

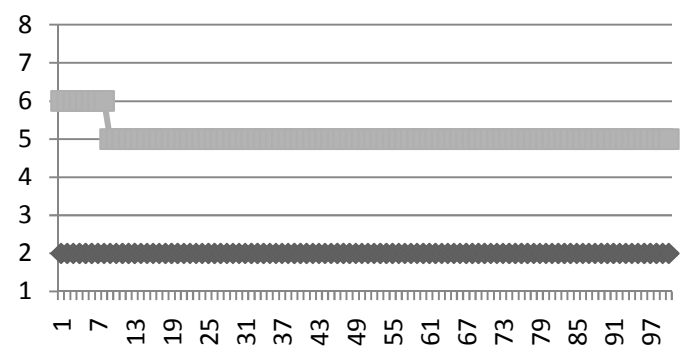

(2) Dependente x (8) Hostil

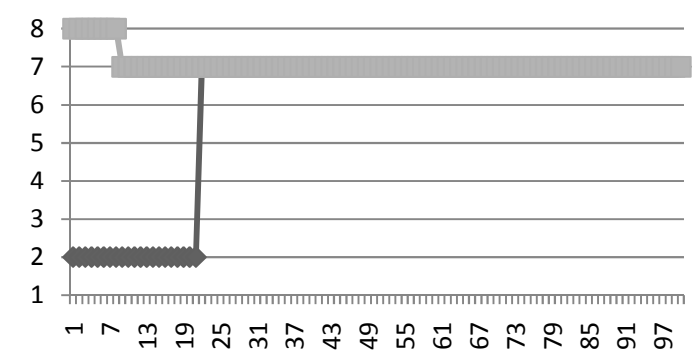

(2) Dependente x (3) Relaxado

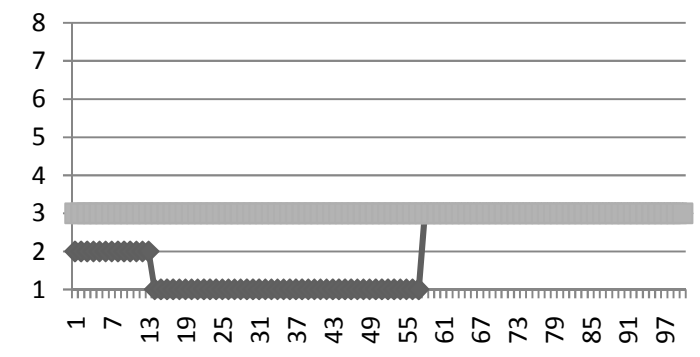

(2) Dependente x (5) Entediado

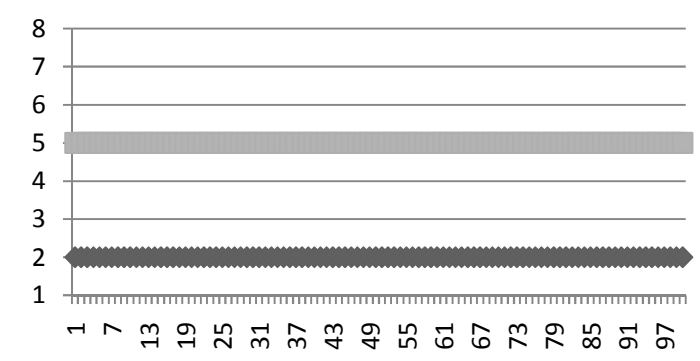

(2) Dependente x (7) Arrogante

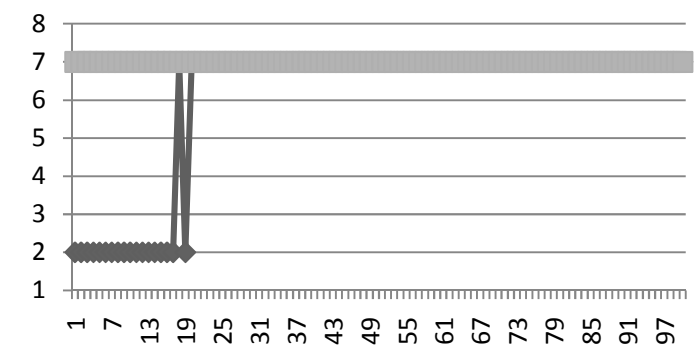

(3) Relaxado x (3) Relaxado

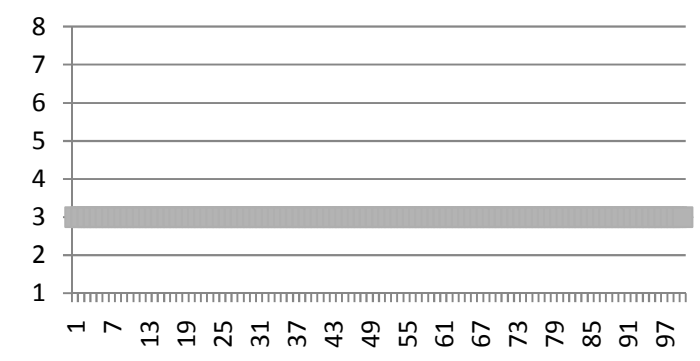

Prisioneiro 2

Figura B.2: Gráficos que apresentam a evolução do estado afetivo ao longo das iterações. 
(3) Relaxado x (4) Dócil

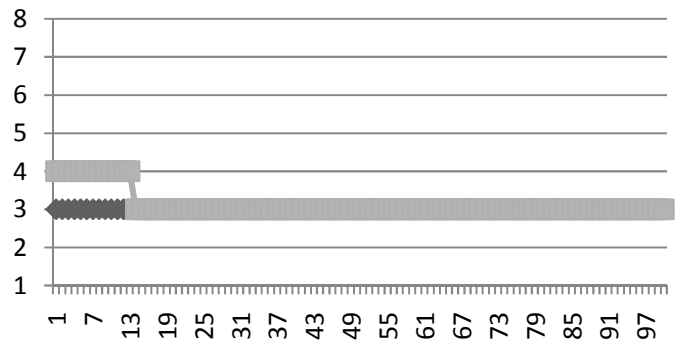

(3) Relaxado x (6) Arrogante

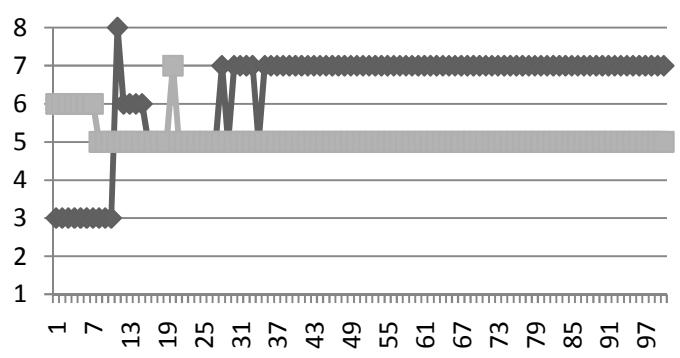

(3) Relaxado x (8) Hostil

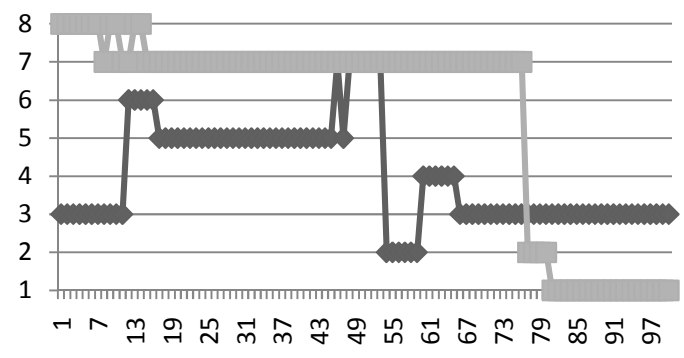

(4) Dócil x (5) Entediado
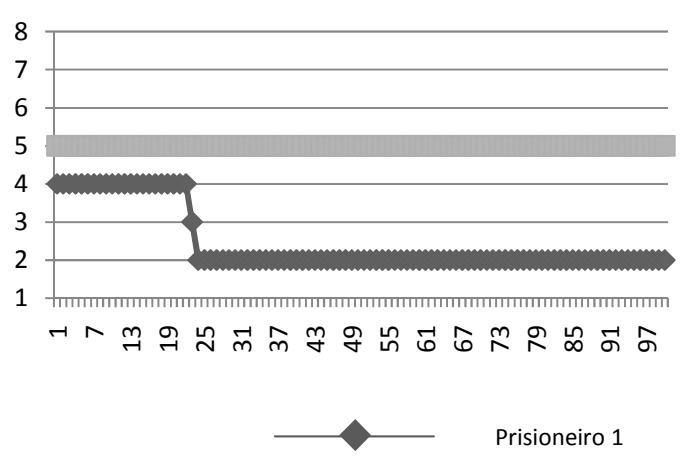

(3) Relaxado x (5) Entediado

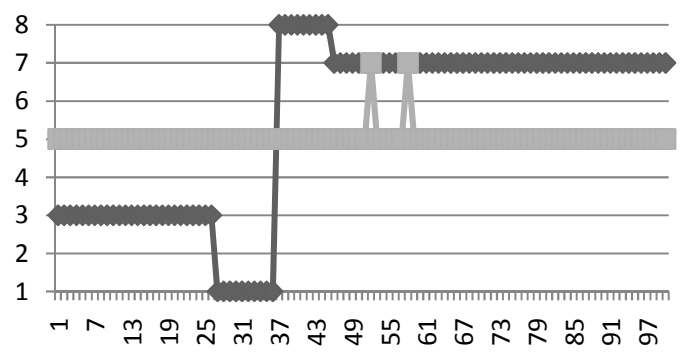

(3) Relaxado x (7) Arrogante

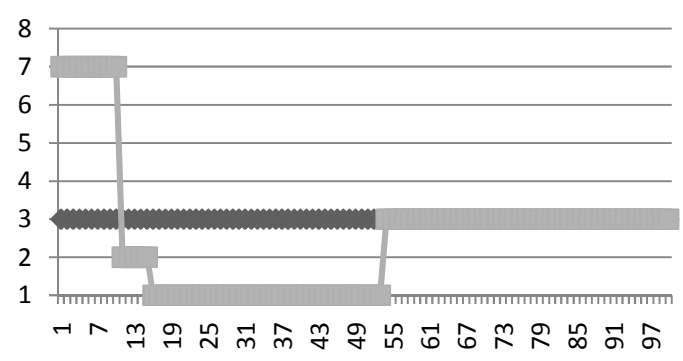

(4) Dócil x (4) Dócil

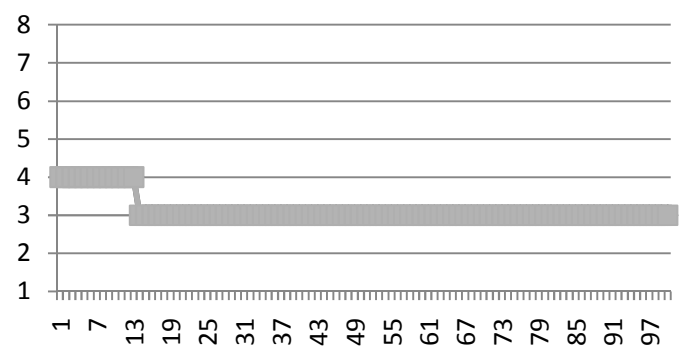

(4) Dócil x (6) Arrogante

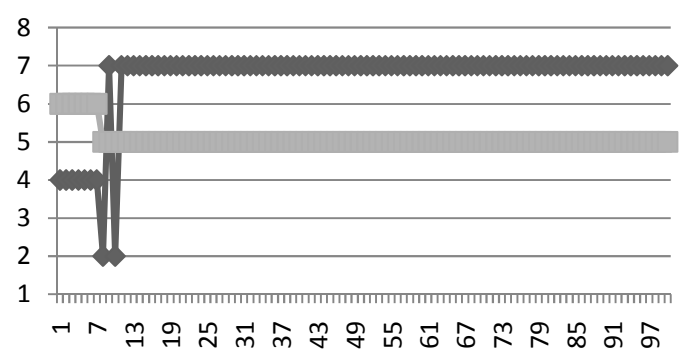

Prisioneiro 2

Figura B.3: Gráficos que apresentam a evolução do estado afetivo ao longo das iterações. 
(4) Dócil x (7) Arrogante

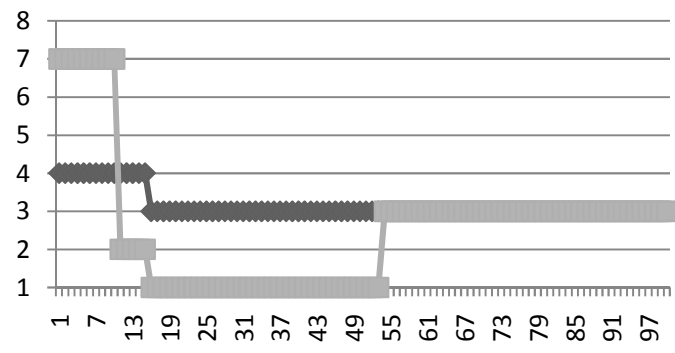

(5) Entediado x (5) Entediado

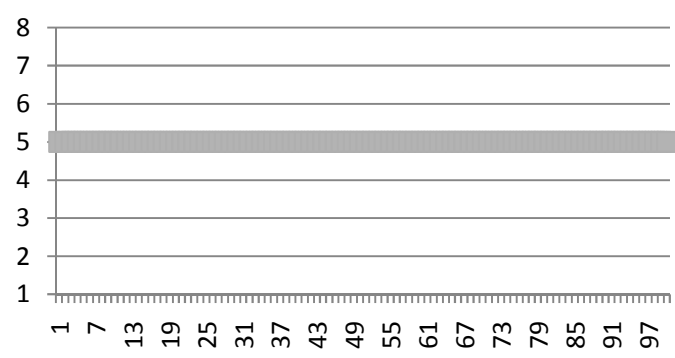

(5) Entediado x (7) Arrogante

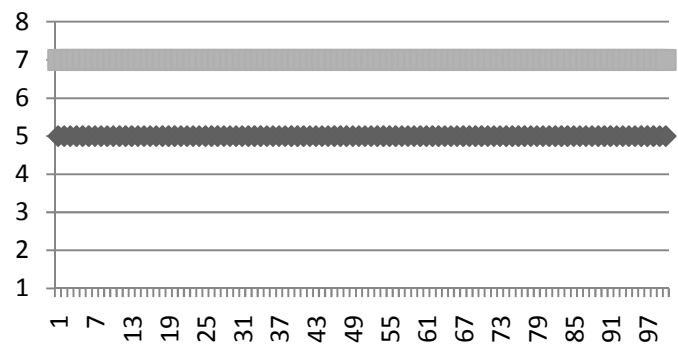

(6) Arrogante x (6) Arrogante

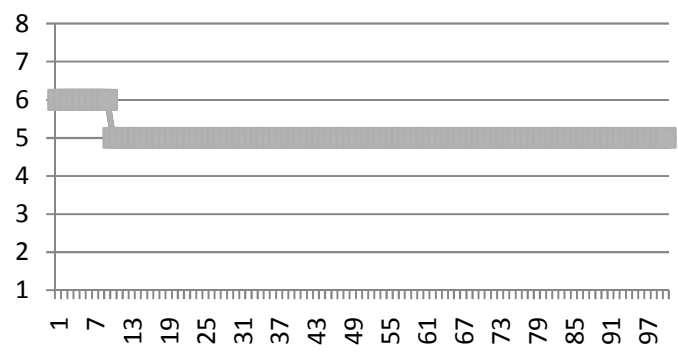

(4) Dócil x (8) Hostil

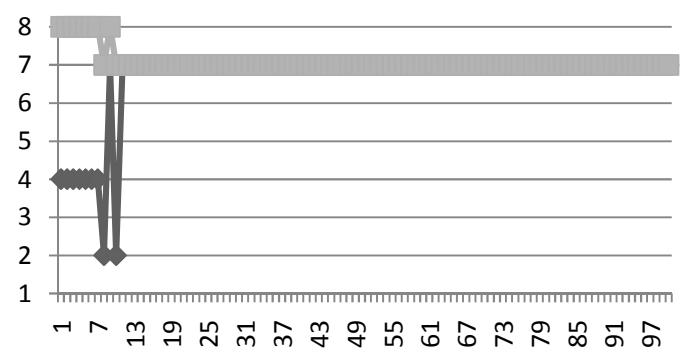

(5) Entediado x (6) Arrogante

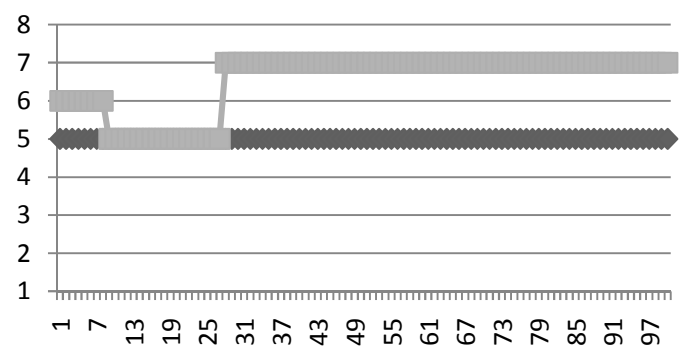

(5) Entediado x (8) Hostil

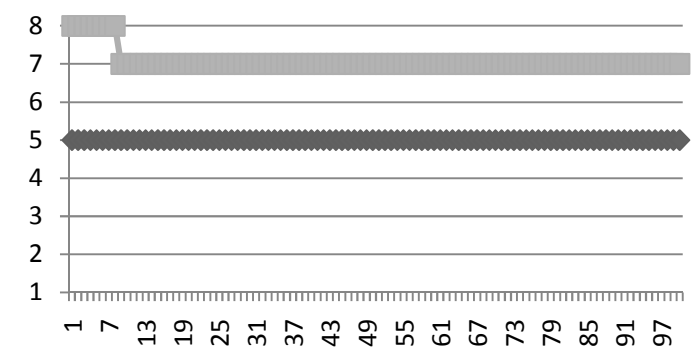

(6) Arrogante x (7) Arrogante

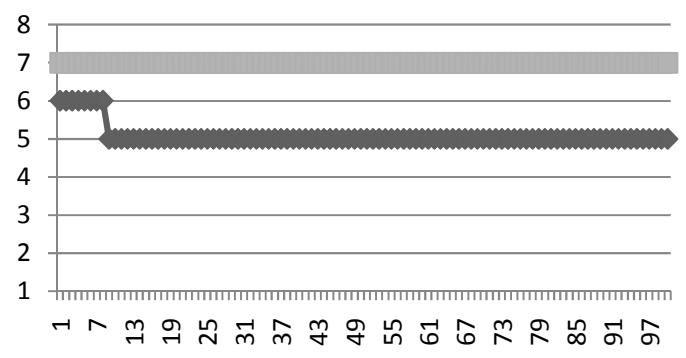

Prisioneiro 2

Figura B.4: Gráficos que apresentam a evolução do estado afetivo ao longo das iterações. 
(6) Arrogante x (8) Hostil

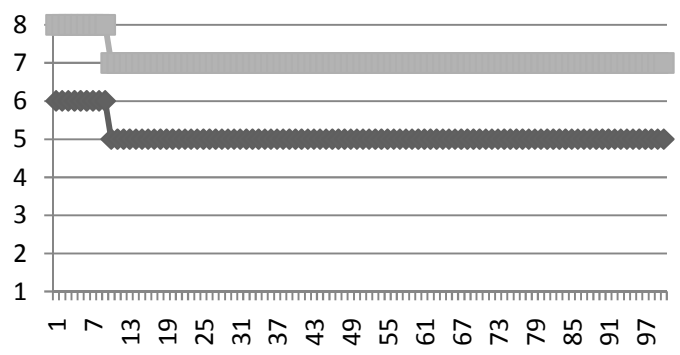

(7) Arrogante x (8) Hostil

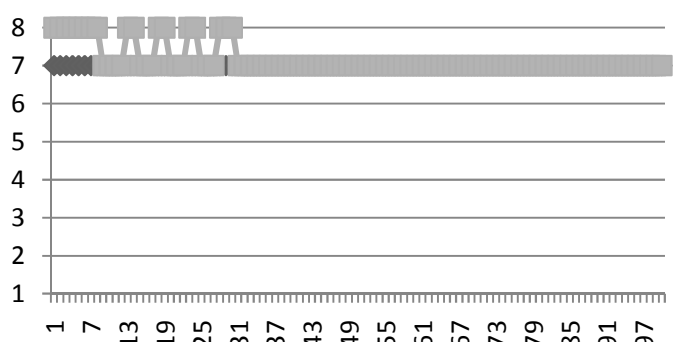

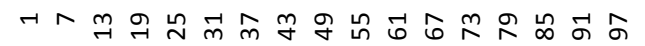

(7) Arrogante x (7) Arrogante

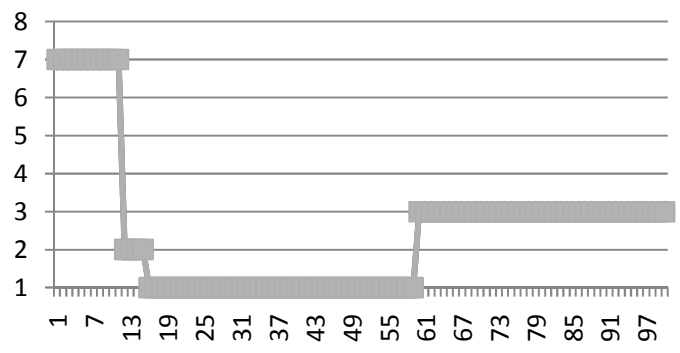

(8) Hostil x (8) Hostil

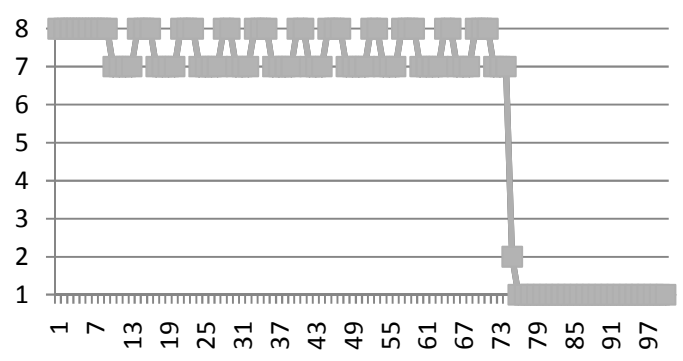

Prisioneiro 2

Figura B.5: Gráficos que apresentam a evolução do estado afetivo ao longo das iterações. 


\section{Referências Bibliográficas}

Bates(1994) Joseph Bates. The role of emotion in believable agents. Communications of the ACM, páginas $122-125$. Citado na pág. 3

Bates et al.(1992) Joseph Bates, A. Bryan Loyall, e W. Scott Reilly. An architecture for action, emotion, and social behavior. Em 4th European Workshop On On Modelling Autonomous Agents, páginas 55-68, S.Martino al Camino. Citado na pág. xi, 5

Bordini et al.(2007) Rafael H. Bordini, Jomi Fred Hübner, e Michael Wooldridge. Programming Multi-Agent Systems in AgentSpeak using Jason. Wiley-Interscience, Chichester. Citado na pág. xi, 40, 41, 51

Bower(1981) Gordon H. Bower. Mood and memory. American Psychology, páginas 129-148. Citado na pág. 31, 49

Byl(2004) Penny Baillie-De Byl. Programming Believable Characters For Computer Games. Charles River Media, Hingham. Citado na pág. 2, 3

Damásio(1996) António R. Damásio. O erro de Descartes. Companhia das Letras, São Paulo. Citado na pág. $3,22,25,31,32,50$

Davidson(1994) Richard J. Davidson. On emotion, mood, and related affective constructs. Em Paul Ekman e Richard J. Davidson, editors, The nature of emotion. Oxford University Press, New York. Citado na pág. 46

Davidson(1999) Richard J. Davidson. Basic emotions. Em Tim Dalgleish e Mick Power, editors, Handbook of Cognition and Emotion, páginas 45-60. John Wiley, Sussex. Citado na pág. 27

Davis(2007) Wayne Davis. Iterated prisoner's dilemma online game and simulation. http://www . iterated-prisoners-dilemma.net/, 2007. Último acesso em 15/03/2010. Citado na pág. 57

de Souza et al.(2007) Carmen Vera Rodrigues de Souza, Ricardo Primi, e Fabiano Koich Miguel. Validade do teste wartegg: Correlação com 16pf, bpr-5 e desempenho profissional. Avaliação Psicológica, páginas 39-49. Citado na pág. xiii, 16

Ekman(1992) Paul Ekman. Are there basic emotions? Psychological Review, páginas 550-553. Citado na pág. 27

Ekman e Friesen(1967) Paul Ekman e Wallace Friesen. Head and body cues in the judgment of emotion: A reformulation. Perceptual And Motor Skills, páginas 711-724. Citado na pág. 29

Ekman e Friesen(1978) Paul Ekman e Wallace Friesen. Facial Action Coding System. Consulting Psychologists Press, Palo Alto. Citado na pág. 23 
Fehr e Russell(1984) Beverly Fehr e James A. Russell. Concept of emotion viewed from a prototype perspective. Journal Of Experimental Psychology, páginas 464-486. Citado na pág. 21

Fioravanti(2006) Ana Carolina Monnerat Fioravanti. Propriedades Psicométricas do Inventário de Ansiedade Traço-Estado. Dissertação (mestrado), Pontifícia Universidade Católica do Rio de Janeiro, Rio de Janeiro. Citado na pág. 18

Garcia(2006) L. F. Garcia. Teorias psicométricas da personalidade. Em Carmen Flores-Mendoza e Roberto Colom, editors, Introdução a Psicologia das Diferenças Individuais, páginas 219-242. Artmed, Porto Alegre. Citado na pág. xi, xiii, 13, 15, 17, 18, 19

Gazzaniga e Heatherton(2005) Michael S. Gazzaniga e Todd F. Heatherton. Ciência Psicológica: Mente, Cérebro e Comportamento. Artmed, Porto Alegre. Citado na pág. xi, 13, 15, 17, 18, $21,26,27,29,30,31,32$

Gebhard(2005) Patrick Gebhard. Alma: a layered model of affect. Em Proceedings Of The Fourth International Joint Conference On Autonomous Agents And Multiagent Systems, páginas 29-36, Utrecht. Citado na pág. xi, xiii, $7,8,22,45,53,54$

Goldberg(1992) Lewis R. Goldberg. The development of markers for the big-five factor structure. Psychological Assessment, páginas 26-42. Citado na pág. 20

Isbister(2006) Katherine Isbister. Better Game Characters by Design: A Psychological Approach. Morgan Kaufmann, San Francisco. Citado na pág. xi, 28, 29

Izard(1993) Carroll E. Izard. Four systems for emotion activation: Cognitive and noncognitive processes. Psychological Review, páginas 68-90. Citado na pág. 30

Jiang et al.(2007) Hong Jiang, Jose M. Vidal, e Michael N. Huhns. Ebdi: An architecture for emotional agents. Em Proceedings of the 6th International Conference on Autonomous Agents and Multiagent Systems, Honolulu. Citado na pág. 7

Kasap e Magnenat-Thalmann(2007) Zerrin Kasap e Nadia Magnenat-Thalmann. Intelligent virtual humans with autonomy and personality: State-of-the-art. Journal Of Intelligent Decision Technologies, páginas 3-15. Citado na pág. 24, 47

Kasap et al.(2009) Zerrin Kasap, Maher Ben Moussa, Parag Chaudhuri, e Nadia MagnenatThalmann. Making them remember - emotional virtual characters with memory. IEEE Computer Graphics And Applications, páginas 20-29. Citado na pág. xi, 8, 9, 45, 52, 53

Konar(2000) Amit Konar. Behavioral and Cognitive Modeling of the Human Brain Artificial Intelligence and Soft Computing. CRC Press, New York. Citado na pág. 2

Kshirsagar e Magnenat-Thalmann(2002) Sumedha Kshirsagar e Nadia Magnenat-Thalmann. A multilayer personality model. Em Proceedings Of The 2nd International Symposium On Smart Graphics, páginas 107-115, Hawthorne. Citado na pág. xi, 6

Laird e van Lent(2001) John Laird e Michael van Lent. Behavior modeling in commercial games. AI Magazine, páginas 15-25. Citado na pág. 2

Laird(2008) John E. Laird. Extending the soar cognitive architecture. Em Proceeding of the 2008 conference on Artificial General Intelligence 2008, páginas 224-235, Amsterdam. Citado na pág. 9 
Ledoux(1996) Joseph E. Ledoux. The Emotional Brain. Simon And Schuster, New York. Citado na pág. 31

Loyall(1997) Aaron Bryan Loyall. Believable Agents: Building Interactive Personalities. Dissertação (mestrado), Carnegie Mellon University, Pittsburgh. Citado na pág. 3

Marinier(2008) Robert P. Marinier. A Computational Unification of Cognitive Control, Emotion, and Learning. Tese (doutorado), Universidade de Michigan, Ann Arbor. Citado na pág. 8

Marreiros(2007) Maria Goreti Carvalho Marreiros. Agentes de Apoio à Argumentação e Decisão em Grupo. Tese (doutorado), Universidade do Minho, Porto. Citado na pág. 31

Mateas(2002) Michael Mateas. Interactive Drama, Art and Artificial Intelligence. Dissertação (mestrado), Carnegie Mellon University, Pittsburgh. Citado na pág. 3

Matthews et al.(2003) Gerald Matthews, Ian J. Deary, e Martha C. Whiteman. Personality Traits. Cambridge University Press, Cambridge. Citado na pág. 13, 15

McCarthy(1979) John McCarthy. Ascribing mental qualities to machines. Philosophical Perspectives In Artificial Intelligence, páginas 161-195. Citado na pág. 1

McCrae(2006) Robert R. McCrae. O que é personalidade? Em Carmen Flores-Mendoza e Roberto Colom, editors, Introdução a Psicologia das Diferenças Individuais, páginas 20-218. Artmed, Porto Alegre. Citado na pág. 16, 17, 20

McCrae e Costa(1999) Robert R. McCrae e Paul T. Costa. A five-factor theory of personality. Em Lawrence A. Pervin e Oliver P. John, editors, Handbook of personality: Theory and research, páginas 139-153. Guilford, New York. Citado na pág. 18

McCrae e John(1992) Robert R. McCrae e Oliver P. John. An introduction to the five-factor model and its applications. Journal Of Personality, páginas 175-215. Citado na pág. 45

Mehrabian(2009) Albert Mehrabian. A general powerful system for assessing temperament personality. http://www.kaaj.com/psych/scales/temp.html, 2009. Último acesso em 15/03/2010. Citado na pág. xiii, 21

Mehrabian(1995) Albert Mehrabian. Pleasure-arousal-dominance: A general framework for describing and measuring individual differences in temperament. Current Psychology, páginas 261292. Citado na pág. xiii, $21,45,46,53,59$

Miikkulainen(2006) Risto Miikkulainen. Creating intelligent agents in games. The Bridge, páginas 5-13. Citado na pág. 1, 2

Morris(1992) William N. Morris. A functional analysis of the role of mood in affective systems. Review Of Personality And Social Psicology, páginas 256-293. Citado na pág. 21

Nareyek(2001) Alexander Nareyek. Intelligent agents for computer games. Computers And Games, páginas 414-422. Citado na pág. 1, 2

Niedenthal e Setterlund(1994) Paula M. Niedenthal e Marc B. Setterlund. Emotion congruence in perception. Personality and Social Psychology Bulletin, páginas 401-411. Citado na pág. 30 
Niedenthal et al.(2000) Paula M. Niedenthal, Jamin B. Halberstadt, Jonathan Margolin, e Ase H. Innes-Ker. Emotional state and the detection of change in facial expression of emotion. European Journal of Social Psychology, páginas 211-222. Citado na pág. 30

Oatley e Johnson-Laird(1987) Keith Oatley e P. N. Johnson-Laird. Towards a cognitive theory of emotions. Cognition and Emotion, páginas 29-50. Citado na pág. 26

Oliveira e Sarmento(2003) Eugénio Oliveira e Luís Sarmento. Emotional advantage for adaptability and autonomy. Em Proceedings of the second international joint conference on Autonomous agents and multiagent systems, páginas 305-312, Melbourne. Citado na pág. 2

Ortony et al.(1988) Andrew Ortony, Gerald L. Clore, e Allan Collins. The Cognitive Structure of Emotion. Cambridge University Press, Cambridge. Citado na pág. xi, xiii, 24, 25, 45, 47, 48, 61, 73

Peckham(2008) Matt Peckham. Video games may top 62 billion worldwide by 2012. http: //blogs.pcworld.com/gameon/archives/006550.html, 2008. Último acesso em 15/03/2010. Citado na pág. 1

Pervin e John(2001) Lawrence A. Pervin e Oliver P. John. Handbook of Personality: Theory and Research. The Guilford Press, New York. Citado na pág. 13

Pervin e John(2003) Lawrence A. Pervin e Oliver P. John. Personalidade - Teoria e Pesquisa. Artmed, Porto Alegre. Citado na pág. xi, 13, 15, 17, 20

Phelps et al.(2006) Elizabeth A. Phelps, Sam Ling, e Marisa Carrasco. Emotion facilitates perception and potentiates the perceptual benefits of attention. Psychological Science, páginas 292-299. Citado na pág. 30

Picard(1997) Rosalind Picard. Affective Computing. MIT Press, Boston. Citado na pág. xi, xiii, 3, $9,21,24,25,26,27,29$

Plutchik(2002) Robert Plutchik. Emotions and Life: Perspectives from Psychology, Biology, and Evolution. American Psychological Association, Washington. Citado na pág. xi, 23

Plutchik(1980) Robert Plutchik. A general psychoevolutionary theory of emotion. Em Robert Plutchik e Henry Kellerman, editors, Emotion: Theory, research and experience, páginas 3-33. Academic Press Inc, New York. Citado na pág. 23

Rodrigues(2007) Paula Salgado Lucena Rodrigues. Um Sistema de Geração de Expressões Faciais Dinâmicas em Animações Faciais 3D com Processamento de Fala. Tese (doutorado), PUC Rio, Rio de Janeiro. Citado na pág. xi, 28

Romano et al.(2005) Daniela M. Romano, Gary Sheppard, James Hall, Adam Miller, e Zhinan Ma. Basic: A believable, adaptable socially intelligent character for social presence. Em The 8th Annual International Workshop On Presence, páginas 21-22, London. Citado na pág. 45

Roseman et al.(1996) Ira J. Roseman, Ann Aliki Antoniou, e Paul E. Jose. Appraisal determinants of emotions: Constructing a more accurate and comprehensive theory. Cognition And Emotion, páginas 241-278. Citado na pág. 24

Russell e Norvig(2003) Stuart Russell e Peter Norvig. Inteligência Artificial. Editora Campus, Rio de Janeiro. Citado na pág. 2, 56, 57 
Sloman(2001) Aaron Sloman. Beyond shallow models of emotion. Cognitive Processing: International Quarterly of Cognitive Science, páginas 177-198. Citado na pág. 25

Stenberg(2000) Robert J. Stenberg. Psicologia Cognitiva. Artmed, Porto Alegre. Citado na pág. 29, 30,31

Strongman(2003) Kenneth T. Strongman. The Psychology of Emotion. John Wiley and Sons Ltd, Chichester. Citado na pág. 22, 24

Vinayagamoorthy et al.(2006) Vinoba Vinayagamoorthy, Marco Gillies, A. Steed, E. Tanguy, X. Pan, C. Loscos, e M. Slater. Building expression into virtual characters. Em Eurographics Conference State of the Art Reports, Vienna. Citado na pág. 21, 26, 45

Weiss(2001) Gerhard Weiss. Multiagent Systems - A Modern Approach to Distributed Artificial Intelligence. MIT Press, Boston. Citado na pág. 33

Wooldridge(2002) Michael Wooldridge. An Introduction to MultiAgent Systems. John Wiley and Sons, Chichester. Citado na pág. 33

Yu e Choi(2005) Chan-Woo Yu e Jin-Young Choi. Behavior decision model based on emotion and dynamic personality. Em Proceedings Of The International Conference On Control, Automation And Systems. Citado na pág. xi, 6, 7 